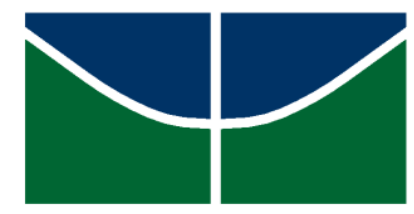

UNIVERSIDADE DE BRASÍLIA

FACULDADE DE ECONOMIA, ADMINISTRAÇÃO E CONTABILIDADE - FACE PROGRAMA DE PÓS-GRADUAÇÃO EM ADMINISTRAÇÃO - PPGA

ANA CAROLINA REZENDE COSTA

POLÍTICAS E PRÁTICAS DE GESTÃO DE PESSOAS PRODUZEM SERVIDORES PÚBLICOS RESILIENTES? VALIDAÇÃO DE UM MODELO ESTRUTURAL E DE MODELOS DE MENSURAÇÃO.

BRASÍLIA-DF 
Ana Carolina Rezende Costa

\section{POLÍTICAS E PRÁTICAS DE GESTÃO DE PESSOAS PRODUZEM SERVIDORES PÚBLICOS RESILIENTES? VALIDAÇÃO DE UM MODELO ESTRUTURAL E DE MODELOS DE MENSURAÇÃO.}

Dissertação submetida ao Programa de Pós-Graduação em Administração da Universidade de Brasília como requisito parcial para a obtenção do grau de Mestre em Administração.

Orientadora: Profa. Dra. Gisela Demo. 


\section{POLÍTICAS E PRÁTICAS DE GESTÃO DE PESSOAS PRODUZEM SERVIDORES PÚBLICOS RESILIENTES? VALIDAÇÃO DE UM MODELO ESTRUTURAL E DE MODELOS DE MENSURAÇÃO.}

Dissertação submetida ao Programa de Pós-Graduação em Administração da Universidade de Brasília como requisito parcial para a obtenção do grau de Mestre em Administração.

Área de Concentração: Estratégia, Marketing e Inovação.

Aprovada em:

Profa. Dra. Gisela Demo

Orientadora (Universidade de Brasília - PPGA/UnB)

Profa. Dra. Áurea de Fátima Oliveira

Examinadora Externa (Universidade Federal de Uberlândia - UFU/MG)

Profa. Dra. Tatiane Paschoal

Examinadora Interna (Universidade de Brasília - PPGA/UnB)

Prof. Dr. Antônio Isidro da Silva Filho

Examinador Interno (Universidade de Brasília - PPGA/UnB) - Suplente 
"Alegrai-vos na esperança, sede pacientes na tribulação, perseverai na oração."

Romanos 12:12 


\section{AGRADECIMENTOS}

Agradeço a Deus por me conceder saúde e guiar o meu caminho. Agradeço por ter me dado força, serenidade e por ter permitido que eu estivesse exatamente como estou hoje. $\mathrm{O}$ Senhor sabe de todas as coisas!

Aos meus pais, pelo apoio, colo, carinho, orações, conforto na rotina, cuidado, amor, lanchinhos... Tudo o que eu fizer por vocês ainda será pouco! À minha irmã, pelo exemplo, apoio, amor, amizade de sempre e por me encorajar a enfrentar desafios. Ao namorado, pela paciência, amor, apoio, companheirismo e pelo lindo exemplo de viver a vida de uma maneira

mais leve. A vocês, meu reconhecimento pelo amor e apoio em todas as circunstâncias! Aos demais familiares, sou grata pela torcida e carinho. Amo vocês! Vocês todos são essenciais para mim!

Agradeço à minha querida orientadora, Profa. Gisela Demo, por todo o ensinamento, cuidado, carinho, atenção, confiança e exemplo. Não canso de agradecer a Deus por tê-la comigo nesta caminhada. Obrigada por me encorajar e me incentivar a querer sempre mais e pela competência com que me conduziu na elaboração deste trabalho.

Agradeço também às professoras Áurea de Fátima Oliveira e Tatiane Paschoal pela preciosa contribuição para a construção desse trabalho.

Aos demais professores e colaboradores do PPGA, obrigada pelo esforço na formação de mestres e doutores capacitados. Que a busca por uma sociedade mais justa e humana se faça presente no meio acadêmico.

Aos colegas do PPGA, sou grata pelos momentos de aprendizado, de frustrações, de dúvidas, de anseios e também de diversão que compartilhei com vocês.

Pelo imenso apoio em todas as oportunidades e ainda pelos momentos de descontração, agradeço aos meus queridos colegas de trabalho.

Por fim, mas não menos importantes, pelos amigos de toda a vida, sempre ao meu lado, ainda que distantes... Obrigada por entenderem minha ausência neste momento e por torcerem pelo meu sucesso. 


\section{RESUMO}

É consensual que as pessoas constituem competências essenciais de diferenciação estratégica organizacional. Nesse sentido, o contexto moderno de trabalho exige que o trabalhador seja flexível e capaz de se adequar constantemente a novas exigências e desafios, ou seja, um trabalhador resiliente. Assim, sustentada na relevância da resiliência no ambiente de trabalho e na importância de estratégias eficazes de gestão de pessoas (GP) nas organizações, esta pesquisa tem por objetivo identificar a influência das políticas e práticas de GP na resiliência no trabalho dos servidores técnico-administrativos da Fundação Universidade de Brasília. Os resultados deste estudo quantitativo foram analisados por meio de análise fatorial confirmatória e análise de regressão, utilizando a modelagem por equações estruturais. Como resultado, tem-se que a política de envolvimento é preditora da resiliência no trabalho, desvelando uma significativa explicação para a resiliência no trabalho. Como contribuições, esse estudo engendrará um diagnóstico para os gestores da instituição. Ademais, contribui com os estudos empíricos na área de GP, na investigação de antecedentes da resiliência no trabalho, no caso, a percepção de políticas e práticas de GP, e, sobretudo, na análise de uma relação entre variáveis ainda não explorada na literatura. Limitações e sugestões para estudos futuros são discutidas.

Palavras-chave: políticas e práticas de gestão de pessoas; resiliência no trabalho; validação confirmatória de escala; modelagem por equações estruturais. 


\begin{abstract}
It has been a consensus that people are essential skills of organizational strategic differentiation. In this sense, the modern work environment requires that employees have to be flexible and able to constantly adapt to new demands and challenges, namely a resilient employee. Thus, supported in the relevance of resilience in the workplace and the importance of effective strategies for human resources (HR) in organizations, this research purposes to identify the influence of HR policies and practices in resilience at work of public server technical-administrative of the University of Brasilia Foundation. The results of this quantitative study were analyzed using confirmatory factor analysis and regression analysis by using structural equation modeling. As a result, the engagement policy is a predictor of resilience at work, revealing a significant explanation for the resilience at work. As contributions, this study engender a diagnosis for the institution managers. Moreover, it contributes to the empirical studies on the HR area, the background investigation of resilience at work, in this case, HR policies and practices perception, and mainly the analysis of a relationship between not yet explored variables in the literature. Limitations and suggestions for future studies are discussed.
\end{abstract}

Key-words: human resource management policies and practices; resilience at work; confirmatory factor analysis; structural equation modeling. 


\section{SUMÁRIO}

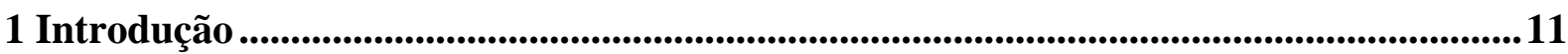

2 Referencial Teórico …............................................................................................................... 16

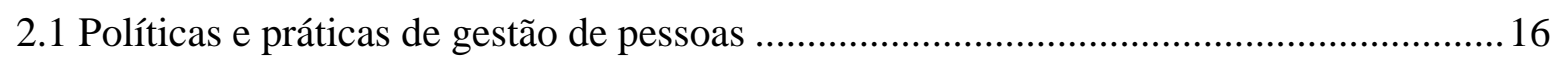

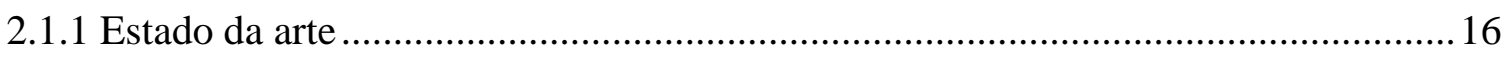

2.1.2 Revisão bibliométrica de políticas e práticas de GP .................................................29

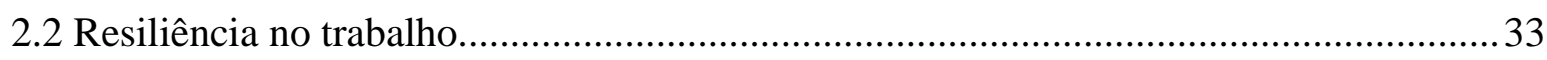

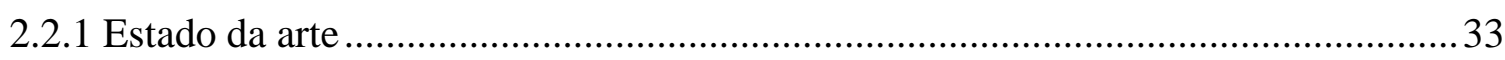

2.2.2 Revisão bibliométrica de resiliência no trabalho .......................................................4

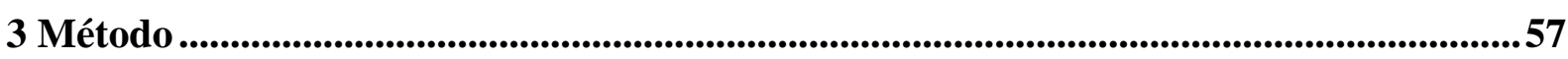

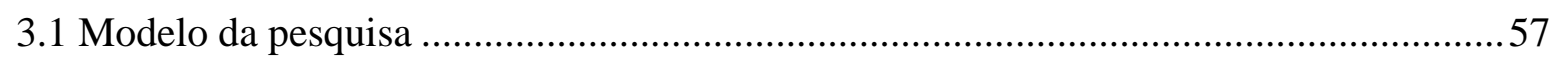

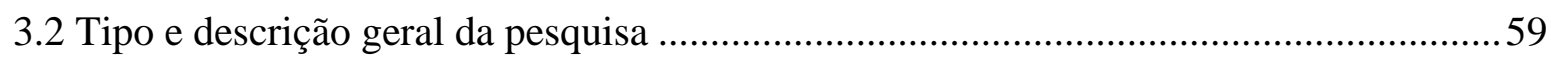

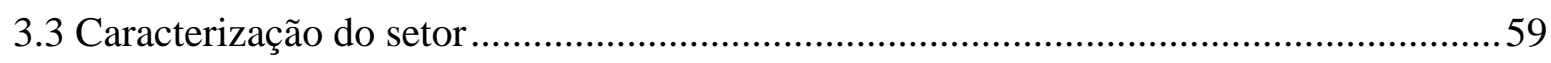

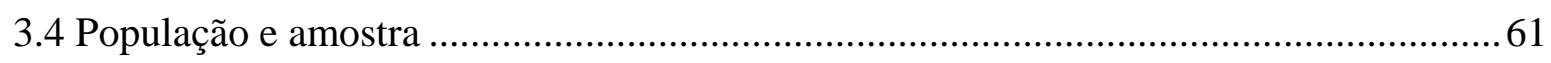

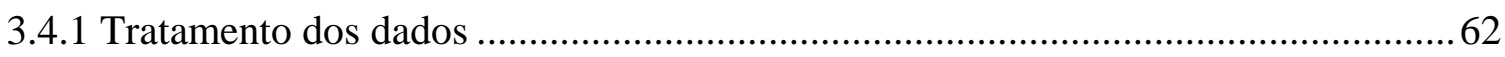

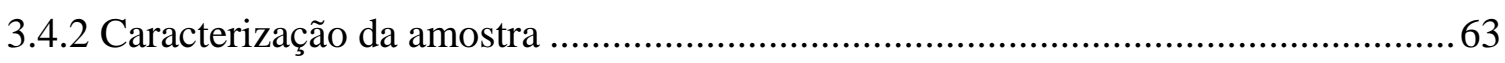

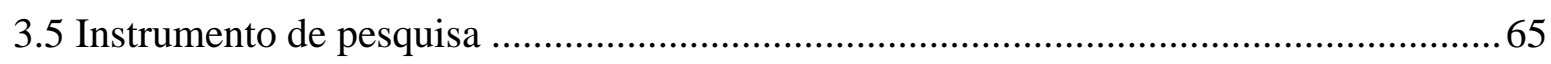

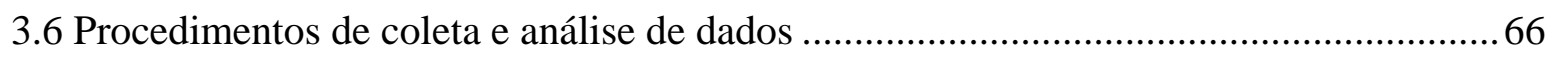

4 Resultados e Discussão ................................................................................................68

4.1 Identificação da percepção em relação às políticas e práticas de gestão de pessoas .......68

4.2 Identificação da resiliência no trabalho dos servidores da FUB .....................................73

4.3 Validação confirmatória dos modelos de mensuração ……………………………….....76

4.3.1 Validação confirmatória do modelo de políticas de práticas de gestão de pessoas .77

4.3.2 Validação confirmatória do modelo de resiliência no trabalho .................................79

4.4 Modelo estrutural de predição entre políticas e práticas de gestão de pessoas e

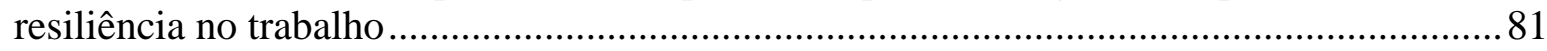

5 Conclusão ................................................................................................................................. 87

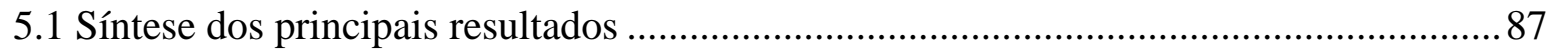

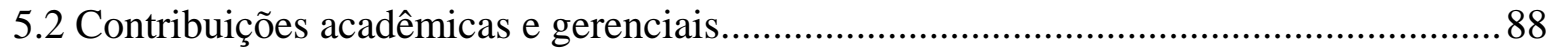

5.3 Limitações e recomendações para estudos futuros …………………………………........ 89

Referências .........................................................................................................................92

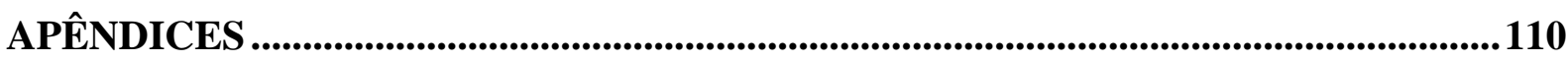

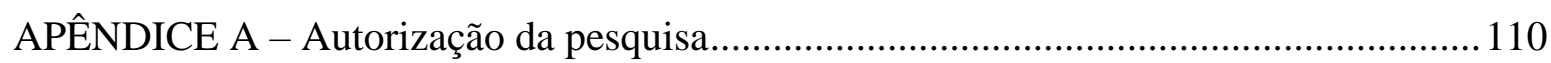

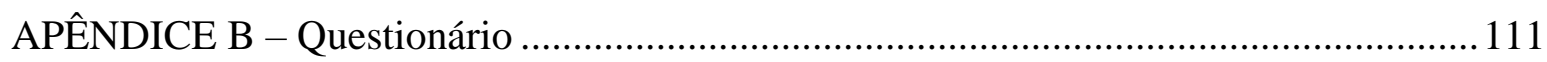

ANEXOS …......................................................................................................................................... 115 
ANEXO A - Lista de periódicos com classificação Qualis igual a superior a B1 Administração, Ciências Contábeis e Turismo

ANEXO B - Lista de periódicos com classificação Qualis igual ou superior a B1 -

Psicologia

\section{LISTA DE FIGURAS}

Figura 1 - Protocolo da Seleção de Estudos de Políticas e Práticas de GP ............................. 31

Figura 2 - Protocolo da Seleção de Estudos de Resiliência no Trabalho ................................. 44

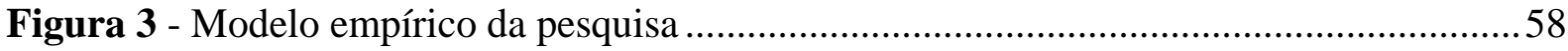

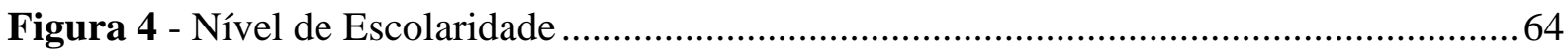

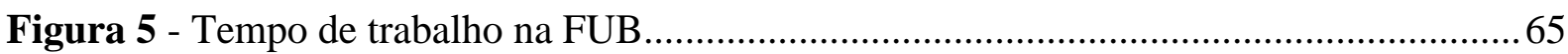

Figura 6 - Distribuição da frequência dos fatores da EPPRH ............................................. 72

Figura 7 - Distribuição da frequência dos itens da Escala de Resiliência no Trabalho............ 75

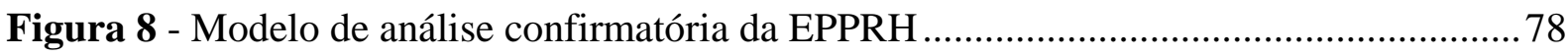

Figura 9 - Modelo de análise confirmatória da Escala de Resiliência no Trabalho ................ 80

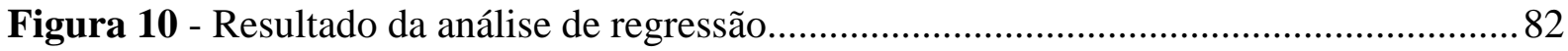

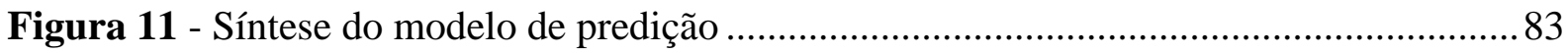

Figura 12 - Estudos que abordaram consequentes de envolvimento......................................84

\section{LISTA DE TABELAS}

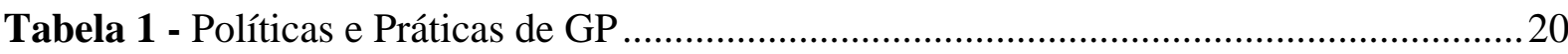

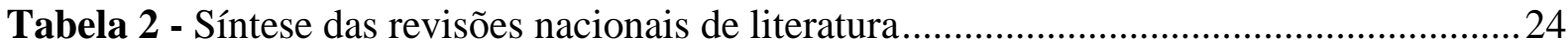

Tabela 3 - Estágios de um Processo de Revisão Sistemática .................................................. 30

Tabela 4 - Títulos dos artigos, Autor(es), Ano de publicação, Periódicos e Classificações Qualis

Tabela 5 - Síntese da categorização dos artigos teórico-empíricos analisados ...................... 49

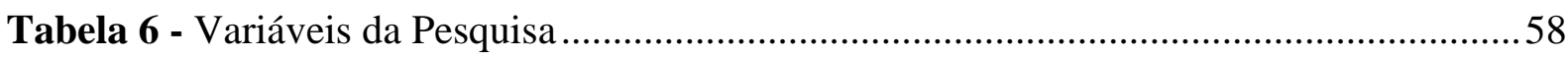

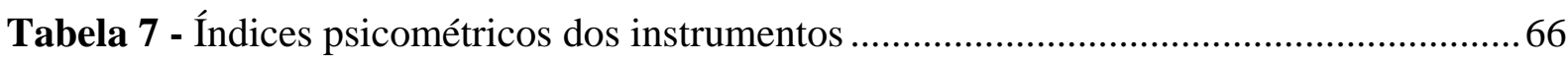

Tabela 8 - Média, desvio-padrão, moda, mínimo e máximo dos itens da EPPRH.................. 68

Tabela 9 - Média, desvio-padrão, moda, mínimo e máximo dos fatores da EPPRH ..............70

Tabela 10 - Média, desvio-padrão, moda, mínimo e máximo da Escala de Resiliência no Trabalho.

Tabela 11 - Índices de ajuste da análise confirmatória da EPPRH 77

Tabela 12 - Índices de ajuste da análise confirmatória da Escala de Resiliência no Trabalho 79 


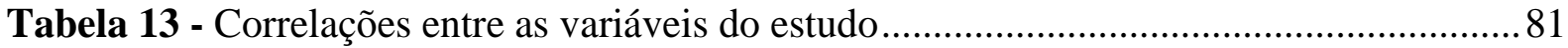

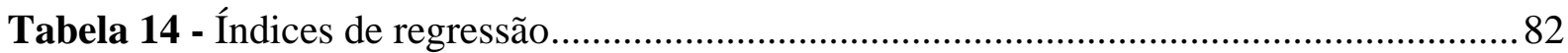




\section{Introdução}

Ao assumirem um papel relevante nas organizações atualmente, as pessoas constituemse como competências essenciais de diferenciação estratégica, uma vez que são as principais protagonistas na consecução dos resultados organizacionais e as responsáveis pela produção de conhecimento. Nesse sentido, as políticas de gestão de pessoas (GP) são importantes quando estão alinhadas às metas da organização, fornecendo condições para que as pessoas contribuam efetivamente para o alcance de resultados superiores (Armstrong, 2014; Bohlander \& Snell, 2009; Boudreau \& Lawler, 2014; Deadrick \& Stone, 2014; Demo, Martins, \& Roure, 2013; Legge, 1995, 2006; Mathis \& Jackson, 2003).

Em vista da emergência da gestão estratégica de pessoas associada à tese do alinhamento estratégico, surgiram novas ferramentas de GP úteis à construção de sistemas produtivos ao promoverem melhores resultados, além de valorizarem o envolvimento, a integração e o desenvolvimento dos colaboradores (Mascarenhas \& Kirschbaum, 2008). Assim, do ponto de vista da GP estratégica, políticas e práticas podem ser mutuamente reforçadas para ajudar no alcance dos objetivos organizacionais (Morris \& Snell, 2010), pois elas fornecem ferramentas para capturar e comunicar a visão estratégica e os objetivos da organização de maneira que podem ser mais facilmente entendidos e executados pelos colaboradores (Vakola, Soderquist, \& Pratascos, 2007).

Nesse sentido, as políticas de GP ganham destaque ao favorecerem o comprometimento dos colaboradores, bem como a produtividade, a lucratividade e a qualidade nas organizações (Guest, 1987; Schneider \& Bowen, 1985; Ulrich, Halbrook, Meder, Stuchlik, \& Thorpe, 1991). Tendo isso em vista, as políticas de GP devem ser constantemente monitoradas e adequadas ao ambiente e necessidades organizacionais (Abdullah, 2010; Cardoso, 2006; Rynes, Gerhart, \& Minette, 2004). Também, as políticas de GP têm que constituir um documento público, acessível a todos na organização, pois elas só serão úteis e eficazes se devidamente conhecidas e compreendidas por todos (Singar \& Ramsden, 1972).

Visto que os profissionais que trabalham com gestão de pessoas facilitam o desenvolvimento de alta performance e de uma força de trabalho competente nas organizações (Inyang \& Akaegbu, 2014), é importante conhecer os resultados de políticas e práticas de GP constatados empiricamente por estudos científicos relacionais, os quais, segundo Horta, Demo e Roure (2012), vêm apresentando crescimento nos últimos anos, o que demonstra um aumento da importância das políticas de GP para as organizações. 
Nesse contexto, alguns estudos mostraram que as políticas de GP influenciam o bemestar no trabalho (Horta, Demo, \& Roure, 2012; Martins \& Demo, 2014; Rubino, Demo, \& Traldi, 2011; Souza, Bertolini, \& Ribeiro, 2014) e, adicionalmente, as relações de confiança nas organizações (Horta et al., 2012).

Ademais, Majumder (2012) e Nannetti, Mesquita e Teixeira (2015) verificaram forte relação entre práticas de GP e a satisfação dos empregados e ainda, como consequência, a qualidade percebida do serviço influenciou positivamente a satisfação dos clientes (Nannetti, Mesquita, \& Teixeira, 2015).

Neste cenário da GP como propulsora de resultados, Legge (2006) já havia apontado as direções futuras da GP estratégica: a ligação entre práticas de GP e performance. Os estudos de Guest e Conway (2011), Kim e Lee (2012) e Gomide e Tanabe (2012) evidenciaram a associação entre políticas e práticas de GP com uma maior efetividade organizacional. Katou (2012) mostrou que políticas e práticas de GP têm um efeito positivo sobre o desempenho organizacional avaliado por meio de atitudes (satisfação, comprometimento, motivação) e comportamentos (faltas, volume de negócios, disputas) dos empregados.

Nesse sentido, Sheehan (2013) destacou o melhor uso de práticas de seleção com um desempenho laboral superior, aumento da rentabilidade e baixa rotatividade. Leite, Leite e Albuquerque (2013) indicaram que as políticas e práticas de GP, especificamente aquelas baseadas nas estratégias para atrair, desenvolver e reter os profissionais, são vantajosas e eficazes para a empresa.

Práticas efetivas de GP também influenciam e facilitam o processo de fusão entre empresas, como pode ser verificado nos resultados da pesquisa que identificou a percepção dos funcionários da área financeira, incorporada por um grande banco brasileiro, sobre ações adotadas para promover sua alocação, integração, orientação, capacitação e adaptação (Brandão, Silva, Freitas, Pereira, \& Santos, 2013).

Outros estudos empíricos também ressaltaram a influência de políticas e práticas de gestão de pessoas no processo de institucionalização da cultura de segurança (Vieira, Silva, \& Silva, 2014); valores pessoais e percepção de justiça organizacional (Demo, 2010); comprometimento dos colaboradores (Ventura \& Leite, 2014); e desenvolvimento da carreira dos funcionários (Badejo, 2015).

A partir dos resultados desses estudos empíricos, parece possível afirmar que um conjunto de políticas e práticas de GP, sincronizadas com a estratégia organizacional, provocam um impacto positivo na organização, seja ela pública ou privada. 
O sucesso na implementação dos objetivos organizacionais depende muito de quão bem a organização desenvolve seu ciclo de gestão de pessoas, selecionando as pessoas certas, avaliando suas performances e desenvolvendo as competências necessárias para garantir o sucesso de suas estratégias de negócios (Devanna, Fombrun, \& Tichy, 1984), além de proporcionar aos seus trabalhadores a satisfação de condições objetivas no trabalho, como renda e estabilidade no emprego; e condições subjetivas, como segurança, afeto, apoio e reconhecimento social (Ribeiro, Mattos, Antonelli, Canêo, \& Goulart, 2011).

Outrossim, o mundo laboral contemporâneo demanda que o trabalhador seja flexível, adaptável a mudanças e capaz de se moldar constantemente a novas exigências - um trabalhador, portanto, resiliente (Ribeiro et al., 2011). Os autores ressaltam que no tocante à compreensão do processo de resiliência em contextos organizacionais, é importante destacar os fatores de risco e de proteção que permitem a superação das condições adversas e a convivência com a incerteza inerente ao ambiente organizacional atual, dinâmico e globalizado.

Esses fatores de risco abrangem tensões originárias de múltiplos eventos estressantes ou de tensões acumuladas a partir de uma variedade de outros fatores, quais sejam a pressão e a responsabilidade do trabalho, falta de tempo para a família, falta de apoio dos pares ou das chefias/superiores, pouca liberdade de criação, falta de autonomia nas atividades, medo de perder o emprego, obrigação de ter que efetuar cortes no quadro de trabalhadores e assédio moral (Job, 2003b). Já os fatores de proteção, segundo o autor, podem ser considerados como redutores das influências negativas de se aceitar o risco e de buscar formas adaptativas e criativas de enfrentar uma dificuldade, em que podem ser citados a autonomia, a autoestima, o respeito, o reconhecimento, a participação da família e dos amigos e o apoio dos pares e das chefias/superiores, muitos dos quais são estimulados em práticas de gestão de pessoas concernentes à política de envolvimento dos colaboradores (Demo, Neiva, Nunes, \& Rozzett, 2014).

Nesse sentido, para Siqueira e Gomide (2008), o suporte social no trabalho é um importante fator de proteção e promoção da saúde e do bem-estar. Com esse pensamento, Luthar, Chicchetti e Becker (2000) e Angst (2009) afirmam que o suporte social ou o contexto de apoio é um facilitador para o processo de resiliência.

Assim, o funcionamento e a estrutura de uma organização podem ter um grande impacto na saúde e no bem-estar de seus colaboradores, o que, por sua vez, tem impacto na efetividade da organização como um todo (Hernandez, 2007). Segundo Job (2003b), com maior 
autonomia e treinamento, os trabalhadores se sentem mais valorizados e motivados, conseguindo, assim, aumentar sua autoestima e, portanto, sua resiliência.

Haja vista a inexistência de estudos que explorem a relação entre as políticas e práticas de GP e a resiliência no trabalho e tendo na literatura um suporte que indica a possibilidade dessa relação, foi proposto o seguinte problema de pesquisa: as políticas e práticas de gestão de pessoas influenciam a resiliência no trabalho?

Por conseguinte, sustentada na relevância da resiliência no ambiente de trabalho e na importância de estratégias eficazes de gestão de pessoas nas organizações, esta pesquisa teve por objetivo identificar e descrever a influência das políticas e práticas de gestão de pessoas na resiliência no trabalho dos servidores técnico-administrativos da Fundação Universidade de Brasília - FUB/UnB.

Para a consecução do objetivo geral, foram propostos os seguintes objetivos específicos:

I - identificar a percepção em relação às políticas e práticas de gestão de pessoas dos servidores técnico-administrativos da FUB;

II - identificar a resiliência no trabalho dos servidores técnico-administrativos da FUB;

III - testar os modelos de mensuração das variáveis do estudo fazendo sua validação confirmatória;

IV - testar o modelo estrutural de predição das políticas e práticas de gestão de pessoas sobre a resiliência no trabalho.

É pertinente destacar que o papel estratégico da GP aplica-se não só ao contexto privado, com agentes ativos da competitividade e de resultados de lucratividade, mas também ao contexto público, que possui como clientes os cidadãos e a sociedade como um todo, devendo, para tanto, também obter resultados em termos de efetividade (produtividade, atendimento, celeridade, qualidade).

A relevância dessa pesquisa está na contribuição que apresenta aos trabalhos empíricos na área de administração estratégica de gestão de pessoas, sobretudo na investigação da resiliência no trabalho como consequente da percepção de políticas e práticas de GP, tema ainda pouco explorado, porém bastante promissor para a compreensão do comportamento, da percepção humana e do desempenho do trabalhador (Emílio \& Martins, 2012).

Por fim, um trabalho científico precisa apresentar contribuições acadêmicas e práticas, visto que a administração é uma ciência essencialmente aplicada e nessas contribuições residem a justificativa e a relevância do trabalho.

No que se refere às contribuições acadêmicas, esse estudo buscou preencher a lacuna na literatura no que tange à relação entre políticas e práticas de gestão de pessoas e resiliência no 
trabalho, avançando teoricamente na identificação de consequentes de políticas e práticas de GP. Além disso, os instrumentos de medida utilizados são atuais e com bons índices psicométricos, inclusive, no caso da escala de percepção das políticas e práticas de gestão de pessoas, validada transculturalmente. No que tange ao lócus de pesquisa, a contribuição também merece ser destacada pelo caráter inovador da pesquisa no setor público, pois a prevalência de estudos relacionados encontra-se na área privada para as duas variáveis. Sucintamente, podem ser apontados alguns estudos empíricos publicados em 2015 na temática de políticas e práticas de GP na área pública: Costa, Borges e Barros (2015); Dias e Borges (2015); e Maccali, Kuabara, Takahashi, Roglio e Bohes (2015). Com relação à resiliência no trabalho, foram identificados estudos relacionais sobre o tema no setor público brasileiro somente datando dos últimos 5 anos (Belancieri, Beluci, Silva, \& Gasparelo, 2010; Carvalho, Borges, Vikan, \& Hjemdal, 2011; Carvalho, Teodoro, \& Borges, 2014; Santos \& Moreira, 2014), o que corrobora a recenticidade desse tema na área pública. O presente estudo, além de contribuir com a produção dos estudos relacionais, aborda a resiliência no setor público como variável critério.

Outrossim, como contribuição prática, esse estudo engendrou um diagnóstico para os gestores da instituição, na medida em que identificou a percepção das atuais políticas e práticas de gestão de pessoas, bem como da autoavaliação da resiliência dos servidores da FUB/UnB. Um dos motivadores para a realização desse estudo na Fundação Universidade de Brasília é que a pesquisadora é servidora pública da instituição. 


\section{Referencial Teórico}

\subsection{Políticas e práticas de gestão de pessoas}

A seção que se apresenta refere-se à variável políticas e práticas de GP, contemplando o estado da arte com seus principais conceitos, fundamentos, pressupostos, revisões sobre o tema, medidas e estudos empíricos recentes relacionados à área. Além disso, é apresentado um levantamento bibliométrico da produção acadêmica nacional de 2015, complementando a pesquisa de Demo, Fogaça, Fernandes e Sá (2015), que desenvolveu uma revisão dos artigos publicados entre 2010 e 2014.

\subsubsection{Estado da arte}

A GP está preocupada com todos os aspectos de como as pessoas são empregadas e geridas nas organizações (Armstrong, 2014). O autor define a GP como uma abordagem estratégica, integrada e coerente para o emprego, o desenvolvimento e o bem-estar das pessoas nas organizações. Na visão de Bohlander e Snell (2009), a GP é o processo de gerenciar talentos humanos para atingir os objetivos da organização. Já Mathis e Jackson (2003) descrevem a GP como a habilidade de gerenciar os recursos humanos, por meio de políticas e práticas, para conquistar e manter vantagem competitiva. Nesse trabalho, conforme indica a literatura (Legge, 1995, 2006), os termos GP e RH (Recursos Humanos) são utilizados como sinônimos.

Ao final dos anos 80, a situação da GP estratégica no Brasil ainda era incipiente (Curado, Wood, \& Lins, 1995; Dutra, 1987). Esses autores destacam que, em geral, a maior preocupação das áreas de RH restringia-se a aspectos operacionais do trabalho, sem haver intenção prevalecente com um alinhamento estratégico da organização nem com resultados a longo prazo. As atividades que caracterizam uma GP estratégica, como o treinamento, o recrutamento interno, a busca por práticas ideais e a utilização de terceirização e descentralização de processos ainda eram pouco difundidas (Lacombe \& Tonelli, 2001).

A partir de 1995, como apontado por Fischer (1998), surgiu uma nova tendência no cenário de GP nas organizações brasileiras. Inúmeras mudanças no ambiente econômico e social levaram ao desenvolvimento de uma nova função de gestão de pessoas relacionada com o surgimento de um parceiro estratégico nas organizações (Deadrick \& Stone, 2014). Os autores pontuam que a GP evoluiu a partir de uma função de pessoal para uma de relações 
humanas, posteriormente de relações de trabalho, relações industriais, e mais recentemente, a função estratégica de GP.

Nesse ponto de vista, Legge (1995) afirma que, além de uma perspectiva diferenciada de melhor tratamento das pessoas, advinda da clássica administração de pessoal, a GP é realmente distinta por ser uma atividade central de gestão estratégica, já que as pessoas passaram a ser consideradas pela alta administração como o mais importante recurso organizacional a ser gerenciado, envolvendo-as no alcance das metas da organização. Em suma, a GP representa a descoberta da administração de pessoal pelos principais executivos da organização (Legge, 1995). Assim, nascem novos papéis, desafios e perspectivas para a GP. Tal proposta conceitual norteou o presente estudo.

Fischer (1998) destaca que, com o reconhecimento da importância do cliente diante de ambientes tão competitivos, não apenas os processos produtivos foram impactados. As empresas repensaram também os processos de pessoas, a exemplo do que já vinha acontecendo em outros países. Assim, segundo o autor, algumas políticas e práticas passaram a ser adotadas com um enfoque mais estratégico e tornaram-se dependentes do envolvimento das pessoas nas organizações, o que traçou uma nova perspectiva a ser seguida pela atual GP.

Nessa direção, Lacombe e Tonelli (2001) afirmam que, durante a década de 90, o conceito de GP como vantagem competitiva ampliou ainda mais o leque das atividades necessárias a um gerenciamento de pessoas. As pessoas passaram a representar um papel estratégico e relevante no contexto organizacional atual, quando fontes tradicionais de vantagem competitiva, como tecnologia, não eram mais consideradas suficientes para garantir uma posição competitiva sustentável (Demo et al., 2013).

Considerando os conceitos, fundamentos e pressupostos da gestão de pessoas, de acordo com Mascarenhas e Kirschbaum (2008), a emergência da gestão estratégica de pessoas associada à tese do alinhamento estratégico propiciou o surgimento de novas ferramentas de GP úteis à construção de sistemas produtivos que valorizem o envolvimento, a integração e o desenvolvimento dos funcionários ou colaboradores. Sob essa perspectiva, Armstrong (2014) argumenta que a GP deve ser coerente com os valores organizacionais vigentes, sendo suas principais características a estratégia com ênfase na integração; o foco no empreendimento e nos valores do negócio; e o tratamento das pessoas como recursos valiosos para a organização (capital humano). Para isso, a área de GP precisa primar por um maior bem-estar das pessoas, permitindo-lhes uma maior realização pessoal e profissional (Demo, 2012).

Conforme Guest (1987), os fundamentos da GP envolvem os seguintes objetivos: de integração, isto é, os recursos humanos integrados aos planos estratégicos da organização; de 
comprometimento dos empregados com a organização; de flexibilidade/adaptabilidade das estruturas e funções organizacionais; e de qualidade, isto é, qualidade em relação às pessoas, ao desempenho, aos padrões e à imagem pública. Além de estar alinhada ao planejamento e à estratégia organizacional, Bohlander e Snell (2009) argumentam que a gestão de pessoas deve ser devidamente suportada por teorias coesas e consistentes.

Da mesma maneira, a partir do pressuposto de que a GP precisa ser alçada ao nível estratégico das organizações, Legge (2006) ressalta dois pontos importantes para a GP: as políticas de GP devem ser integradas ao planejamento estratégico da organização e usadas para reforçar uma cultura organizacional condizente com os interesses da organização; e os recursos humanos constituem uma valiosa fonte de vantagem competitiva. Para a autora, a GP estratégica estuda como as relações de trabalho são gerenciadas pela organização de forma a alcançar suas metas. A proposta de Legge (2006) está de acordo com a visão baseada em recursos da firma apresentada por Barney (1991), a qual defende que os talentos e suas interações são recursos valiosos na produção de conhecimento e consecução dos objetivos organizacionais, premissas essas que definem os pressupostos e fundamentos das políticas e práticas de GP.

Nesse contexto, a moderna GP distingue-se da clássica administração de pessoal. Legge (1995) propõe que, em se tratando de gestão de recursos humanos, as teorias podem ser agrupadas em duas versões: a conservadora (hard) e a moderna (soft). A versão conservadora foca principalmente a questão da integração das políticas de RH com a estratégia empresarial, com ênfase nos aspectos quantitativos e calculativos, entendendo as pessoas como qualquer outro recurso econômico, um modo racional (Armstrong, 2014). E a versão moderna, de acordo com Legge (1995), além de primar pela integração de atividades de RH e estratégias empresariais, entende as pessoas como patrimônio organizacional valioso e fonte de vantagem competitiva. Os funcionários e colaboradores passam a ser insumos proativos do processo produtivo e não meros recursos passivos. Segundo Armstrong (2014), a versão moderna tem suas raízes na escola de relações humanas e enfatiza a comunicação, a motivação e a liderança.

Devanna, Fombrun e Tichy (1984) ressaltam que a GP é reconhecida como importante propulsora da efetividade organizacional e que o sucesso na implementação dos objetivos organizacionais estratégicos depende muito de quão bem a organização desenvolve seu ciclo de recursos humanos, selecionando as pessoas certas, avaliando e recompensando suas performances e desenvolvendo as necessidades para garantir o sucesso de suas estratégias de negócios. Nessa linha, Inyang e Akaegbu (2014) argumentam que os profissionais de RH 
facilitam o desenvolvimento de alta performance e de uma força de trabalho competente ao serem os responsáveis por desenhar e implementar estratégias de GP para nortear a prestação de serviços e aumentar a efetividade organizacional.

Do ponto de vista da GP estratégica, políticas e práticas podem ser mutuamente reforçadas para ajudar no alcance dos objetivos organizacionais (Morris \& Snell, 2010). Elas fornecem ferramentas para capturar e comunicar a visão estratégica e os objetivos da organização em termos claros que podem ser mais facilmente entendidos e executados pelos colaboradores (Vakola et al., 2007). Para Armstrong (2014), a GP envolve a aplicação de políticas e práticas nas áreas de organização, recursos utilizados, aprendizagem e desenvolvimento, desempenho e recompensa e da prestação de serviços que melhorem o bemestar dos trabalhadores.

Nesse cenário, as políticas de GP ganham destaque no processo de desenvolvimento, valorização e retenção de talentos, estando geralmente alinhadas às estratégias da organização, favorecendo o comprometimento dos empregados (Ribeiro, Roglio, \& Pécora, 2013). Além disso, as políticas de GP precisam ser guiadas pela lógica de competências desenvolvidas em conformidade com os requisitos dos processos de negócios (Serpell \& Ferrada, 2007). Tendo isso em vista, certas políticas de GP, como sistema de recompensas, treinamento, desenvolvimento e comunicação devem ser constantemente monitoradas e adequadas com o ambiente e necessidades da organização (Abdullah, 2010; Cardoso, 2006; Rynes et al., 2004).

E como podem ser definidas as políticas e práticas de GP? Em um esforço para diferenciar esses conceitos, Martín-Alcázar, Romero-Fernández e Sánchez-Gardey (2005) argumentam que as estratégias de GP definem as diretrizes para a gestão da força de trabalho. As políticas, por sua vez, buscam coordenar as práticas para que tenham coerência e sigam na mesma direção. Para os autores, as práticas estão no menor nível entre os três e representam as ações de fato. Na visão de Armstrong (2014), as políticas de GP definem o posicionamento e as expectativas com relação à forma de tratamento dos indivíduos e delas derivam as principais ações dos gestores ao se depararem com problemas na área de GP. As políticas servem ainda, segundo o autor, como ponto de referência para o desenvolvimento de práticas organizacionais e para decisões tomadas pelas pessoas, além de promoverem um tratamento equitativo entre os indivíduos.

Grande número de autores usa a expressão “políticas de GP”, as quais são subdivididas em práticas ou ações (Dessler, 2003; Guest, 1989; Legge, 1995; Mathis \& Jackson, 2003; Singar \& Ramsden, 1972; Sisson, 1994; Storey, 1995). Contudo, não há consenso quanto aos 
termos utilizados, uma vez que foram observadas nomenclaturas diversas na literatura que se referem, direta ou indiretamente, a políticas de GP, tais como: processos, atividades, sistemas, funções e técnicas de GP (Demo, Fogaça, Fernandes, \& Sá, 2015).

Para esse estudo, entendem-se políticas como propostas articuladas da organização no que tange a relações humanas, com o objetivo de alcançar os resultados almejados (Demo, Nunes, Mendes, Ferreira, \& Melo, 2011). Dessa forma, as políticas de GP definem o referencial teórico e prático construído para possibilitar a consecução dos objetivos e finalidades da organização, funcionando como guias de pensamento e ação para a área de GP (Demo, Nunes et al., 2011). Com referência a práticas de GP, elas são entendidas como rotinas e ações organizacionais que operacionalizam as políticas de GP (Demo et al., 2014; Legge, 1995).

A Tabela 1 sintetiza o modelo proposto por Demo et al. (2014), apresentando as seis políticas de GP com seus principais autores, pontos abordados na literatura (práticas) e as respectivas definições propostas.

Tabela 1

Políticas e Práticas de GP

\begin{tabular}{|c|c|c|}
\hline Políticas & Autores & Pontos abordados na literatura \\
\hline $\begin{array}{l}\text { Recrutamento e } \\
\text { Seleção }\end{array}$ & 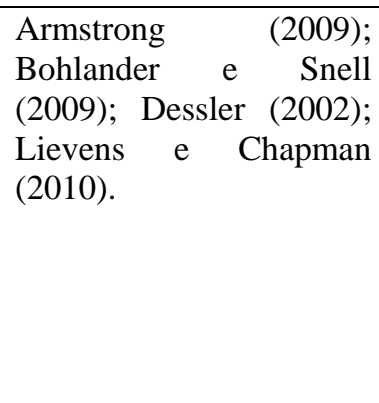 & $\begin{array}{l}\text { Ampla divulgação dos processos de recrutamento externo } \\
\text { e interno; } \\
\text { Informações a respeito de etapas, critérios, desempenhos e } \\
\text { resultados do processo seletivo divulgados aos candidatos; } \\
\text { Utilização de vários instrumentos de seleção; } \\
\text { Testes de seleção conduzidos por pessoas capacitadas e } \\
\text { imparciais; } \\
\text { Processos seletivos elaborados a fim de atrair candidatos } \\
\text { competentes e profissionais qualificados; } \\
\text { Recrutamento interno prioritário ao externo. }\end{array}$ \\
\hline
\end{tabular}

Definição: proposta articulada da organização, com construções teóricas e práticas, para procurar colaboradores, estimulá-los a se candidatar e selecioná-los, buscando harmonizar valores, interesses, expectativas e competências da pessoa com características e demandas do cargo e da organização.

\begin{tabular}{|c|c|c|}
\hline Envolvimento & $\begin{array}{l}\text { Bohlander e } \\
\text { (2009); Dessler }\end{array}$ & $\begin{array}{l}\text { Adaptação dos colaboradores aos seus cargos; } \\
\text { Coerência entre discurso e prática gerencial; } \\
\text { Tratamento respeitoso, atencioso e preocupação com o } \\
\text { bem-estar; } \\
\text { Clima de compreensão, cooperação e confiança entre } \\
\text { gestores e subordinados e entre colegas; } \\
\text { Integração dos colaboradores; } \\
\text { Estímulo à participação e comunicação constantes; } \\
\text { Autonomia na realização das tarefas e na tomada de } \\
\text { decisões; } \\
\text { Reconhecimento e feedback contínuos; } \\
\text { Identificação de necessidades, valores e preocupações dos } \\
\text { colaboradores, estabelecendo relacionamentos; } \\
\text { Existência de canais de comunicação interna. }\end{array}$ \\
\hline
\end{tabular}

Definição: proposta articulada da organização, com construções teóricas e práticas, para criar um vínculo afetivo com seus colaboradores, contribuindo para seu bem-estar, em termos de reconhecimento, relacionamento, participação e comunicação. 


\begin{tabular}{|c|c|c|}
\hline Políticas & Autores & Pontos abordados na literatura \\
\hline $\begin{array}{l}\text { Treinamento, } \\
\text { Desenvolvimento \& } \\
\text { Educação }\end{array}$ & $\begin{array}{l}\text { Bohlander e Snell } \\
\text { (2009); Borges-Andrade, } \\
\text { Abbad e Mourão (2006); } \\
\text { Dessler } \\
\text { Goldstein } \\
\text { (1994); } \quad \text { (2002); Sisson } \\
(2007) \text { Winterton }\end{array}$ & $\begin{array}{l}\text { Diferenças entre treinamento (curto prazo), } \\
\text { desenvolvimento e educação (médio e longo prazos); } \\
\text { Estímulo à aprendizagem, ao compartilhamento e à } \\
\text { produção de conhecimento; } \\
\text { Desenvolvimento de competências necessárias ao } \\
\text { desempenho das funções; } \\
\text { Investimento em desenvolvimento e educação; } \\
\text { Treinamentos: levantamento contínuo de necessidades, } \\
\text { avaliação pelos participantes e transferência; } \\
\text { Investimento em métodos modernos de treinamento, } \\
\text { desenvolvimento gerencial e gestão de carreira (educação } \\
\text { a distância e universidades corporativas). }\end{array}$ \\
\hline
\end{tabular}

Definição: proposta articulada da organização, com construções teóricas e práticas, para prover aos colaboradores a aquisição sistemática de competências e estimular a contínua aprendizagem e produção de conhecimento.

\begin{tabular}{lll}
\hline Condições de & Bohlander e Snell & Incentivo à saúde e à qualidade de vida no trabalho; \\
Trabalho & (2009); Dessler (2002); & Oferta de benefícios básicos e complementares; \\
Loudoun e Johnstone & Programas de prevenção de acidentes e promoção da \\
(2010); Sisson (1994). & saúde; \\
& Ergonomia; \\
& Preocupação com a segurança; \\
& Plano flexível de benefícios (plano cafeteria); \\
& Oferta de materiais, equipamentos e tecnologia adequados \\
& ao desempenho eficaz das funções; \\
& Facilidades e conveniência no local de trabalho. \\
\hline
\end{tabular}

Definição: proposta articulada da organização, com construções teóricas e práticas, para prover aos colaboradores boas condições de trabalho em termos de benefícios, saúde, segurança e tecnologia.

\begin{tabular}{llll}
\hline Avaliação de & Bohlander e & Snell & Realizações periódicas; \\
Desempenho e & (2009); Dessler (2002); & Subsídio para a elaboração de um plano de \\
Competências & Devanna et al. (1984); desenvolvimento dos colaboradores e para as tomadas de \\
& Latham, Sulsky e ecisão sobre promoções e aumento de salário; \\
& Macdonald (2007). & $\begin{array}{l}\text { Discussão (elaboração conjunta) e divulgação aos } \\
\text { colaboradores dos critérios e resultados. }\end{array}$ \\
\hline
\end{tabular}

Definição: proposta articulada da organização, com construções teóricas e práticas, para avaliar o desempenho e as competências dos colaboradores, subsidiando as decisões sobre promoções, planejamento de carreira e desenvolvimento.

\begin{tabular}{lll}
\hline Remuneração e & Bohlander e Snell & Remuneração compatível com a formação; \\
Recompensas & (2009); Dessler (2002); & Remuneração compatível com as oferecidas no mercado; \\
& Devanna et al. (1984); & Existência de incentivos como prêmios e promoções; \\
Gerhart (2010); Hipólito & Plano de carreira/progressão funcional claramente \\
& (2001); Sisson (1994). & $\begin{array}{l}\text { definido e conhecido por todos; } \\
\text { Consideração das expectativas e sugestões dos } \\
\end{array}$ \\
& $\begin{array}{l}\text { colaboradores, recompensas customizadas; } \\
\text { Remuneração condicionada aos resultados. }\end{array}$ \\
\hline
\end{tabular}

Definição: proposta articulada da organização, com construções teóricas e práticas, para recompensar o desempenho e as competências dos colaboradores em termos de remuneração e incentivos.

Nota. Fonte: Demo, G., Neiva, E. R., Nunes, I., \& Rozzett, K. (2014). Políticas e práticas de recursos humanos. In Siqueira, M. M. M. (Org.), Novas Medidas do Comportamento Organizacional: Ferramentas de Diagnóstico e de Gestão (pp. 240-245). Porto Alegre: Artmed.

Quanto às revisões nacionais de literatura sobre GP em geral, Tonelli, Caldas, Lacombe e Tinoco (2003) fizeram um balanço da produção em RH do período de 1991 a 2000, publicada em alguns periódicos científicos brasileiros (RAUSP, RAP, RAE e RAC) e no EnANPAD (Encontro da Associação Nacional de Pós-Graduação e Pesquisa em 
Administração). Os resultados indicam que, embora a produção da área tenha aumentado significativamente em volume, o perfil acadêmico de $\mathrm{RH}$ no Brasil era preocupante à época: seu escopo temático era contestado pelo recente crescimento e autonomia do campo de comportamento organizacional; sua base epistemológica era eminentemente funcionalista; a base metodológica era frágil, predominando estudos de caso tipicamente ilustrativos de teoria consolidada (ou seja, sem maior pretensão de indução ou criação de teoria); e a diversidade de origem era baixa: mais de $65 \%$ da produção vinham de apenas 7 programas de pós-graduação.

Nesse sentido, Wood, Tonelli e Cooke (2011) sintetizaram estudos anteriores ao realizarem um levantamento da evolução da GP do período de 1950 a 2010. Os resultados mostram um enfoque em alinhar a GP com o novo cenário do mercado que se apresentava no Brasil, constituído pela abertura de mercado, empreendedorismo emergente, aumento da concorrência e uma busca cada vez maior por inovação, qualidade e eficiência. Conforme destacam os autores, práticas como atração, valorização, retenção de talentos e capacitação passaram a ser de suma importância para as organizações, mostrando-se o principal desafio estratégico da GP no novo milênio, delineando os conceitos, fundamentos e pressupostos da nova GP (Demo et al., 2015).

Já Barreto, Silva, Fischer, Albuquerque e Amorim (2011) investigaram a produção acadêmica dos principais periódicos nacionais e internacionais sobre oito temas emergentes em gestão de pessoas: gestão estratégica de pessoas, gestão da diversidade, gestão de talentos, gestão de pessoas internacional, aprendizagem organizacional, responsabilidade social, gestão de gerações e modalidades de trabalho flexível. Esses temas destacaram-se em uma revisão prévia da literatura em artigos publicados entre 2005 e 2009. A análise dos artigos investigados mostrou os temas gestão de pessoas internacional, gestão estratégica de pessoas, aprendizagem organizacional e gestão da diversidade como os que têm atraído mais atenção dos pesquisadores.

Abrangendo o período de 2000 a 2010, outra revisão nacional encontrada foi a de Mascarenhas e Barbosa (2013), que analisou quatro aspectos dos textos em gestão de pessoas: sua contribuição, referencial teórico, procedimentos metodológicos e discussão. O objetivo era esclarecer suas fragilidades diante das políticas editoriais preconizadas por top journals, em português e inglês, e apontar direções para evolução. Para evoluir qualitativamente nesta década, os autores sugeriram uma agenda de pesquisas visando alcançar impacto, rigor e relevância da produção em Administração no Brasil. Ainda, os autores destacaram que deveria ser dada uma preferência a estudos empíricos, executados segundo metodologias rigorosas e que revelem sua aplicabilidade. 
Com o objetivo de caracterizar a produção científica brasileira sobre a gestão de pessoas entre 2001 e 2010, Meneses, Coelho, Ferreira, Paschoal e Silva (2014) realizaram um estudo em 121 periódicos nacionais de Administração, Ciências Contábeis e Turismo, classificados entre A1 e B4 pela Capes (Coordenação de Aperfeiçoamento de Pessoal de Nível Superior). Os resultados desse trabalho evidenciaram um campo marcado por estudos teórico-empíricos que descrevem facetas da gestão de funções de recursos humanos, sobretudo a da avaliação, a partir da percepção de públicos diversos amostrados de modo não-probabilístico em uma organização por vez, cujo acesso transversal se deu por levantamentos de opinião e estudos de casos operados por questionários e entrevistas, que resultaram no uso prevalente de técnicas estatísticas e de análise de conteúdo.

Adicionalmente, por meio de uma revisão da literatura em periódicos de alto impacto do período de 2001 a 2014, Trindade, Trindade e Nogueira (2015) realizaram uma pesquisa buscando artigos sobre o futuro e as tendências da GP. Como resultado, foram identificados oito grandes temas emergentes que podem ser ponto de partida para o pesquisador interessado em explorar o campo da GP. Um dos temas identificados foi "O impacto das políticas e práticas de RH no valor da empresa”, indicando a importância de se relacionar políticas e práticas de GP com variáveis do comportamento organizacional.

No que tange especificamente às políticas e práticas de GP, o trabalho de Demo, Fogaça, Nunes, Edrei e Francischeto (2011) apresentou uma síntese do estado da arte e o cenário de diversos estudos científicos de primeira linha do período de 2000 a 2010. Os resultados desse trabalho apontam a relevância estratégica para as organizações dos estudos sobre políticas de gestão de pessoas, ratificando os achados de Tonelli et al. (2003). Como sugestão, foi proposto relacionar as políticas e práticas de GP a outras variáveis do comportamento organizacional e combinar diferentes perspectivas metodológicas para analisar com maior propriedade seus efeitos no bem-estar dos colaboradores e nos resultados organizacionais.

Nessa acepção, Demo et al. (2015) desenharam um panorama dos estudos nacionais sobre políticas e práticas de GP, apresentando uma revisão bibliométrica dos trabalhos publicados nos periódicos de primeira linha de Administração e Psicologia, no período de 2010 a 2014, com o objetivo de complementar a revisão de Demo, Fogaça et al. (2011). Quanto aos resultados desse estudo, o aumento dos indicadores de produção científica no período analisado apontam o vigor acadêmico da área e a relevância estratégica para as organizações dos estudos relacionados às políticas e práticas de GP, corroborando com os resultados das pesquisas de Tonelli et al. (2003) e Demo, Fogaça et al. (2011). Além disso, 
Demo et al. (2015) identificaram a necessidade de estudos que relacionem as políticas de GP a variáveis do comportamento organizacional, bem como a construção e validação de medidas sobre o tema.

A Tabela 2 apresenta uma síntese das revisões nacionais de literatura encontradas quanto à GP, organizada por ordem cronológica de publicação.

Tabela 2

Síntese das revisões nacionais de literatura

\begin{tabular}{|c|c|c|}
\hline Autores & Período & Principais conclusões \\
\hline Tonelli et al. (2003) & 1991 a 2000 & $\begin{array}{l}\text { a produção aumentou em volume, escopo temático } \\
\text { contestado, base epistemológica eminentemente } \\
\text { funcionalista, base metodológica frágil, sem pretensão } \\
\text { de indução ou criação de teoria, baixa diversidade de } \\
\text { origem dos estudos }\end{array}$ \\
\hline Wood et al. (2011) & 1950 a 2010 & $\begin{array}{l}\text { enfoque em alinhar a GP com o novo cenário do } \\
\text { mercado que se apresentava no Brasil }\end{array}$ \\
\hline Barreto et al. (2011) & 2005 a 2009 & $\begin{array}{l}\text { temas que têm atraído a atenção dos pesquisadores: } \\
\text { gestão de pessoas internacional, gestão estratégica de } \\
\text { pessoas, aprendizagem organizacional e gestão da } \\
\text { diversidade }\end{array}$ \\
\hline Demo, Fogaça et al. (2011) & 2000 a 2010 & $\begin{array}{l}\text { sugestão de agenda de pesquisa: relacionar as políticas e } \\
\text { práticas de GP a outras variáveis do comportamento } \\
\text { organizacional e combinar diferentes perspectivas } \\
\text { metodológicas }\end{array}$ \\
\hline Mascarenhas e Barbosa (2013) & 2000 a 2010 & $\begin{array}{l}\text { sugestão de agenda de pesquisa: alcançar impacto, rigor } \\
\text { e relevância da produção em Administração no Brasil; } \\
\text { dar preferência a estudos empíricos e metodologias } \\
\text { rigorosas que revelem sua aplicabilidade }\end{array}$ \\
\hline Meneses et al. (2014) & 2001 e 2010 & $\begin{array}{l}\text { predominância de estudos teórico-empíricos que } \\
\text { descrevem facetas da gestão de funções de recursos } \\
\text { humanos, percepção de públicos diversos, modo não- } \\
\text { probabilístico, uma organização por vez, acesso } \\
\text { transversal, levantamentos de opinião e estudos de } \\
\text { casos, questionários e entrevistas, uso prevalente de } \\
\text { técnicas estatísticas e de análise de conteúdo. }\end{array}$ \\
\hline Trindade et al. (2015) & 2001 a 2014 & identificação de oito grandes temas emergentes em GP \\
\hline $\begin{array}{l}\text { Demo et al. }(2015) \\
\text { (específica sobre políticas e } \\
\text { práticas de GP) }\end{array}$ & 2010 a 2014 & $\begin{array}{l}\text { aumento dos indicadores de produção científica, vigor } \\
\text { acadêmico da área, relevância estratégica dos estudos } \\
\text { relacionados às políticas e práticas de GP }\end{array}$ \\
\hline
\end{tabular}

Nota. Fonte: Elaborada pela autora.

Quanto às medidas do construto, as políticas e práticas de GP utilizadas nessa pesquisa têm como base a síntese do estado da arte construído por Demo (2012), bem como os trabalhos de Demo et al. $(2012$, 2014) para desenvolver e validar a Escala de Políticas e Práticas de Recursos Humanos (EPPRH). A EPPRH é uma versão aprimorada e completa da Escala de Percepção de Políticas de GP (EPPGP), composta por 4 fatores e 19 itens, e desenvolvida e validada por Demo (2008). Os itens da escala são práticas de RH referentes aos grupos de políticas, que são os fatores. Foram acrescentadas à EPPGP as políticas de 
recrutamento e seleção e de avaliação de desempenho e competências. Assim, a EPPRH contempla 6 políticas de RH: recrutamento e seleção; envolvimento; treinamento, desenvolvimento \& educação; condições de trabalho; avaliação de desempenho e competências; e remuneração e recompensas.

Para compor a versão-piloto da EPPRH, os 19 itens da EPPGP, bem como todos os que foram elaborados para representar as políticas incluídas nessa nova medida, foram revisados e atualizados com base na literatura científica. Partiu-se, então, para a definição da quantidade de itens da escala e sua elaboração, sendo que a versão-piloto da EPPRH continha 88 itens (Demo, Neiva, Nunes, \& Rozzett, 2012).

Primeiramente foi realizada uma análise semântica dos itens, em que participaram 27 pessoas de 12 organizações de diversas áreas de atuação. Nessa etapa caíram 20 itens e a EPPRH ficou composta por 68. Em seguida, procedeu-se à análise de juízes, ou de consistência dos itens, composta por 12 pessoas peritas na área da variável (professores, gestores e pesquisadores de GP). Os itens que não conseguiram uma concordância de $80 \%$ de aplicação aos fatores ou que não conseguiram se encaixar em apenas um fator foram descartados do instrumento. Estes somaram 18 e a EPPRH contou com 50 itens em sua versão de aplicação (Demo et al., 2012).

A amostra para validação foi composta por 632 sujeitos, oriundos de 245 organizações de diversos setores públicos e privados, de atuação local, regional, nacional e multinacional. Para a Análise Fatorial Exploratória foram utilizados 304 indivíduos, selecionados aleatoriamente, a partir da amostra de 632. Já na Análise Fatorial Confirmatória da EPPRH foi utilizada a amostra de 632 colaboradores (Demo et al., 2012).

Com relação à confiabilidade, precisão ou fidedignidade dos fatores, Pasquali (2008) atesta que alfas $(\alpha)$ acima de 0,70 são considerados confiáveis. Já Nunnally e Berstein (1994) sugerem valores acima de 0,80 para alta confiabilidade. Na EPPRH, todos os 6 fatores apresentaram alta confiabilidade, com alfas maiores que 0,80 (Demo et al., 2012).

O estudo do desenvolvimento e validação da EPPRH no Brasil (Demo et al., 2012) foi a base para a validação realizada nos Estados Unidos (Demo \& Rozzett, 2012), da qual resultou um modelo reduzido de 32 itens, os mesmos seis fatores e um ajuste ainda melhor na validação confirmatória. Essa versão norte-americana pode ser denominada "versão reduzida da EPPRH”. Essa versão reduzida foi então traduzida por Demo et al. (2014) e foi um dos instrumentos de medida utilizados na presente pesquisa.

Assim, a EPPRH foi desenvolvida para suprir uma lacuna na literatura, tendo em vista que não foram encontrados outros instrumentos abrangentes e com boa confiabilidade de 
medida de políticas e práticas de gestão de pessoas, além da EPPGP desenvolvida e validada por Demo (2008). Foram encontradas na literatura internacional apenas a escala de Práticas de Trabalho de Alto Desempenho, com foco na política de desempenho, desenvolvida e validada por Huselid (1995), composta por 13 itens e um alfa de Cronbach de 0,67; e indicadores pontuais de práticas de gestão de recursos humanos de Guest (1998) e Pfeffer (2005).

A GP estratégica, conforme já destacado, estuda como as relações de trabalho, formalizadas por meio de políticas e práticas, são gerenciadas pela organização de forma a alcançar suas metas (Legge, 2006). Posto que os profissionais que trabalham com gestão de pessoas facilitam o desenvolvimento de alta performance e de uma força de trabalho competente nas organizações (Inyang \& Akaegbu, 2014), é importante conhecer os resultados empíricos recentes de estudos científicos relacionais de políticas e práticas de GP.

Segundo Lacombe e Chu (2008), grande parte dos estudos sobre GP aborda o tema considerando que suas políticas e práticas podem ser utilizadas para influenciar o comportamento dos funcionários de forma alinhada com a estratégia da organização. Assim, é possível perceber um crescimento da importância das políticas de GP para as organizações nos últimos anos, o que pode ser concluído pelo aumento da produção acadêmica sobre o tema (Horta et al., 2012).

Nesse sentido, Uysal (2012) encontrou fortes correlações positivas e significativas entre algumas políticas de GP citadas na literatura, quais sejam recrutamento e seleção, treinamento, avaliação de desempenho e remuneração. Esse resultado é importante para a compreensão das inter-relações entre políticas de GP com a intenção de reforçar seu efeito nos resultados organizacionais apresentados pelos empregados.

Neste cenário da GP como propulsora de resultados, Legge já havia apontado em 2006 as direções futuras da GP estratégica: a ligação entre práticas de GP e performance. Foram encontrados diversos estudos que atestam que políticas e práticas de GP afetam favoravelmente a performance das organizações (Boselie, Dietz, \& Boone, 2005; Menezes, Wood, \& Gelade, 2010; Subramony, 2009). Guest e Conway (2011) confirmaram a associação entre a adoção de mais práticas de GP, maior efetividade organizacional e melhorias em uma série de indicadores de desempenho. Kim e Lee (2012), ao estudarem empresas de consultoria na Coréia do Sul, encontraram evidências de que as políticas e práticas de GP melhoram tanto as capacidades estratégicas quanto o desempenho organizacional.

Essa associação entre políticas e práticas de GP e perfomance ou desempenho organizacional também é válida para pequenas empresas. O estudo conduzido por Katou 
(2012) mostrou que políticas e práticas de GP têm um efeito positivo sobre o desempenho organizacional avaliado por meio de atitudes (satisfação, comprometimento, motivação) e comportamentos (faltas, volume de negócios, disputas) dos empregados. Na pesquisa de Sheehan (2013), os resultados indicaram que o melhor uso de práticas de seleção está associado com desempenho laboral superior, além de apresentar resultado significativo positivo em termos de aumento da rentabilidade, inovação e baixa rotatividade.

No estudo de Leite et al. (2013), os resultados indicaram que as políticas e práticas de GP, especificamente aquelas baseadas nas estratégias para atrair, desenvolver e reter os profissionais, são vantajosas e eficazes para a empresa. Gomide e Tanabe (2012) também encontraram correlação entre práticas de GP e efetividade organizacional. Nesse âmbito, as práticas de GP, ainda que pouco estruturadas, foram consideradas bem-sucedidas para gerar produtividade, além de engajamento, participação e consolidação de valores (Ladain, Costa, $\&$ Salles, 2012).

Na mesma perspectiva, Adebisi e Oladipo (2015) avaliaram a influência da política de recompensas na produtividade dos colaboradores. Com a pesquisa, os autores concluíram que a produtividade aumenta quando a recompensa estiver ligada à performance. Os autores enfatizam que a política de GP de recompensa é uma estratégia-chave se usada corretamente pela administração, pois tem a capacidade de atrair a força de trabalho, além de retê-la e transformá-la em funcionários comprometidos com a instituição.

Ainda, ALDamoe, Yazam e Ahmid (2011) concluíram que a retenção de funcionários media a relação entre práticas de GP e desempenho organizacional. As percepções dos funcionários quanto às políticas e práticas de GP também influenciam tanto o esforço de trabalho discricionário quanto a assistência ao colega de trabalho (Frenkel, Restubog, \& Bednall, 2012).

Os resultados da pesquisa de Ventura e Leite (2014), em uma instituição de ensino superior, indicam que a gestão estratégica de pessoas influencia o comprometimento dos docentes com a instituição e com a sua missão profissional como professores. Os autores entendem que a legitimidade e credibilidade do modelo de gestão estratégica de pessoas são fatores que se reforçam pelas ações, apresentadas com as práticas de GP, e pelas diretivas, estabelecidas nas políticas de GP, especialmente com estratégias eficazes de comunicação. Da mesma forma, a pesquisa de Scheible e Bastos (2006) concluiu que as percepções, por parte dos funcionários, das práticas de gestão de $\mathrm{RH}$ influenciam o comprometimento organizacional. 
Já Rodrigues, Reis e Gonçalves (2014) realizaram um estudo com o objetivo de investigar como as características das metas e recompensas praticadas influenciam a motivação dos servidores públicos no trabalho. Os resultados mostram que a motivação dos funcionários é influenciada de forma direta e significativa pela valência da missão institucional, pela instrumentalidade ligada às recompensas e pela autoeficácia no alcance das metas.

Alguns estudos apontam que as políticas de GP influenciam o bem-estar no trabalho (Martins \& Demo, 2014; Nishii, Lepak, \& Schneider, 2008; Souza et al., 2014; Turner, Huemann, \& Keegan, 2008). Além do bem-estar, as políticas de GP influenciam as relações de confiança nas organizações (Horta et al., 2012; Mariotti \& Souza, 2009; Tzafrir, 2005).

Ademais, o estudo de Vieira, Silva e Silva (2014) mostrou evidências empíricas sobre a influência das políticas e práticas de GP no processo de institucionalização da cultura de segurança. Os autores destacaram que os programas de capacitação e desenvolvimento de pessoas têm contribuído significativamente para a evolução da empresa, corroborando que a efetividade e a aceitação das políticas de GP estão relacionadas aos valores e à cultura organizacional (Stone, Stone-Romero, \& Lukaszewski, 2007).

Jia, Shaw, Tsui e Park (2014) desenvolveram uma perspectiva socioestrutural quanto às relações de trabalho, as quais são efetivadas por políticas e práticas de GP, ao mostrarem por meio de estudos empíricos que tais relações estão associadas à criatividade das equipes de trabalho, e ainda que essa associação é mediada pela densidade de comunicação relatada no ambiente de trabalho.

Neiva e Goulart (2012), ao analisarem atitudes e percepção dos indivíduos diante da mudança organizacional em três empresas, concluíram que as políticas de GP são preditoras dessas, principalmente as políticas de recrutamento e seleção, recompensas, avaliação de desempenho e envolvimento. Já o estudo de Demo (2010) mostrou relação positiva e forte entre políticas de GP e justiça organizacional em organizações brasileiras públicas e privadas.

Majumder (2012) verificou forte relação entre práticas de GP e satisfação dos empregados em bancos privados de Bangladesh. Similarmente, Nannetti et al. (2015) concluíram que as melhores práticas de RH influenciam a satisfação dos funcionários e ainda que a qualidade percebida do serviço influencia positivamente a satisfação dos clientes. Também com relação à satisfação dos clientes, o estudo de Cantarello, Filippini e Nosella (2012) encontrou relação dessa variável com as práticas de GP.

A partir dos resultados desses estudos empíricos, parece possível afirmar que um conjunto holístico de políticas e práticas profícuas de GP devidamente sincronizado com a 
estratégia empresarial realmente impacta o desempenho da organização, tanto no nível individual, quanto no nível do grupo e também na organização como um todo.

Ainda, pode-se dizer que a gestão estratégica de pessoas é o repensar das políticas, práticas e atividades de GP, integrando-as aos objetivos organizacionais, considerando-se as variáveis ambientais e os múltiplos atores envolvidos, com vistas a facilitar a implantação dos planos da organização, bem como alavancar sua competitividade e capacidade de resiliência (Armstrong, 2014; Buren, Greenwood, \& Sheehan, 2011; Cascio, 2015; Lacombe \& Tonelli, 2001; Leite \& Albuquerque, 2011).

Por fim, haja vista que práticas de GP abrangem os chamados fatores de proteção importantes para superação de condições adversas e convivência com a incerteza inerente ao ambiente organizacional contemporâneo, o que se traduz na resiliência no trabalho (Job, 2003b), a presente pesquisa propõe verificar se a resiliência também pode ser um resultado de políticas e práticas de GP. Dessa forma, será estudada em seção posterior, uma vez que constitui a variável critério do estudo.

\subsubsection{Revisão bibliométrica de políticas e práticas de GP}

A bibliometria, como área de estudo da Ciência da Informação, tem um papel significativo na análise da produção científica de um país, uma vez que revela o grau de desenvolvimento de uma área do conhecimento de um campo científico ou de saber (Araújo \& Alvarenga, 2011). Nessa mesma perspectiva, Deadrick e Gibson (2009) asseveram que a análise da natureza das publicações em periódicos é uma forma de avaliar o desenvolvimento de um campo.

Dessa maneira, com o objetivo de apresentar um panorama das pesquisas relacionadas às políticas e práticas de gestão de pessoas, foi realizada uma revisão bibliométrica dos estudos publicados no Portal de Periódicos da Capes, em nível nacional, nos periódicos de Administração e Psicologia de primeira linha (classificação Qualis da Capes igual ou superior a B1), do ano de 2015, a fim de complementar publicação recente de Demo et al. (2015), que apresentou uma revisão bibliométrica abrangendo o período de 2010 a 2014.

De acordo com a nova plataforma de consulta da Capes (https://sucupira.capes.gov.br/sucupira/public/consultas/coleta/veiculoPublicacaoQualis/listaC onsultaGeralPeriodicos.jsf, recuperado em 16, novembro, 2015), são 70 periódicos nacionais com Qualis igual a superior a B1 da área de Administração, Ciências Contábeis e Turismo. A lista com os respectivos periódicos encontra-se no Anexo A. Já da Psicologia, em que 
também se publica sobre políticas e práticas de GP, conforme a classificação da Capes obteve-se 134 periódicos nacionais com Qualis igual ou superior a B1. No Anexo B consta a lista desses periódicos.

Os artigos pesquisados deveriam conter nos títulos, resumos ou palavras-chave os seguintes termos: "políticas e práticas de gestão de pessoas", "políticas e práticas de recursos humanos", "políticas de gestão de pessoas", "políticas de recursos humanos", "práticas de gestão de pessoas" ou "práticas de recursos humanos", e ainda os termos relacionados às políticas específicas em si: "envolvimento" ("participação", "reconhecimento", "comunicação"), "recrutamento e seleção", "condições de trabalho", "treinamento, desenvolvimento e educação", "avaliação de desempenho e competências" ou "remuneração e recompensas". Além disso, os artigos deveriam ser revisados por pares.

Utilizou-se a metodologia da Systematic Review (Revisão Sistemática), proposta e apresentada por Dybå e Dingsøyr (2008), que consiste em um método estruturado para identificar estudos relevantes sobre um tema em particular. Na Revisão Sistemática, segundo os autores, em cada estágio da pesquisa extraem-se os trabalhos selecionados, que em seguida são submetidos a nova revisão. A Tabela 3 apresenta os estágios de um processo de Revisão Sistemática.

Tabela 3

Estágios de um Processo de Revisão Sistemática

\begin{tabular}{l}
\hline 1. Planejamento da revisão \\
\hline 1.1. Identificação da necessidade de uma revisão \\
\hline 1.2. Desenvolvimento de um protocolo de revisão \\
\hline 2. Condução da revisão \\
\hline 2.1. Identificação da pesquisa \\
\hline 2.2. Seleção de estudos primários \\
\hline 2.3. Avaliação da qualidade do estudo \\
\hline 2.4. Extração de dados \\
\hline 2.5. Sínteses dos dados \\
\hline 2.6. Relatar a revisão \\
\hline
\end{tabular}

Nota. Fonte: Gonzalez, R. A, \& Bruni, A. L. (2015). Esforço Discricionário no Trabalho: Elementos Conceituais e Proposta para uma Agenda de Pesquisa. Anais do Encontro de Gestão de Pessoas e Relações de Trabalho, Salvador, BA, 5 . 
O processo de filtragens sucessivas da presente revisão bibliométrica, que constitui um protocolo de pesquisa, segundo Dybå e Dingsøyr (2008), é apresentado na Figura 1.

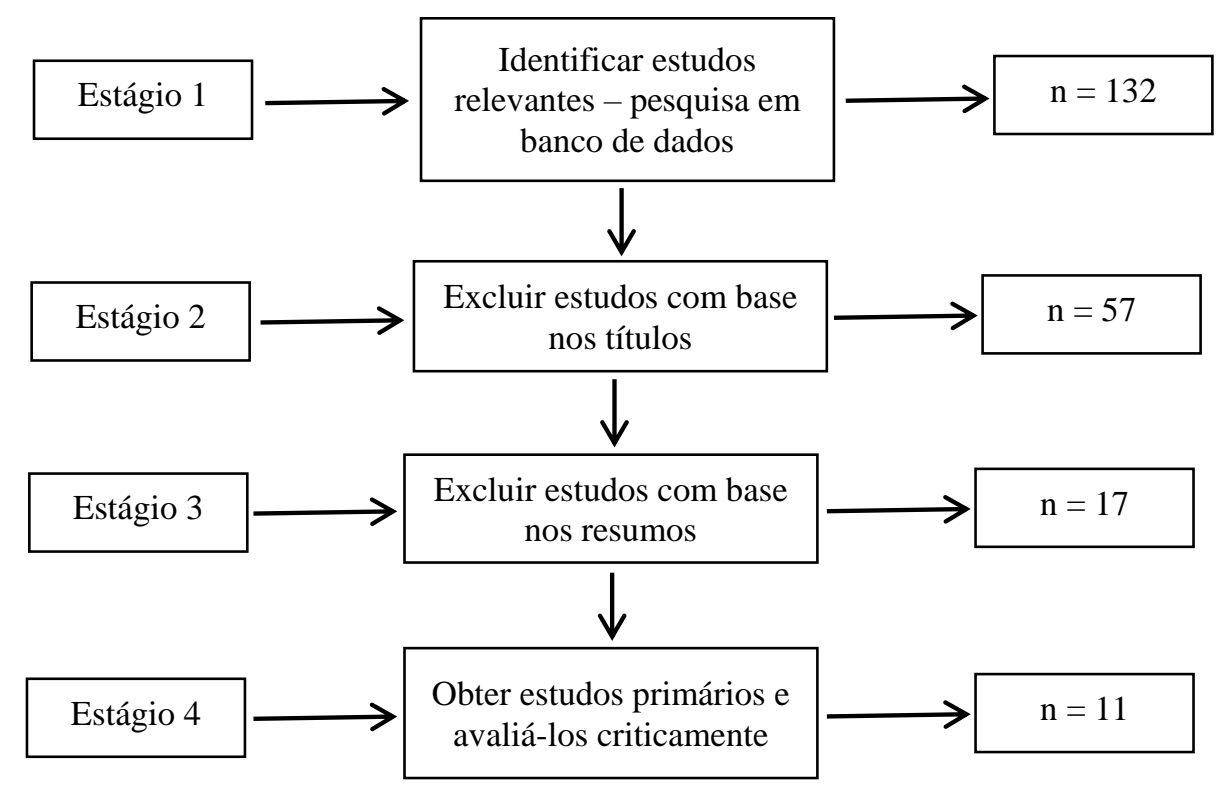

Figura 1. Protocolo da Seleção de Estudos de Políticas e Práticas de GP

Fonte: Adaptado de Dybå, T., \& Dingsøyr, T. (2008). Strength of evidence in Systematic Reviews in software engineering. Proceedings of the Second ACM-IEEE international symposium on Empirical software engineering and measurement. Empirical Software Engineering and Measurement (ESEM'08), 178-187.

Conforme apontado na Figura 1, no primeiro estágio retornaram 132 trabalhos, utilizando-se como parâmetro de busca as palavras-chave mencionadas. Esse universo de 132 artigos constituiu-se na base inicial para o processo de seleção dos artigos. Em seguida, foram excluídos os artigos que se encontravam duplicados, acessados por mais de uma base de dados e que não condisseram com a temática em questão, mas apenas citavam o tema. Nesse estágio, cuja seleção foi feita com base no título, restaram 57 trabalhos. Em seguida, por meio da leitura dos resumos, procedeu-se ao estágio 3 da seleção, restando 17 trabalhos. No estágio 4, última etapa da seleção, os trabalhos foram selecionados a partir da leitura crítica do seu inteiro teor, considerando-se aqueles que tratam mais diretamente do tema da pesquisa, restando 11 trabalhos.

Para se proceder à revisão bibliométrica dos 11 artigos selecionados, utilizou-se as seguintes categorias de análise, conforme proposta de Demo et al. (2015): 1. Nome do Periódico; 2. Instituição de Origem dos Autores; 3. Autores que mais Publicaram no Período de Análise; 4. Enquadramento do Estudo; e, ainda, 5. Assuntos mais Pesquisados dentro do Tema Políticas e Práticas de GP. Para os artigos classificados como teórico-empíricos, categorizou-se ainda: 6. Natureza da Pesquisa; 7. Setor da Economia; 8. Ramo de Atuação das 
Empresas Pesquisadas; 9. Instrumentos Utilizados para Coleta de Dados; e 10. Técnicas de Análise de Dados.

Dos 11 artigos encontrados, com relação aos nomes dos periódicos, os resultados assemelham-se àqueles obtidos na bibliometria de Demo et al. (2015). Em 2015, a Revista Psicologia: Organizações e Trabalho publicou 3 artigos relacionados à políticas e práticas de GP, seguida pela REAd com 2 publicações e as demais (RAM, RAC, Organizações \& Sociedade, Revista de Administração FEA-USP, RAE e Cadernos Ebape) com 1 publicação cada.

Com relação à instituição de origem dos autores, verifica-se uma mudança de panorama com relação à bibliometria de 2010 a 2014 (Demo et al., 2015). Em 2015, a Universidade Federal do Paraná (UFPR) consta com 5 autores; a Universidade Federal de Minas Gerais (UFMG) e a Pontifícia Universidade Católica do Rio de Janeiro (PUC-Rio) com 4 autores; a Universidade Federal do Rio Grande do Sul (UFRGS), a Universidade do Minho (Portugal) e a Universidade Federal da Bahia (UFBA) com 3 autores; e, em seguida, a Universidade Fundação Mineira de Educação e Cultura de Minas Gerais (FUMEC) e a UnB com 2 autores.

No que tange aos autores que mais publicaram, não houve destaque em 2015, pois todos os autores publicaram uma única vez. Merece ser ressaltado, porém, que as pesquisadoras Gardênia Abbad (UnB), Gisela Demo (UnB) e Luciana Mourão (Universo) se destacaram na análise realizada por Demo et al. (2015), e em 2015 Gardênia Abbad (UnB) publicou um artigo.

Além disso, 80\% dos artigos pesquisados por Demo et al. (2015) enquadraram-se como teórico-empíricos. Em 2015 esse porcentual ficou ainda maior, com 100\% dos artigos classificados como teórico-empíricos.

Com relação aos assuntos mais estudados dentre os periódicos nacionais de primeira linha publicados em 2015, treinamento e aprendizagem, condições de trabalho e liderança estão em evidência. Podem ser citados, também, mas com menor expressividade, os temas: desempenho, gestão de talentos, vínculos organizacionais, recrutamento e seleção e burnout.

Dos 11 estudos teórico-empíricos, no que tange à natureza, houve uma inversão com relação aos dados apresentados por Demo et al. (2015), em que havia a predominância de estudos quantitativos. Em 2015, 64\% dos estudos são classificados como qualitativos, seguidos por $27 \%$ como quantitativos e $9 \%$ como multimétodo (quali-quanti).

O setor da economia que prevaleceu, assim como no estudo de Demo et al. (2015), foi o privado, representando 36\% dos estudos empíricos, porém com menor magnitude, já que pesquisas nos setores público e em ambos os setores representaram $27 \%$ cada. Com relação ao 
ramo de atuação, há uma grande variedade, predominando a categoria “diversos setores" em $45 \%$ dos artigos.

Corroborando com a predominância de estudos qualitativos encontrados em 2015, o instrumento de coleta de dados preponderante foi a entrevista, realizada em 7 pesquisas; resultado distinto da bibliometria que abrangeu 2010 a 2014 (Demo et al., 2015), em que prevaleceu o questionário, condizendo com a maioria de pesquisas quantitativas desse período. Com relação à técnica de análise de dados, das publicações de 2015, a análise de conteúdo foi dominante, seguida por análise de regressão e correlação naqueles estudos classificados como quantitativos ou multimétodo (quali-quanti).

\subsection{Resiliência no trabalho}

A seção que se apresenta refere-se à variável resiliência no trabalho, contemplando seu estado da arte, revisões sobre o tema, medidas e estudos empíricos recentes relacionados. Também, é apresentado um levantamento bibliométrico da produção acadêmica nacional sobre resiliência no trabalho.

\subsubsection{Estado da arte}

O cenário laboral vem sofrendo grandes modificações nas últimas décadas. O contexto moderno de trabalho exige que o trabalhador seja flexível, adaptável a mudanças e capaz de se adequar constantemente a novas exigências, aos desafios e dificuldades enfrentados diariamente (Ribeiro et al., 2011; Taboada, Legal, \& Machado, 2006). Conceitos e métodos empregados pelas organizações são capazes de levar o trabalhador a ter atitudes desejadas pela organização, podendo causar, em alguns casos, um movimento obscuro entre a atitude demandada pela organização e a atitude desejada pelo trabalhador, colocando, então, à prova, sua resiliência, ou seja, levando-o a atitudes que o façam adaptar-se ao trabalho, de forma que alcance resultados positivos mesmo em um contexto adverso (Cimbalista, 2006).

De acordo com Job (2003b), a esfera do trabalho é, provavelmente, a fonte principal de significado e ordem da vida humana. Portanto, é importante investigar o modo de ser sujeito no ambiente de trabalho globalizado e as maneiras por meio das quais o indivíduo é resiliente diante de adversidades, pois saber enfrentar situações difíceis pode ser a diferença entre desempenho adequado e inadequado e entre manter-se saudável ou adoecer (Emílio \& Martins, 2012). Com esse ponto de vista, Taboada, Legal e Machado (2006) destacam que se 
torna mister voltar as pesquisas para as potencialidades e habilidades do homem a fim de compreender sua saúde mental e não focar somente em estudos voltados para as patologias, doenças mentais e carências humanas, o que preconiza a psicologia positiva.

Além disso, do ponto de vista da empresa, há razões objetivas para uma maior preocupação com investimentos em mudanças na estrutura organizacional de trabalho, visando eliminar ou diminuir fatores de risco à saúde mental (Codo, 1988). Nesse sentido, parece haver uma tendência em incorporar, no local de trabalho, programas de intervenção oriundos da psicologia positiva na gestão do estresse (Tetrick \& Winslow, 2015). Para as autoras, esses programas podem ser bem sucedidos para a promoção da saúde dos colaboradores.

Desde o final da década de 1970, o conceito de resiliência, palavra originária do latim resiliens (Pinheiro, 2004), começou a ser estudado com mais atenção pela psiquiatria e pela psicologia do desenvolvimento (Lopes \& Martins, 2011). Contudo, o conceito de resiliência é antigo e seu uso é comum no campo da física e engenharia, tendo sido utilizado pela primeira vez pelo inglês Thomas Young, em 1807, para remeter à capacidade de um material receber uma energia de deformação sem sofrê-la de modo permanente (Barlach, Limongi-França, \& Malvezzi, 2008; Oliveira, Reis, Zanelato, \& Neme, 2008).

No campo das ciências humanas, o conceito de resiliência passou a ser utilizado somente no final do século XX para caracterizar indivíduos que seriam imunes a qualquer adversidade (Emílio \& Martins, 2012). No Brasil, os estudos sobre a resiliência são recentes, uma vez que os primeiros trabalhos publicados nessa área podem ser encontrados somente a partir do final da década de 1990 (Lopes \& Martins, 2011) e, ainda, somente nos últimos dez anos a resiliência tem estado presente nos congressos internacionais de Psicologia (Batista, 2010).

Em princípio, o termo resiliência era entendido como sinônimo de invulnerabilidade (Luthar, Cicchetti, \& Becker, 2000). Essa compreensão trouxe influências na maneira de pensar o construto no campo psicológico, que durante décadas considerou a resiliência como uma característica inata ao indivíduo e fixa (Emílio \& Martins, 2012). Por isso, o foco das pesquisas era concentrado inicialmente em determinados traços de personalidade (Ribeiro et al., 2011).

No entanto, com a evolução das pesquisas sobre o tema, passou-se a admitir a vulnerabilidade das pessoas a situações adversas, sendo pessoas resilientes aquelas que conseguiam se recuperar e apresentavam um desenvolvimento saudável na vida adulta (Souza \& Cerveny, 2006). Com relação à superação de adversidades, Yunes (2003) destaca que não 
significa que não ocorram mudanças no indivíduo, como sugere o termo invulnerabilidade. Passou-se também a considerar o desenvolvimento da resiliência nos indivíduos, o que não era possível ao ser concebida como um traço de personalidade (Ribeiro et al., 2011).

Indivíduos resilientes eram aqueles que não experimentavam o estresse ou não se sentiam atingidos por uma adversidade ou um risco (Poletto, Wagner, \& Koller, 2004). Já para Rutter (1993), a resiliência é um conceito muito usado para explicar diferenças nos efeitos que um mesmo nível de estresse tem sobre diferentes indivíduos. Contudo, Brandão, Mahfoud e Gianodorli-Nascimento (2011), ao estudarem conceitos e origens da resiliência de uma maneira abrangente, perceberam que, de modo geral, em relação às concepções adotadas sobre o tema, ingleses e norte-americanos entendem a resiliência como resistência ao estresse, enquanto brasileiros e pesquisadores falantes de línguas latinas têm uma concepção que entende a resiliência ora como resistência ao estresse, ora como associada a processos de recuperação e superação de abalos emocionais causados pelo estresse.

Ademais, a resiliência é considerada um processo que permite encarar adversidades por meio da interação de aspectos sociais e intrapsíquicos (características e capacidades de cada indivíduo) com o seu ambiente (Alvarez, Moraes, \& Rabinovich, 1998; Cecconello, 2003; Yunes, 2003). Buscando alternativas e com a confiança em si mesmo, a resiliência tem sido apontada como importante preditor de adaptação a condições adversas de vida e trabalho, felicidade e recuperação de situações traumáticas (Batista \& Oliveira, 2008).

Campanella (2006) afirma que a resiliência é um dos processos que explicam a superação de crises e adversidades em indivíduos, grupos e organizações. Barlach, LimongiFrança e Malvezzi, em 2008, cunharam o termo "resiliência no trabalho" quando investigaram estresse e coping em executivos e alunos de cursos de educação continuada, destacando que a resiliência no trabalho decorre da capacidade individual de ressignificação de situações adversas (Gomide, Silvestrin, \& Oliveira, 2015).

Para Lazarus e Folkman (1984), uma maneira de gerenciar e extinguir o estresse é realizando o coping, que se refere às formas como se tenta mudar as circunstâncias, ou a forma como são interpretadas, de modo a torná-las mais favoráveis e menos ameaçadoras. $\mathrm{O}$ coping pode ainda ser definido como o conjunto de estratégias que as pessoas utilizam para se adaptarem aos eventos adversos que acontecem (Antoniazzi, Dell'Aglio, \& Bandeira, 1998).

Hockenbury e Hockenbury (2003) descreveram duas formas para gerenciar o estresse: estratégias de coping com enfoque no problema e com enfoque na emoção. Na primeira forma, os esforços são dirigidos para administrar ou mudar um estressor ameaçador ou 
nocivo. Já na segunda forma, os esforços são direcionados para regular ou aliviar o impacto de ordem emocional da situação estressante.

Assim, sendo a resiliência a totalidade da experiência do sujeito no sentido de adaptarse e superar adversidades, e coping as estratégias de solução pontual de uma situação de tensão, fica claro que ambos os conceitos estão intimamente correlacionados (Taboada et al., 2006).

Portanto, entre os mecanismos mediadores da resiliência, podem estar incluídas estratégias pessoais de coping (Rutter, 2007). Dessa maneira, das variáveis que contribuem para uma maior resiliência, destacam-se as estratégias de coping (Busnello, Schaefer, \& Kristensen, 2009).

Todavia, a complexidade da resiliência não se resume à existência de diversos aspectos que podem influenciar o processo de adaptação do indivíduo, ou às inúmeras formas e proporções em que esses aspectos podem estar combinados (Reppold, Mayer, Almeida, \& Hutz, 2012). Masten (2001), Luthar et al. (2000) tratam a resiliência como um processo dinâmico, multidimensional ou ecossistêmico. Nesse sentido, Waller (2001) acrescenta que a resiliência é compreendida de forma sistêmica, a partir da relação indivíduo-contexto.

De acordo com Barlach et al. (2008), o conceito de resiliência no âmbito organizacional refere-se à existência ou construção de recursos adaptativos de maneira que preserve a relação saudável entre o indivíduo e seu trabalho, num ambiente permeado por diversas rupturas, as quais são características do trabalho flexível e globalizado. Por conta disso, é importante que os profissionais que lidam com as relações estabelecidas entre o homem e o trabalho atentem para o fenômeno da resiliência, com o objetivo de compreender e desempenhar ações de proteção e prevenção à saúde do colaborador no contexto de trabalho atual (Ribeiro et al., 2011), as quais se traduzem em práticas de GP. Para Batista e Oliveira (2012), compreender a resiliência enquanto potencialidade humana pode se constituir em um indicador capaz de influenciar atitudes e comportamentos no trabalho.

No que tange à compreensão do processo de resiliência em contextos organizacionais, é importante destacar os fatores de risco e de proteção que permitem a superação das condições adversas e a convivência com a incerteza inerente ao ambiente organizacional atual (Ribeiro et al., 2011). Além dos fatores de risco e de proteção, as estratégias de enfrentamento (coping) também têm sido importantes na compreensão da capacidade de resiliência de um indivíduo (Oliveira et al., 2008).

Os fatores de risco são tensões originárias de múltiplos eventos estressantes ou de uma variedade de outros fatores, quais sejam: a pressão e a responsabilidade do trabalho, a falta de 
tempo para a família, a falta de apoio dos pares ou dos superiores, pouca liberdade de criação, a falta de autonomia nas atividades, o medo de perder o emprego, a obrigação de ter que efetuar cortes no quadro de trabalhadores e o assédio moral (Job, 2003b). Quando expostos aos fatores de risco, há uma maior probabilidade de os indivíduos adquirirem uma doença (Sapienza \& Pedromônico, 2005). Já os fatores de proteção auxiliam na superação das dificuldades (Eisensten \& Souza, 1993; Ralha-Simões, 2001). Podem ser citados como fatores de proteção a um trabalhador dentro do contexto de trabalho adverso a autonomia, a autoestima, o respeito, o reconhecimento, a participação da família e dos amigos e o apoio dos pares e dos superiores (Job, 2003b).

Ao considerar a importância dos fatores de risco e dos fatores de proteção para compreender o fenômeno da resiliência, é importante destacar que, no contexto organizacional, os recursos de que dispõem os trabalhadores para o enfrentamento das adversidades não estão presentes apenas em seu campo de trabalho, mas também em outros aspectos de suas vidas (Ribeiro et al., 2011). Por isso, embora haja evidências empíricas de que grande parte da diversidade existente entre padrões de adaptação individual possa ser resultante da combinação dos efeitos dos fatores de risco e proteção, o estudo da resiliência não deve estar limitado à investigação de tais elementos (Reppold et al., 2012).

A resiliência tende a ser particularmente importante e, muitas vezes, essencial em momentos de transição, mudanças e incertezas, os quais comumente produzem nos indivíduos um nível elevado de estresse (Ribeiro et al., 2011). Desse modo, a investigação da resiliência em trabalhadores é emergente na literatura de gestão, bem como de suma importância para os gestores organizacionais, pois é um assunto promissor para a compreensão do comportamento, da percepção humana e do desempenho do trabalhador. No entanto, ainda é objeto de um número reduzido de pesquisas, o que configura importante lacuna na literatura científica (Emílio \& Martins, 2012) e, portanto, deve ser mais estudada para que seja possível compreender como se deve intervir para promover a resiliência (Angst, 2009).

No que tange às revisões nacionais de literatura sobre o tema, podem ser citadas a de Souza e Cerveny (2006) e a de Oliveira, Reis, Zanelato e Neme (2008). O artigo de Souza e Cerveny (2006) traz uma revisão da literatura sobre a resiliência psicológica, apresentando um levantamento das pesquisas publicadas desde a introdução do conceito no campo das Ciências da Saúde, que as autoras afirmam como a década de 1970. Pelo levantamento realizado, em geral, a maior parte dos temas pesquisados inclui homossexuais, etnia, família e saúde, adolescentes e crianças; e os temas menos estudados foram profissional, casal, racismo, gêmeos. Como agenda de pesquisa, as autoras sugerem que sejam realizados levantamentos e 
revisões da literatura focalizados em temas específicos, pois assim será possível compreender com mais profundidade como a resiliência tem sido conceituada e aplicada, particularmente na realidade brasileira.

Já Oliveira et al. (2008) fizeram um levantamento bibliográfico de pesquisas relacionadas à resiliência no período de 2000 a 2006. Os dados apontam que há ênfase nas pesquisas básicas, prevalência de população de adultos nos estudos analisados e utilização da entrevista como principal instrumento. Os resultados também indicam que o conceito de resiliência está em construção; além disso, os autores afirmam que a resiliência tem relação direta com os fatores de risco e de proteção e, por último, que é necessário o desenvolvimento de programas de prevenção e intervenção no contexto organizacional.

Para Pesce et al. (2005), o aumento do interesse pelo conceito de resiliência evidencia a necessidade do desenvolvimento de medidas apropriadas desse construto. Dessa maneira, para que se estenda a amplitude dos estudos sobre resiliência e se consolidem os achados sobre o tema, torna-se importante a utilização de instrumentos de medida válidos e fidedignos, de rápida aplicação e interpretação (Lopes \& Martins, 2011). No contexto das organizações, esse problema ainda é maior, uma vez que foi localizado apenas um instrumento validado no Brasil para uso com trabalhadores (Batista \& Oliveira, 2008).

Uma breve revisão dos estudos sobre resiliência no trabalho revela que o problema da medida é um aspecto preocupante, pois a medida nem sempre se relaciona com o conceito de resiliência (Harland, Harrison, Jones, \& Reiter-Palmon, 2005). Outrossim, os estudos sobre resiliência no contexto do trabalho são ainda recentes (Harland et al., 2005; Luthans, 2002; Luthans \& Youssef, 2007; Todd \& Worell, 2000) e medidas de resiliência são raras (Gomide et al., 2015). Dessa forma, percebe-se a necessidade de se ampliar os estudos sobre resiliência, e de se disponibilizar medidas com boas características psicométricas, não só com populações de adolescentes, como é comumente encontrado nos estudos brasileiros, mas também com populações adultas e de trabalhadores (Lopes \& Martins, 2011). Para Carvalho, Teodoro e Borges (2014), um instrumento de medida da resiliência pode ser útil para subsidiar as decisões de gestão organizacional. Os autores sugerem aprofundar o fenômeno da resiliência no contexto do trabalho e das organizações.

Portanto, faz-se necessário identificar os instrumentos de medida de resiliência existentes na literatura científica. A Resilience Scale, desenvolvida por Wagnild e Young (1993), foi adaptada e validada para a população brasileira por Pesce et al. (2005), com uma amostra de adolescentes. A escala original é um inventário com 25 itens, com um alfa de Cronbach de 0,91 , que mede os níveis de adaptação psicossocial positiva em face de eventos 
de vida importantes. Nessa medida, a estrutura fatorial da resiliência é composta por dois fatores: competência e aceitação de si mesmo e da vida. Já no estudo de Pesce et al. (2005), foram identificados três fatores: resolução de ações e valores; independência e determinação; autoconfiança e capacidade de adaptação a situações, com alfa de Cronbach de 0,80 na amostra total.

Além disso, o Inventário de Fatores Protetores de Baruth, ou Baruth Protective Factors Inventory (BPFI), desenvolvido por Baruth e Carroll (2002), possui 16 itens e mede a resiliência por meio da avaliação de 3 fatores: personalidade adaptativa (alfa de Cronbach de 0,76), meio suportivo (alfa de 0,98) e experiências compensatórias (alfa de 0,83), e com alfa geral de 0,93 (Baruth \& Carroll, 2002; Lopes \& Martins, 2011).

A Connor-Davidson Resilience Scale, ou CD-RISC (Connor \& Davidson, 2003), é um instrumento que teve sua origem a partir de um programa norte-americano de pesquisa sobre transtorno de estresse pós-traumático (Reppold et al., 2012). Internacionalmente reconhecida e amplamente utilizada, a CD-RISC corresponde a um instrumento formado por 25 itens autorrespondidos distribuídos em 5 fatores, quais sejam: competência pessoal, padrões elevados e tenacidade; confiança nos próprios instintos, tolerância a afeto negativo e efeitos de fortalecimento do estresse; aceitação positiva da mudança e as relações seguras; controle; e influências espirituais. Há ainda uma versão reduzida da CD-RISC, sendo unidimensional de 10 itens: a CD-RISC-10. A CD-RISC-10 foi traduzida para o português pelas pesquisadoras Lopes e Martins (2011) em estudo que tinha como objetivo traduzir os itens para a língua portuguesa, adaptar semanticamente e validar a estrutura fatorial da versão abreviada da CDRISC-10 com uma amostra brasileira. A análise fatorial exploratória confirmou uma estrutura unifatorial, com cargas fatoriais variando entre 0,53 e 0,72 , com os 10 itens traduzidos da escala original e bom índice de confiabilidade (alfa de Cronbach de 0,82). Quanto às limitações, embora o conjunto dos participantes investigados fosse bastante heterogêneo, não contemplou amostras clínicas, não sendo possível concluir sobre as propriedades psicométricas da CD-RISC-10 para essas populações no Brasil (Lopes \& Martins, 2011).

Utilizando uma amostra de 150 estudantes, o estudo de Harland, Harrison, Jones e Reiter-Palmon (2005) avaliou a relação entre os comportamentos do líder e a resiliência do subordinado. Os autores desenvolveram uma escala de resiliência unifatorial, composta por 4 itens, com alfa de Cronbach de 0,85. O foco desses 4 itens é sobre o crescimento e a aprendizagem.

Já a escala RFS (Resilience Factors Scale), desenvolvida e testada por Takviriyanun (2008), é composta por 6 fatores e 25 itens, com alfa de Cronbach de 0,89. A RFS foi 
utilizada para medir a resiliência de jovens tailandeses em situação de risco, especialmente quanto à utilização do álcool pelos adolescentes.

Ademais, a Escala de Resiliência para Adultos (Resilience Scale for Adults - RSA) foi originalmente desenvolvida e validada por pesquisadores noruegueses e validada transculturalmente na Bélgica e no Irã. A última versão da RSA foi traduzida para o português brasileiro em 2009, tendo aspectos de sua validade avaliada em uma amostra de estudantes universitários. A estrutura da RSA é composta por 6 fatores, quais sejam: percepção de si mesmo, futuro planejado, competência social, estilo estruturado, coesão familiar e recursos sociais, com alfas de Cronbach variando de 0,56 a 0,79 (Carvalho et al., 2014). A versão da RSA adaptada ao idioma português do Brasil foi aplicada em estudo desenvolvido com uma amostra de servidores públicos brasileiros e noruegueses (Carvalho et al., 2011). Também, Carvalho et al. (2014), com o objetivo de investigar propriedades de validade fatorial para a RSA quando os respondentes são servidores públicos, realizaram uma pesquisa com servidores públicos de uma universidade federal. Os resultados apontaram a confirmação da estrutura da RSA, mantendo-se composta pelos mesmos 6 fatores, com alfas de Cronbach variando de 0,51 a 0,75 .

Ainda, para avaliar a resiliência de maneira geral, existe a escala validada por Martins, Emílio e Siqueira (2011). A escala, denominada Escala de Avaliação de Resiliência (EAR), apresenta em sua versão reduzida 23 itens e avalia 5 fatores: adaptação ou aceitação positiva de mudança (alfa de Cronbach de 0,87), espiritualidade (alfa de 0,90), resignação diante da vida (alfa de 0,73), competência pessoal (alfa de 0,72) e persistência diante das dificuldades (alfa de 0,78).

Especificamente para o contexto do trabalho e organizações, Batista e Oliveira (2008) partiram da versão da Escala de Resiliência, previamente adaptada e validada para adolescentes brasileiros por Pesce et al. (2005), e validaram a Escala de Resiliência em um contexto organizacional. Os resultados da análise indicaram a existência de dois fatores em contraposição aos três fatores do estudo com adolescentes, porém só um fator apresentou confiabilidade satisfatória. Assim, a Escala de Resiliência no Trabalho (Batista \& Oliveira, 2012) possui uma estrutura unifatorial de 15 itens, agregando, em sua maioria, itens do primeiro fator da escala de Pesce et al. (2005) e dois itens do último fator, demonstrando alta confiabilidade (alfa de Cronbach de 0,90) e porcentagem de variância explicada de cerca de $33 \%$. Dessa maneira, pode-se concluir que a escala de Batista e Oliveira (2008) é a única publicada em periódico científico nacional (Batista \& Oliveira, 2012; Gomide et al., 2015), 
efetivamente voltada ao contexto do trabalho nas organizações e com índice de confiabilidade satisfatório, e por isso, foi a medida utilizada na presente pesquisa.

Sendo na pesquisa empírica que se encontra o principal caminho para verificar as possibilidades de diálogo entre diferentes disciplinas (Mendes, 2002), bem como a aplicabilidade dos construtos, torna-se mister conhecer os resultados empíricos recentes de estudos científicos relacionais sobre resiliência.

O estudo de Carvalho, Borges, Vikan e Hjemdal (2011) teve como objetivo analisar a relação entre a resiliência e a socialização organizacional junto a novos servidores de duas universidades públicas, em contextos culturais distintos, quais sejam Brasil e Noruega. As pesquisas em socialização organizacional apontam que a adaptação do indivíduo a um novo cargo e a uma nova organização tende a ser um evento estressor e a resiliência poderia auxiliar a compreensão das diferenças nos resultados de socialização entre indivíduos numa mesma organização. Os resultados demonstram, de modo geral, que a resiliência contribuiu significativamente para explicar os resultados de socialização organizacional, independentemente da nacionalidade e da ocupação. A capacidade preditiva da resiliência em relação à socialização organizacional foi maior entre os novos servidores brasileiros.

Job (2003b) visava medir o grau de resiliência dos indivíduos de uma fábrica multinacional do setor eletroeletrônico. A fábrica encontrava-se num momento de grande incerteza (reestruturação, redução de quadros e possível venda para um grupo japonês cuja cultura era bastante diferente da cultura europeia reinante). Como conclusão, a pesquisa de Job (2003b) identificou que, com maior autonomia e treinamento, as pessoas se sentem mais valorizadas e motivadas, conseguindo, assim, aumentar sua autoestima e, portanto, sua resiliência. Foi identificado, ainda, que o grupo gerencial precisava de apoio no sentido de aumentar sua autoconfiança, e assim, sua resiliência, uma vez que esse grupo é o mais solicitado num momento de grande incerteza quanto ao futuro da organização.

Diante das evidências da literatura, o estudo recente de Gomide et al. (2015) testou um modelo preditivo para bem-estar no trabalho inédito na literatura, consideradas as avaliações sobre os suportes organizacionais (organizacional e social) como antecedentes, mediados pela resiliência no trabalho. O primeiro estudo teve como objetivo validar um instrumento de medida para resiliência no trabalho. Para isso, o instrumento de medida de resiliência construído e validado por Batista e Oliveira (2008) foi adaptado para situações relativas ao trabalho. Já o segundo estudo objetivou adaptar e validar os instrumentos de satisfação com o suporte organizacional percebido e de satisfação com os suportes sociais no trabalho. Por fim, o terceiro estudo foi realizado para testar o poder de mediação da variável resiliência no 
trabalho sobre a relação entre as variáveis satisfações com os suportes organizacionais percebidos e a variável bem-estar no trabalho. Como resultado, o modelo proposto não se confirmou. Contudo, a satisfação com os suportes organizacionais são antecedentes consistentes tanto de resiliência quanto do bem-estar em ambientações corporativas, assim como resiliência também foi preditora de bem-estar.

Emílio e Martins (2012) almejaram identificar e descrever as percepções de resiliência e de autoconceito profissional em policiais militares de uma cidade do interior de São Paulo. Para a medida das variáveis foram utilizadas as escalas de Avaliação de Resiliência em sua forma reduzida e a Escala de Autoconceito Profissional. Os resultados indicaram que os participantes do estudo possuem bons níveis de resiliência, sendo, portanto, capazes de enfrentar as adversidades e de aprender com elas, o que lhes é bastante saudável. Além disso, possuem bom autoconceito profissional. As autoras destacam a importância de a sociedade local poder contar com policiais militares com essas características. Entretanto, Emílio e Martins (2012) ressaltaram que esse grupo não percebe que o trabalho pode afetar sua saúde, talvez por uma atitude de superconfiança, o que preocupa pelos efeitos que essa percepção pode ter em sua saúde e no seu trabalho.

Já a pesquisa de Nalin e França (2015) investigou a importância da resiliência, da satisfação socioeconômica, do tempo de aposentadoria e do planejamento para o bem-estar na aposentadoria de 270 participantes. Os resultados da regressão revelaram a resiliência determinada - maestria, adaptabilidade, desenvoltura e perseverança - e a satisfação socioeconômica como os principais preditores de bem-estar na aposentadoria.

Ademais, o estudo de Batista e Oliveira (2012) investigou sobre um modelo teórico que contemplou como variáveis preditoras percepção de suporte organizacional, afeto e resiliência, e como variável critério a confiança do empregado na organização. Dentre as 4 escalas utilizadas na pesquisa, para a variável resiliência foi utilizada a Escala de Resiliência, desenvolvida por Batista e Oliveira (2008), a mesma escala que foi utilizada na presente pesquisa. Os resultados indicaram que o principal preditor da confiança do empregado é a percepção de suporte organizacional. Afeto foi eliminado de todos os modelos, enquanto que resiliência explicou pequeno porcentual de confiança nos padrões éticos.

Por fim, as organizações têm cada vez mais procurado adotar programas de fortalecimento da resiliência a fim de evitar o absenteísmo, o comportamento contraproducente no trabalho e outros problemas relacionados com o estresse; no entanto, a eficácia desses programas ainda não está clara (Vanhove, Herian, Perez, Harms, \& Lester, 2015). Em estudo recente, os autores realizaram uma meta-análise com o objetivo de 
minimizar essa limitação na literatura, sintetizando a eficácia de programas de resiliência implementados em contextos organizacionais. Os resultados demonstram que o efeito global desses programas foi pequeno e que os efeitos do programa diminuem ao longo do tempo. Por outro lado, uma análise revelou que os programas destinados a pessoas que possam correr maior risco de experimentar o estresse mostrou o efeito oposto sobre o tempo. Os autores sugerem que, para otimizar os programas de construção de resiliência, os desenvolvedores devem cuidadosamente avaliar as necessidades, identificando os indivíduos com risco elevado.

Como visto, a resiliência, tanto no Brasil quanto no exterior, é estudada não apenas como diagnóstico, mas em estudos relacionais como variável preditora, o que ratifica a relevância de também se estudar seus antecedentes, que foi a proposta da presente pesquisa.

\subsubsection{Revisão bibliométrica de resiliência no trabalho}

Assim como na seção referente às políticas e práticas de GP, a revisão bibliométrica do tema resiliência no trabalho tem por objetivo identificar o panorama de publicações a fim de se conhecer o desenvolvimento da área.

Dessa forma, serão apresentados os resultados de uma revisão bibliométrica dos estudos empíricos engendrados em nível nacional a partir de busca no Portal de Periódicos da Capes, o qual agrega os periódicos nacionais classificados pelo sistema Qualis, além das principais bases nacionais e internacionais de periódicos (Scielo, Science Direct, Gale, Sage, Springer Link, American Psychological Association, PePSIC, Oxford Journals, Wiley, JSTOR, Cambridge Journals, Web of Science e Emerald, dentre outras).

O período de análise foi de 2001 (janeiro) a 2015 (novembro) para retratar o cenário da produção científica brasileira sobre o tema no novo milênio. Tal análise permitiu a identificação de lacunas na literatura. A busca foi realizada no mês de novembro de 2015, somente em periódicos nacionais revisados por pares, utilizando as expressões "resiliência no trabalho", "resiliência organizacional" e "resiliência psicológica" nos títulos, resumos e palavras-chave dos artigos, retornando 13 artigos.

Trabalhos de dissertações, teses, monografias e artigos de anais de eventos são considerados em construção para possível posterior publicação em periódicos, de sorte que não foram considerados no presente levantamento, o qual privilegiou, destarte, a produção brasileira científica de primeira linha. 
Também nessa revisão bibliométrica foi utilizada a metodologia da Systematic Review (Revisão Sistemática), proposta e apresentada por Dybå e Dingsøyr (2008). O processo de filtragens sucessivas do presente trabalho, que constitui um protocolo de pesquisa, segundo Dybå e Dingsøyr (2008), é apresentado na Figura 2.

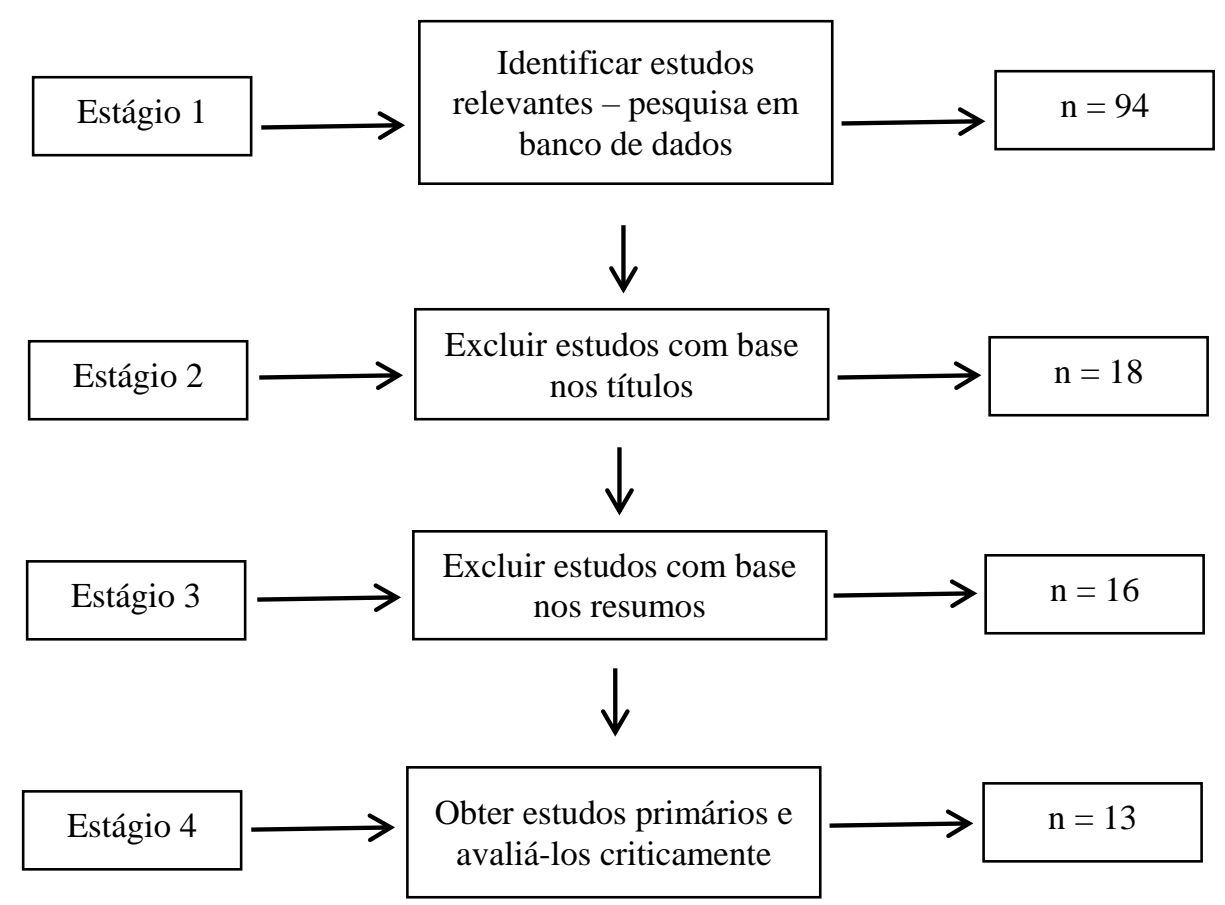

Figura 2. Protocolo da Seleção de Estudos de Resiliência no Trabalho

Fonte: Adaptado de Dybå, T., \& Dingsøyr, T. (2008). Strength of evidence in Systematic Reviews in software engineering. Proceedings of the Second ACM-IEEE international symposium on Empirical software engineering and measurement. Empirical Software Engineering and Measurement (ESEM'08), 178-187.

Conforme apontado na Figura 2, no primeiro estágio retornaram 94 trabalhos, utilizando-se como parâmetro de busca as palavras-chave mencionadas. Esse universo de 94 artigos constituiu-se na base inicial para o processo de seleção dos artigos. Em seguida, foram excluídos os artigos que se encontravam duplicados, acessados por mais de uma base de dados e que não condisseram com a temática em questão, mas apenas citavam o tema. Nesse estágio, cuja seleção foi feita com base no título, restaram 18 trabalhos. Em seguida, por meio da leitura dos resumos, procedeu-se ao estágio 3 da seleção, restando 16 trabalhos. No estágio 4, última etapa da seleção, os trabalhos foram selecionados a partir da leitura crítica do seu inteiro teor, considerando-se aqueles que tratam mais diretamente do tema da pesquisa, restando 13 trabalhos.

Para se proceder à bibliometria, as seguintes categorias de análise dos artigos foram selecionadas, quais sejam, 1. Nome do Periódico, 2. Classificação Qualis do Periódico; 3. Ano de Publicação, 4. Instituição de Origem dos Autores, 5. Autores, 6. Quantidade de 
Autores por Artigo e 7. Enquadramento do Estudo (ensaio teórico ou teórico-empírico). Em segunda instância, para os artigos classificados como teóricos-empíricos, categorizou-se ainda: 8. Abordagem da Pesquisa (quantitativa, qualitativa ou multimétodo), 9. Setor da Economia (primeiro, segundo ou terceiro), 10. Ramo de Atuação das Empresas Pesquisadas, 11. Instrumentos Utilizados para Coleta de Dados e 12. Técnicas de Análise de Dados.

Outrossim, no afã de encerrar a análise da produção nacional, os 13 artigos encontrados serão sintetizados conforme seus objetivos e resultados, na categoria 13 (Propósito/Finalidade).

No que tange aos periódicos que serviram de veículos para a publicação dos artigos, a Revista Psicologia: Organizações e Trabalho (rPOT) e Psicologia: Ciência e Profissão destacaram-se ao publicarem 2 artigos cada uma. Os demais artigos foram publicados em diferentes periódicos. Nota-se que cerca de $80 \%$ dos periódicos são da área de psicologia e apenas em torno de $20 \%$ da área de administração, desvelando que embora o tema tenha merecido a atenção de administradores, a psicologia é a área que domina as investigações sobre resiliência.

A classificação Qualis mais recente (2014) desses periódicos, feita pela Capes, em ambas as áreas (Psicologia e Administração), mostra que a produção concentrou-se em periódicos considerados de primeira linha, ou seja, pertencentes aos estratos B2, B1, A2 e A1, sendo que apenas 2 periódicos, a revista Psicologia: Ciência e Profissão e a Revista de Ciências da Administração, foram classificados como B2. No caso da revista Psicologia: Ciência e Profissão, essa classificação se dá apenas na área de Administração, pois possui classificação A2 em Psicologia e, como visto, foi a revista, juntamente com a rPOT, líder em publicações sobre resiliência no trabalho. Assim, presume-se que o tema desperta interesse de importantes espaços editoriais nacionais. A Tabela 4, organizada por ordem cronológica de publicação, sumariza as informações quanto aos títulos dos artigos, autores, periódicos e suas respectivas classificações Qualis.

Tabela 4

Títulos dos artigos, Autor(es), Ano de publicação, Periódicos e Classificações Qualis

\begin{tabular}{lccc}
\multicolumn{1}{c}{ Artigo } & $\begin{array}{c}\text { Autor(es)/Ano de } \\
\text { publicação }\end{array}$ & Periódico & $\begin{array}{c}\text { Qualis } \\
\text { (2014) }\end{array}$ \\
\hline $\begin{array}{l}\text { Resiliência: em busca de um } \\
\text { conceito }\end{array}$ & Taboada et al. (2006) & $\begin{array}{c}\text { Revista Brasileira de Crescimento e } \\
\text { Desenvolvimento Humano (Centro de } \\
\text { Estudos de Desenvolvimento e } \\
\text { Crescimento do Ser Humano/SP) }\end{array}$ & A2 (Psico) \\
\hline $\begin{array}{l}\text { Resiliência: análise das } \\
\text { publicações no período de } \\
2000 \text { a 2006 }\end{array}$ & Oliveira et al.(2008) & $\begin{array}{c}\text { Psicologia: Ciência e Profissão } \\
\text { (Conselho Federal de Psicologia/DF) }\end{array}$ & $\begin{array}{c}\text { A2 (Psico) e } \\
\text { B2 (Adm) }\end{array}$ \\
\hline
\end{tabular}




\begin{tabular}{|c|c|c|c|}
\hline Artigo & $\begin{array}{c}\text { Autor(es)/Ano de } \\
\text { publicação }\end{array}$ & Periódico & $\begin{array}{l}\text { Qualis } \\
\text { (2014) }\end{array}$ \\
\hline $\begin{array}{l}\text { A resiliência em trabalhadores } \\
\text { da área da enfermagem }\end{array}$ & $\begin{array}{l}\text { Belancieri, Beluci, } \\
\text { Silva e Gasparelo } \\
\text { (2010) }\end{array}$ & $\begin{array}{l}\text { Estudos de Psicologia (Pontifícia } \\
\text { Universidade Católica de Campinas) }\end{array}$ & A1 (Psico) \\
\hline $\begin{array}{l}\text { Resiliência no trabalho } \\
\text { contemporâneo: promoção } \\
\text { e/ou desgaste da saúde mental }\end{array}$ & $\begin{array}{l}\text { Ribeiro, Mattos, } \\
\text { Antonelli, Canêo e } \\
\text { Goulart (2011) }\end{array}$ & Psicologia em Estudo (Maringá, PR) & A1 (Psico) \\
\hline $\begin{array}{l}\text { Validação fatorial da Escala } \\
\text { de Resiliência Connor- } \\
\text { Davidson (Cd-Risc-10) para } \\
\text { Brasileiros }\end{array}$ & $\begin{array}{l}\text { Lopes e Martins } \\
\qquad(2011)\end{array}$ & $\begin{array}{c}\text { Revista Psicologia Organizações \& } \\
\text { Trabalho (Associação Brasileira de } \\
\text { Psicologia Organizacional e do } \\
\text { Trabalho/DF) }\end{array}$ & A2 (Psico) \\
\hline $\begin{array}{l}\text { Resiliência e Socialização } \\
\text { Organizacional entre } \\
\text { servidores públicos brasileiros } \\
\text { e noruegueses }\end{array}$ & Carvalho et al. (2011) & $\begin{array}{c}\text { Revista de Administração } \\
\text { Contemporânea (Anpad - Associação } \\
\text { Nacional de Pós-Graduação e Pesquisa } \\
\text { em ADM/ RJ) }\end{array}$ & $\begin{array}{l}\text { B1 (Psico) e } \\
\text { A2 (Adm) }\end{array}$ \\
\hline $\begin{array}{l}\text { Antecedentes da confiança do } \\
\text { empregado na organização }\end{array}$ & $\begin{array}{l}\text { Batista e Oliveira } \\
\qquad(2012)\end{array}$ & $\begin{array}{l}\text { Estudos de Psicologia (Universidade } \\
\text { Federal do Rio Grande do Norte) }\end{array}$ & A1 (Psico) \\
\hline $\begin{array}{l}\text { Propriedades Psicométricas da } \\
\text { Versão Brasileira da Escala de } \\
\text { Comprometimento com a } \\
\text { Carreira }\end{array}$ & Magalhães (2013) & $\begin{array}{c}\text { Psicologia: Ciência e Profissão } \\
\text { (Conselho Federal de Psicologia/DF) }\end{array}$ & $\begin{array}{l}\text { A2 (Psico) e } \\
\text { B2 (Adm) }\end{array}$ \\
\hline $\begin{array}{l}\text { Escala de resiliência para } \\
\text { adultos: aplicação entre } \\
\text { servidores públicos }\end{array}$ & Carvalho et al. (2014) & $\begin{array}{c}\text { Avaliação Psicológica (Instituto } \\
\text { Brasileiro de Avaliação Psicológica/SP) }\end{array}$ & A2 (Psico) \\
\hline $\begin{array}{l}\text { Características resilientes do } \\
\text { empreendedor associadas ao } \\
\text { insucesso empresarial }\end{array}$ & $\begin{array}{l}\text { Minello e Scherer } \\
\qquad(2014)\end{array}$ & $\begin{array}{l}\text { Revista de Ciências da Administração } \\
\text { (UFSC/SC) }\end{array}$ & B2 (Adm) \\
\hline $\begin{array}{l}\text { Resiliência e morte: } o \\
\text { profissional de enfermagem } \\
\text { frente ao cuidado de crianças e } \\
\text { adolescentes no processo de } \\
\text { finitude da vida }\end{array}$ & $\begin{array}{l}\text { Santos e Moreira } \\
\text { (2014) }\end{array}$ & $\begin{array}{l}\text { Ciências \& Saúde Coletiva (Associação } \\
\text { Brasileira de Saúde Coletiva/RJ) }\end{array}$ & $\begin{array}{l}\text { A2 (Psico) e } \\
\text { B1 (Adm) }\end{array}$ \\
\hline $\begin{array}{l}\text { Bem-estar no trabalho: o } \\
\text { impacto das satisfações com } \\
\text { os suportes organizacionais e } \\
\text { o papel mediador da } \\
\text { resiliência no trabalho }\end{array}$ & Gomide et al. (2015) & $\begin{array}{c}\text { Revista Psicologia Organizações \& } \\
\text { Trabalho (Associação Brasileira de } \\
\text { Psicologia Organizacional e do } \\
\text { Trabalho/DF) }\end{array}$ & A2 (Psico) \\
\hline $\begin{array}{l}\text { Resiliência organizacional e } \\
\text { inovação sustentável: um } \\
\text { estudo sobre o modelo de } \\
\text { gestão de pessoas de uma } \\
\text { empresa brasileira de energia }\end{array}$ & $\begin{array}{c}\text { Vasconcelos, Cyrino, } \\
\text { D'Oliveira e Prallon } \\
\text { (2015) }\end{array}$ & $\begin{array}{c}\text { Cadernos EBAPE.BR (Fundação } \\
\text { Getúlio Vargas) }\end{array}$ & $\begin{array}{l}\text { A2 (Adm) e } \\
\text { B1 (Psico) }\end{array}$ \\
\hline
\end{tabular}

Nota. Fonte: Elaborada pela autora.

Quanto ao ano de publicação, o primeiro estudo nacional datou de 2006, demonstrando a recenticidade das pesquisas no Brasil. Houve picos de produção em 2011 e 2014 (23\% cada ano) e 2 estudos mais recentes de 2015. Em outras palavras, é patente o aumento do interesse dos pesquisadores quanto ao tema, uma vez que cerca de $40 \%$ da produção concentrou-se em 2014 e em 2015.

No que tange às instituições de origem dos autores dos estudos, em primeiro lugar está a Universidade Federal de Uberlândia (UFU - MG), com 3 artigos publicados e empatadas em 
segundo lugar estão a Universidade Estadual Paulista Júlio de Mesquita Filho (Unesp - SP), a Universidade Federal de Minas Gerais (UFMG - MG) e a Universidade Federal de Alfenas (UNIFAL - MG), com 2 artigos cada. As demais instituições contabilizaram apenas 1 artigo no período: Universidade Sagrado Coração (Bauru - SP), em parceria com a Universidade de São Paulo (USP - SP); Universidade Federal da Bahia (UFBA - BA); Escola Brasileira de Administração Pública e de Empresas (EBAPE - RJ), em parceria com a Escola de Gestão e Negócios da Universidade Petrobras (RJ); Universidade do Vale do Itajaí (Univali - SC), em conjunto com a Universidade para o Desenvolvimento do Alto Vale do Itajaí (Unidavi - SC); Universidade Metodista de São Paulo (SP), em parceria com a UFU; Universidade Federal de Santa Maria (UFSM - RS); Fundação Oswaldo Cruz (Fiocruz - RJ); e Universidade Norueguesa de Ciência e Tecnologia, em uma parceria com a UNIFAL e UFMG. Por conseguinte, observa-se uma concentração de estudos relativos à resiliência no trabalho na região sudeste do Brasil, especificamente em Minas Gerais e São Paulo, onde possivelmente há grupos de pesquisa que têm abraçado tal temática.

Igualmente, as autoras que lideraram o ranking de publicações sobre o tema, com 2 artigos cada, são provenientes da Universidade Federal de Uberlândia, da Universidade Federal de Minas Gerais e da Universidade Federal de Alfenas, a saber, Áurea de Fátima Oliveira (professora associada), Lívia de Oliveira Borges (professora titular e bolsista de produtividade) e Virgínia Donizete de Carvalho (professora adjunta), respectivamente. Os demais autores publicaram um artigo cada no período analisado. Ainda, prevaleceu a parceria entre autores, uma vez que apenas um artigo foi publicado por apenas 1 autor e o restante dos trabalhos foram produzidos por 2, 3, 4, ou mesmo 5 autores e, em 54\% deles, permitindo a sinergia entre diferentes instituições, sendo que em um trabalho houve parceria internacional com a Noruega.

Com relação ao enquadramento dos estudos, a maioria, 85\%, foi de estudos teóricoempíricos, ao passo que apenas 2 estudos foram enquadrados como ensaios teóricos, qual seja, o de Ribeiro et al. (2011), que resgatou a concepção processual e contextual da resiliência como promotora da saúde, e o de Taboada et al. (2006), que investigou as principais definições de resiliência e seus conceitos operacionais. Dessa forma, delineia-se importante lacuna na literatura concernente a revisões que discutam melhor o tema, seus fundamentos e pressupostos, haja vista o caráter multidisciplinar do tema, oriundo da física, que depois foi adaptado para as ciências da saúde, encontrou seu espaço nas ciências humanas, especialmente na psicologia, e recentemente vem buscar seu papel na área das organizações, tendo em vista que o mundo do trabalho contemporâneo demanda cada vez 
mais trabalhadores flexíveis, polivalentes, sujeitos à mudança (Ribeiro et al., 2011) e, mormente, com capacidade de lidar com problemas de forma proativa, autônoma e determinada (Batista \& Oliveira, 2008), ou seja, trabalhadores resilientes, que se recuperam de adversidades e se adaptam positivamente em situações de estresse e tensão (Lopes \& Martins, 2011).

Dentre os 11 trabalhos teórico-empíricos verificados, perfazendo 85\% dos artigos, no que tange à abordagem de pesquisa, 64\% são quantitativos e $36 \%$ qualitativos, destacando a ainda predominância de métodos lógico-positivistas no estudo do fenômeno. Desditosamente, não houve nenhum estudo multimétodo, o qual mescla abordagens qualitativas e quantitativas.

O setor da economia que prevaleceu nas pesquisas foi o primeiro setor, público, com 4 dos 11 estudos teórico-empíricos; não obstante, 3 estudos tiveram como lócus de investigação os setores público e privado (primeiro e segundo setores) e 3 somente o segundo setor (privado). Ainda, um estudo não teve seu lócus de investigação categorizado, pois trata-se de pesquisa qualitativa realizada a partir de levantamento bibliográfico. Como cada setor possui suas idiossincracias e especificidades, bem como distintas representações sociais, é salutar observar que mesmo nas poucas pesquisas encontradas, emerge aí mais uma lacuna de pesquisa.

Em contrapartida, verificou-se que os ramos de atuação das empresas pesquisadas foram bem diversificados, mas com destaque para o ramo de educação, onde docentes e servidores técnico-administrativos de universidades públicas constituíram o alvo da pesquisa. Outros ramos investigados foram o de saúde (hospital) e o de energia. Dois estudos não identificaram os ramos, limitando-se a dizer que foram diversos, mas especificando as localidades, a saber, São Paulo e região do Triângulo Mineiro.

Ademais, os questionários foram os instrumentos de coleta de dados mais utilizados, consoante com a natureza quantitativa da maioria dos estudos teórico-empíricos. No caso dos estudos qualitativos, o instrumento utilizado foi a entrevista. Subsequentemente, no tocante às técnicas de análise de dados mais recorrentes, aparecem a análise fatorial, tanto exploratória quanto confirmatória, haja vista que dois dos estudos visaram validar medidas de resiliência, e também análises de estatística descritiva e análises de regressão padrão e hierárquica. Para análises qualitativas, os autores elegeram a análise de conteúdo categorial temática proposta por Bardin e, ainda, um levantamento bibliográfico foi realizado com o objetivo de analisar as publicações sobre resiliência no período de 2000 a 2006 (Oliveira et al., 2008), utilizando análise bibliométrica. 
Vale destacar que métodos estatísticos mais sofisticados, como a modelagem por equações estruturais, a qual permite estudar associação, predição e ainda confirmar modelos de mensuração simultaneamente, foram adotados em um dos estudos, no caso, a análise fatorial confirmatória.

A Tabela 5 sumariza as informações a respeito das análises metodológicas realizadas.

Tabela 5

Síntese da categorização dos artigos teórico-empíricos analisados

\begin{tabular}{llc}
\hline \multicolumn{1}{c}{ Análise Metodológica } & \multicolumn{1}{c}{ Classificação } & Frequência \\
\hline \multirow{2}{*}{ Abordagem da pesquisa } & Quantitativa & $64 \%$ \\
& Qualitativa & $36 \%$ \\
\hline \multirow{3}{*}{ Setor da economia } & Primeiro setor & $36 \%$ \\
& Segundo setor & $27 \%$ \\
& Primeiro e Segundo setores & $27 \%$ \\
& Não se aplica & $10 \%$ \\
\hline \multirow{5}{*}{ Ramo de atuação das empresas } & Diversos & $36 \%$ \\
pesquisadas & Educação & $27 \%$ \\
& Saúde (hospital) & $19 \%$ \\
& Energia & $9 \%$ \\
Instrumentos utilizados para & Não se aplica & $9 \%$ \\
coleta de dados & Questionário & $64 \%$ \\
& Entrevista & $27 \%$ \\
& Análise Documental & $9 \%$ \\
\hline \multirow{2}{*}{ Técnicas de análise de dados* } & Análise de Regressão (Padrão e Hierárquica) & $36 \%$ \\
& Análise de Estatística Descritiva & $27 \%$ \\
& Análise de Conteúdo (Bardin) & $27 \%$ \\
& Análise Bibliométrica & $27 \%$ \\
& & $9 \%$
\end{tabular}

Nota. * as porcentagens não somam $100 \%$ porque há estudos que utilizaram mais de uma técnica. Fonte: Elaborada pela autora.

Por fim, no que tange ao propósito ou principal finalidade dos estudos, iniciando com os teórico-empíricos, que totalizaram $85 \%$ dos estudos, sete foram quantitativos, sendo que dois dedicaram-se a validar medidas de resiliência no contexto brasileiro. Um estudo focou em relacionar a resiliência a outras variáveis do comportamento organizacional e um descreveu as percepções de resiliência e autoconceito.

Quanto à validação de medidas, primeiro Lopes e Martins (2011), ao analisar as medidas de resiliência existentes na literatura nacional e internacional, elegeram a ConnorDavidson Resilience Scale (CD-RISC), uma medida validada por Connor e Davidson (2003) e bastante utilizada em estudos internacionais, como base para fazer a validação no contexto brasileiro. As autoras escolheram essa escala por sua ampla utilização e bons índices psicométricos, possuindo 25 itens distribuídos em cinco fatores (competência pessoal, 
confiança nos próprios instintos e tolerância à adversidade, aceitação positiva da mudança, controle e espiritualidade). Posteriormente, segundo as autoras, Campbell-Sills e Stein (2007) identificaram, em análise fatorial confirmatória da CD-RISC original, uma estrutura mais parcimoniosa, unifatorial, composta por 10 itens; a esse fator único chamaram resiliência e a CD-RISC recebeu nova denominação - CD-RISC-10 e dessa forma, as autoras utilizaram essa versão para validação no Brasil e em contextos de trabalho. A estrutura unifatorial de 10 itens foi confirmada, apresentando boa confiabilidade (alfa de Cronbach de 0,82), tornando-se ferramenta disponível para incrementar a investigação desse fenômeno.

$\mathrm{Na}$ mesma linha, Carvalho et al. (2014) confirmaram a estrutura da Escala de Resiliência para Adultos no contexto de trabalho no serviço público brasileiro. A Resilience Scale for Adults (Escala de Resiliência para Adultos), a qual, conforme os autores, tem demonstrado potencial para explicar fenômenos psicossociais relacionados ao trabalho, foi originalmente desenvolvida e validada por pesquisadores noruegueses. Essa escala foi validada transculturalmente, na Bélgica e no Irã, até finalmente ser adaptada e testada no Brasil por Hjemdal, Roazzi, Dias, Roazzi e Vikan (2009), em uma amostra de estudantes universitários, apresentando estrutura multifatorial com 6 fatores (percepção de si mesmo, futuro planejado, competência social, estilo estruturado, coesão familiar e recursos sociais) e confiabilidade razoável (alfas de Cronbach variando entre 0,56 e 0,79). A estrutura multifatorial da escala foi confirmada pelos autores e os índices de confiabilidade mantiveram-se estáveis. Como conclusão, os autores entendem sua escala como ponto de partida, enfatizando a necessidade de se elaborar um instrumento com outro estilo, que permita dar conta do caráter processual da resiliência, bem como de aprofundar o fenômeno no contexto do trabalho e das organizações.

Como resposta a essa chamada, e já entrando na análise dos estudos relacionais, Gomide et al. (2015), sob a perspectiva da psicologia positiva, testaram o poder mediacional da resiliência no trabalho na relação entre as satisfações com os suportes organizacionais e o bem-estar no trabalho. O modelo de mediação não se confirmou na pesquisa, embora resiliência no trabalho tenha apresentado poder de predição significativo sobre bem-estar no trabalho e satisfações com suportes também explicaram de maneira significativa a resiliência no trabalho. Ademais, nesse trabalho também foi apresentada a validação da Escala de Resiliência no Trabalho, específica para contextos organizacionais, proposta em primeira instância por Batista e Oliveira (2008), desenvolvida com base na Escala de Resiliência previamente adaptada e validada para adolescentes brasileiros por Pesce et al. (2005), a qual inicialmente possuía três fatores, quais sejam, "ações e valores que dão sentido à vida 
(amizade, realização pessoal, satisfação e significado da vida)", “independência e determinação", e "autoconfiança e capacidade de adaptação a situações”. Já a Escala de Resiliência no Trabalho possui uma estrutura unifatorial de 15 itens, agregando, em sua maioria, itens do primeiro fator da escala de Pesce et al. (2005) e dois itens do último fator, demonstrando alta confiabilidade (alfa de Cronbach de 0,87 e de 0,90 no estudo prévio de Batista e Oliveira) e porcentagem de variância explicada de cerca de $33 \%$.

Vale destacar que, apesar de não compor a presente revisão da produção nacional por se tratar de trabalho apresentado em congresso, constante de anais e ainda não publicado em periódico, existe ainda na literatura nacional a escala validada por Martins et al. (2011), denominada Escala de Avaliação de Resiliência (EAR) que, em sua versão reduzida, possui 23 itens e avalia cinco fatores: adaptação ou aceitação positiva de mudança $(\alpha=0,87)$, espiritualidade $(\alpha=0,90)$, resignação diante da vida $(\alpha=0,73)$, competência pessoal $(\alpha=$ $0,72)$ e persistência diante das dificuldades $(\alpha=0,78)$. Portanto, data vênia, a escala de Batista e Oliveira (2008) ainda é a única publicada em periódico científico nacional, efetivamente voltada ao contexto do trabalho nas organizações, suprindo importante lacuna na literatura.

Seguindo nos estudos quantitativos, Carvalho et al. (2011), partindo do pressuposto de que pesquisas sobre socialização organizacional apontam que a adaptação do indivíduo a um novo cargo e a uma nova organização tende a ser um evento estressor e a resiliência poderia auxiliar na compreensão das diferenças nos resultados de socialização entre indivíduos, analisaram a relação entre resiliência e socialização organizacional junto a novos servidores de duas universidades públicas, em contextos culturais distintos, Brasil e Noruega. Os autores concluíram que a resiliência contribuiu significativamente para explicar os resultados de socialização organizacional, independentemente da nacionalidade e da ocupação.

Ademais, Batista e Oliveira (2012) investigaram um modelo teórico que contemplou como variáveis preditoras percepção de suporte organizacional, afeto e resiliência, e como variável critério a confiança do empregado na organização. Dentre as 4 escalas utilizadas na pesquisa, para a variável resiliência foi utilizada a Escala de Resiliência no Trabalho, desenvolvida por Batista e Oliveira (2008). Os resultados indicaram que o principal preditor da confiança do empregado é a percepção de suporte organizacional. Afeto foi eliminado de todos os modelos, enquanto a resiliência explicou pequeno porcentual de confiança nos padrões éticos. Embora as variáveis afeto positivo, afeto negativo e resiliência não tenham se sustentado frente ao poder de predição que a variável percepção de suporte organizacional revelou, segundo as pesquisadoras, é inegável o reconhecimento do poder do ambiente para o desenvolvimento da resiliência. Sendo assim, as autoras sugerem a realização de estudos 
posteriores que investiguem de forma aprofundada a forma como essas variáveis se comportam entre si.

Ainda nos estudos relacionais, Magalhães (2013) investigou as características psicométricas de uma versão brasileira da Escala de Comprometimento com a Carreira (ECC), de Carson e Bedeian (1994), que é composta por três fatores: identidade, planejamento e resiliência. Magalhães (2013) destaca a importância de se investigar os fatores que promovem ou enfraquecem o comprometimento dos trabalhadores, pois esse influencia diversos processos de interesse para o indivíduo e para a organização, tais como o desenvolvimento de competências; a retenção, a satisfação e o desempenho dos colaboradores; e o bem-estar no trabalho. Como resultado da pesquisa, os indicadores de consistência revelaram que todos os três fatores contribuem para aumentar a precisão do instrumento. $\mathrm{O}$ autor sugere que pesquisas futuras investiguem os antecedentes e os consequentes dos três componentes do comprometimento com a carreira, quais sejam resiliência, identidade e planejamento, explorando o significado psicológico e a relevância de cada um desses fatores para a compreensão de variáveis e processos em nível individual e organizacional.

Para finalizar os estudos quantitativos identificados no presente trabalho, Belancieri et al. (2010) averiguaram o nível de resiliência dos trabalhadores de enfermagem de uma rede pública municipal de saúde, visando conhecer as fraquezas e fortalezas desse profissional diante das adversidades a que está submetido. Em relação aos níveis de resiliência verificados na pesquisa, a maioria dos participantes apresentou uma discrepância entre os fatores regulação de emoções e controle de impulsos, o que pode resultar em elevado consumo de energia, prejudicando as atividades laborais. Para as autoras, discutir o caráter social e político da prática dos trabalhadores da área da enfermagem e refletir sobre a importância de sua participação nos rumos da própria profissão poderão minimizar o estado de alienação observado, uma vez que o papel desse profissional não se resume ao saber técnico, mas apresenta também uma função social e política.

Partindo para análise dos quatro estudos teórico-empíricos de cunho qualitativo, Santos e Moreira (2014) debruçaram-se sobre a análise da resiliência de uma equipe de enfermagem de um hospital carioca, pelo recorte do processo de cuidar de crianças e adolescentes com doença crônica, o que inclui lidar com sua finitude. $\mathrm{Na}$ análise dos dados, as autoras aduzem que sobressaiu a relação entre resiliência profissional e o gerir/cuidar do processo de morrer de crianças e adolescentes, desencadeando respostas relacionadas ao tema da resiliência no que toca a buscar saídas que oscilam entre respostas individuais (apoio religioso, psicológico) 
e a busca de um apoio coletivo incipiente baseado em relações pessoais. Como agenda, elas apontam para a necessidade de que se encare o tema como estratégico para a formação profissional em saúde, preconizando um ambiente organizacional no qual práticas de gestão da humanização são a regra.

No mesmo ano, Minello e Scherer (2014) estudaram a resiliência em outro contexto, o do empreendedorismo, ao analisar as características resilientes do empreendedor no intuito de compreender se e como o seu comportamento pode ser associado à descontinuidade do negócio. Como principais resultados, a partir de entrevistas com auxílio da Escala de Comportamento Defensivo, utilizada nesse caso para mensurar a resiliência, os autores encontraram a onipotência como estilo apresentado por 12 dos 13 entrevistados; a afiliação, constatada em 9 dos 13 entrevistados; e a atuação, em 7 dos 13 entrevistados antes do insucesso empresarial. Na visão dos autores, infere-se que esse comportamento de onipotência pode demonstrar a arrogância do indivíduo diante de outras pessoas, o que possivelmente pode influenciar as decisões do empreendedor, a desmotivação de funcionários e, ainda, a insatisfação de clientes, acarretando assim, o insucesso empresarial.

Já em 2015, Vasconcelos et al. relacionaram o conceito de organização inovadora sustentável com o conceito de resiliência organizacional. Para tanto, foi realizado um estudo no departamento de recursos humanos de uma empresa brasileira de energia e os autores identificaram quais são as práticas de gestão de pessoas da empresa que contribuem para que ela seja resiliente, isto é, uma organização que, além de inovadora e sustentável, seja resiliente. Por meio de entrevistas, os pesquisadores concluíram que a empresa é uma organização inovadora sustentável resiliente, pois ela conseguiu desenvolver um departamento de RH que cria práticas e políticas de GP capazes de fazer com que a organização responda com rapidez, eficiência e eficácia às rupturas tecnológicas, organizacionais e sistêmicas, causadas pela reengenharia radical gerada pelo departamento de Pesquisa \& Desenvolvimento da empresa, e gerando, assim, vantagem competitiva sustentável.

Para encerrar a abordagem dos estudos qualitativos, Oliveira et al. (2008), considerando a incipiência das pesquisas quanto à resiliência, apesar de sua importância no desenvolvimento humano, realizaram um levantamento bibliográfico no período de 2000 a 2006. O método adotado compreendeu a análise documental, por meio de um levantamento de pesquisas em bases de dados, com a utilização de palavras-chave. A análise dos dados consistiu na elaboração de categorias de análise tomando como base os resultados encontrados em pesquisas sobre resiliência. Conforme as autoras, os dados apontaram que há 
ênfase nas pesquisas básicas, prevalência de população de adultos nos estudos analisados e utilização da entrevista como principal instrumento. Como principal conclusão, as autoras indicam que o conceito de resiliência está em construção e possui relação direta com os fatores de risco e de proteção, tal qual também apontado por Taboada et al. (2006).

No que tange aos ensaios teóricos e revisões de literatura, esses somaram 2 dos 13 estudos, sendo um ensaio e uma revisão bibliográfica. O ensaio foi engendrado por Ribeiro et al. (2011), com o objetivo de resgatar o conceito de resiliência e sua aplicação na realidade organizacional contemporânea, para promover uma discussão acerca das situações em que a resiliência pode ser promotora da saúde no ambiente laboral, bem como situações em que pode contribuir para o processo de adoecimento do trabalhador. Segundo os autores, no mundo do trabalhado globalizado são exigidas certas características e habilidades que ultrapassam os limites físicos e psíquicos do ser humano, culminando em sua exaustão; destarte, o trabalhador sujeita-se aos estilos de gestão, suporta o ritmo intensificado do trabalho, pressão e responsabilizações que exigem sua adaptação aos objetivos da organização, o que o torna, com o passar do tempo, resiliente.

Nessa perspectiva, Ribeiro et al. (2011) argumentam que os psicólogos precisam delinear sua compreensão dos contextos em que o indivíduo age de forma resiliente, compreendendo que ela não se resume a características individuais e imutáveis de um indivíduo resiliente, mas diz respeito à interação de indivíduos com o contexto organizacional, de forma a vivenciar condições adversas sem que elas provoquem seu adoecimento físico e/ou psíquico, promovendo uma reflexão crítica a todos os colaboradores da organização para que esses também possam refletir criticamente a respeito de seu contexto laboral, identificando a existência de fatores de risco e de proteção para sua saúde.

Ademais, Ribeiro et al. (2011) destacam a relevância de a atividade educativa e reflexiva permear toda a organização, incluindo sua diretoria, de maneira a informá-la e sensibilizá-la para a existência de fatores de risco à saúde do trabalhador em contextos organizacionais, de forma a estabelecerem, em conjunto, políticas preventivas e de promoção da saúde e qualidade de vida no trabalho, bem como do significado por parte dos colaboradores quanto à importância de suas funções na consecução simultânea dos objetivos organizacionais e pessoais de cada colaborador.

Quanto à revisão bibliográfica, Taboada et al. (2006) inauguraram a discussão relativa às definições de resiliência e seus conceitos operacionais. Os autores entendem a resiliência como o processo no qual o indivíduo consegue superar as adversidades, adaptando-se de forma saudável ao seu contexto, qualquer que seja. Os autores depararam-se com um leque de 
definições agrupadas prioritariamente em três eixos principais, a partir de uma perspectiva processual e contextual, em consonância com a proposta de Ribeiro et al. (2011): adaptação/superação; inato/adquirido; e circunstancial/permanente. Os autores também trabalharam temas diretamente relacionados à resiliência, dentre eles estresse, coping ou enfrentamento, fatores de risco, fatores de proteção e vulnerabilidade do trabalhador. Os resultados da revisão levaram os autores a concluir pela carência de definições operacionais claras quanto ao fenômeno, identificando uma lacuna na literatura nesse sentido. Segundo os autores, é preciso especificar de forma mais direta os comportamentos e/ou habilidades sociais e cognitivas relacionados ao processo resiliente, separá-los em categorias e testá-los em populações diversificadas.

Com o objetivo de fazer um paralelo entre a revisão de Oliveira et al. (2008) e a descrita na presente seção, nota-se que Oliveira e colaboradores também pesquisaram bases nacionais e internacionais, mas incluíram bancos de dissertações e teses da Pontifícia Universidade Católica de São Paulo; contudo, varreram um período menor de análise (7 anos contra 15 da presente seção) e focaram o tema resiliência de maneira geral, diferentemente do foco dado nessa bibliometria para a resiliência no trabalho, no contexto organizacional. Eles encontraram 43 trabalhos, lembrando que teses e dissertações também foram contemplados. Se forem considerados apenas os artigos publicados em periódicos, os números não devem ser muito diferentes dos por ora apresentados, ratificando o caráter contemporâneo das pesquisas sobre o tema. Em comum, a presente pesquisa também verificou maior foco em investigações com adultos, porém a maioria da produção por ora analisada compreendeu artigos teóricoempíricos de abordagem quantitativa, ao passo que a revisão de Oliveira et al. (2008) revelou uma maioria de trabalhos de cunho teórico, o que pode ser devido também à inclusão de trabalhos em construção (teses e dissertações), além de, no escopo das pesquisas empíricas, a maioria ter sido qualitativa utilizando como principal instrumento de coleta de dados a entrevista, instrumento também eleito por unanimidade pelos pesquisadores brasileiros cujas pesquisas foram analisadas na presente seção.

Por fim, os resultados da produção nacional aqui coligidos ratificam o caráter contemporâneo, bem como a incipiência das pesquisas quanto ao tema na realidade nacional, o que, em última análise, desvela grandes oportunidades de realização de estudos que contribuam para construção de um arcabouço teórico mais consistente para promover o avanço progressivo do conhecimento teórico-empírico sobre a resiliência no contexto das organizações brasileiras. 
Em suma, nesse capítulo foram apresentadas as revisões da literatura sobre as variáveis da presente pesquisa contendo os principais conceitos e autores, além de revisões da produção nacional, visando um maior embasamento teórico para o estudo. A seguir, tem-se a apresentação do método da pesquisa. 


\section{Método}

São apresentados nesta seção os procedimentos adotados na execução dos objetivos propostos nesse trabalho, a saber, o modelo da pesquisa, o tipo e a descrição geral da pesquisa, a caracterização do setor, população e amostra, instrumento de pesquisa e, por fim, os procedimentos de coleta e análise dos dados. Cabe ressaltar que o método é coerente com o problema de pesquisa formulado, com os objetivos geral (identificar e descrever a influência das políticas e práticas de GP na resiliência no trabalho dos servidores técnico-administrativos da FUB) e específicos (I - identificar a percepção em relação às políticas e práticas de GP dos servidores técnico-administrativos da FUB; II - identificar a resiliência no trabalho dos servidores técnico-administrativos da FUB; III - testar os modelos de mensuração das variáveis do estudo fazendo sua validação confirmatória; IV - testar o modelo estrutural de predição das políticas e práticas de GP sobre a resiliência no trabalho), e com os princípios conceituais estabelecidos na fundamentação teórica.

\subsection{Modelo da pesquisa}

Para estudar a relação entre as variáveis, o modelo de pesquisa adota como variável critério ou endógena a resiliência no trabalho e como variáveis preditoras ou exógenas recrutamento e seleção; envolvimento; treinamento, desenvolvimento \& educação; condições de trabalho; avaliação de desempenho e competências; e remuneração e recompensas, que compõem as políticas e práticas de gestão de pessoas, conforme apresentado na Figura 3. 


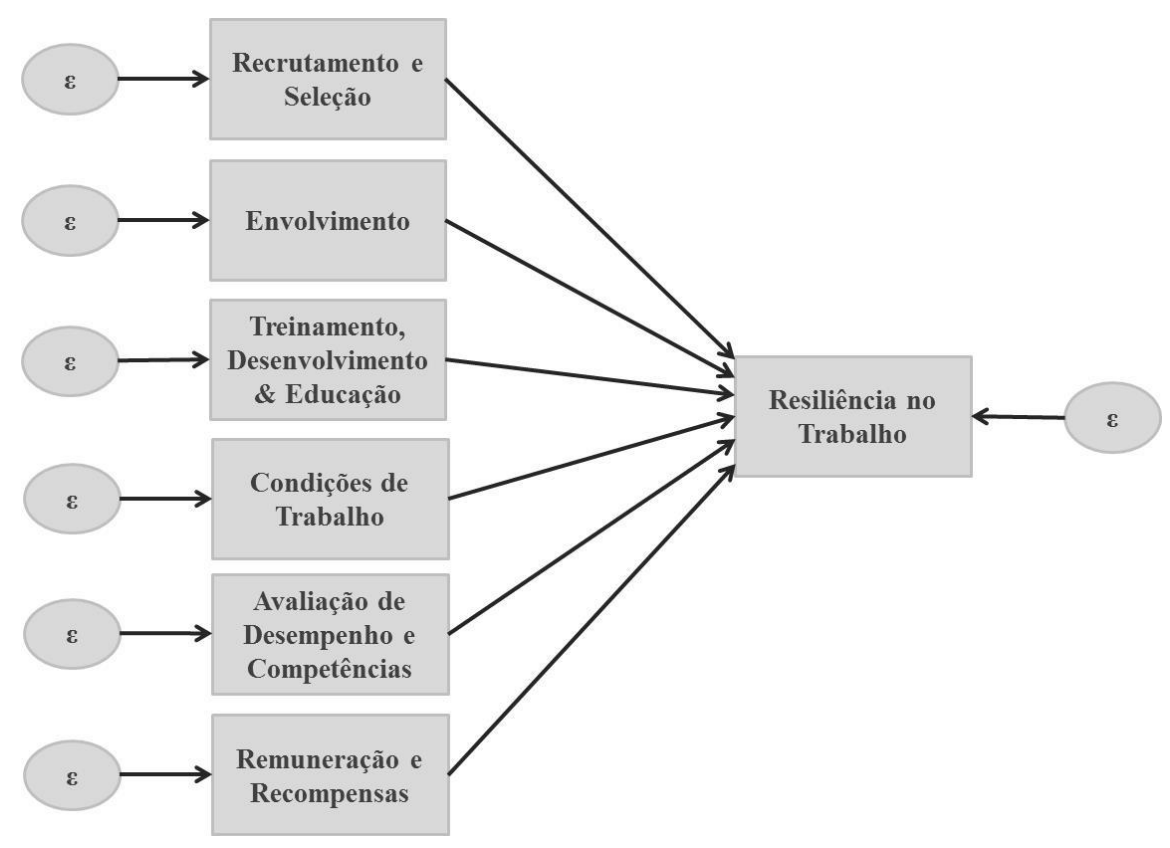

Figura 3. Modelo empírico da pesquisa

Fonte: Elaborada pela autora.

As variáveis pesquisadas encontram-se classificadas e definidas na Tabela 6 .

Tabela 6

Variáveis da Pesquisa

\begin{tabular}{lll}
\hline \multicolumn{1}{c}{ Variável } & Classificação & \multicolumn{1}{c}{ Descrição } \\
\hline $\begin{array}{l}\text { Resiliência no } \\
\text { Trabalho }\end{array}$ & $\begin{array}{c}\text { Critério (endógena, } \\
\text { dependente) }\end{array}$ & $\begin{array}{l}\text { "Capacidade de lidar com problemas de forma pró-ativa, } \\
\text { autônoma e determinada, buscando alternativas, juntamente } \\
\text { com a confiança em si próprio" (Batista \& Oliveira, 2012, p. } \\
250)\end{array}$ \\
\hline & $\begin{array}{l}\text { "Proposta articulada da organização, com construções teóricas e } \\
\text { práticas, para procurar colaboradores, estimulá-los a se }\end{array}$ \\
Recrutamento e & $\begin{array}{l}\text { candidatar e selecioná-los, buscando harmonizar valores, } \\
\text { interesses, expectativas e competências da pessoa com } \\
\text { Seleção }\end{array}$ & $\begin{array}{l}\text { características e demandas do cargo e da organização." (Demo } \\
\text { et al., 2014, p. 247) }\end{array}$ \\
\hline
\end{tabular}

"Proposta articulada da organização, com construções teóricas e

Envolvimento práticas, para criar um vínculo afetivo com seus colaboradores, contribuindo para seu bem-estar, em termos de reconhecimento, relacionamento, participação e comunicação." (Demo et al., 2014, p. 247)

Treinamento, Desenvolvimento \& Educação

Condições de Trabalho

Avaliação de Desempenho e Competências
Preditoras (exógenas, independentes)

"Proposta articulada da organização, com construções teóricas e práticas, para prover aos colaboradores a aquisição sistemática de competências e estimular a contínua aprendizagem e produção de conhecimento.” (Demo et al., 2014, p. 247)

"Proposta articulada da organização, com construções teóricas e práticas, para prover aos colaboradores boas condições de trabalho em termos de benefícios, saúde, segurança e tecnologia." (Demo et al., 2014, p. 247)

"Proposta articulada da organização, com construções teóricas e práticas, para avaliar o desempenho e as competências dos colaboradores, subsidiando as decisões sobre promoções, planejamento de carreira e desenvolvimento." (Demo et al., 2014, p. 248) 


\begin{tabular}{lcl}
\hline \multicolumn{1}{c}{ Variável } & Classificação & \multicolumn{1}{c}{ Descrição } \\
\hline $\begin{array}{l}\text { Remuneração e } \\
\text { Recompensas }\end{array}$ & $\begin{array}{c}\text { Preditoras (exógenas, } \\
\text { independentes) }\end{array}$ & $\begin{array}{l}\text { "Proposta articulada da organização, com construções teóricas e } \\
\text { práticas, para recompensar o desempenho e as competências } \\
\text { dos colaboradores em termos de remuneração e incentivos." } \\
\text { (Demo } \text { et al., 2014, p. 248) }\end{array}$ \\
\hline
\end{tabular}

Nota. Fonte: Elaborada pela autora.

\subsection{Tipo e descrição geral da pesquisa}

Segundo Hair, Babin, Money e Samouel (2005), o tipo de pesquisa pode ser definido em relação a seus fins e a seus meios. No que tange aos fins, de acordo com os objetivos específicos I e II, que visam, respectivamente, identificar a percepção em relação às políticas e práticas de GP e identificar a resiliência no trabalho dos servidores técnico-administrativos da FUB, o estudo realizado tem caráter descritivo, pois conforme Hair et al. (2005, p. 86), "tem seus planos estruturados e especificamente criados para medir as características descritas em uma questão de pesquisa"; e caráter explicativo, em virtude dos objetivos específicos III e IV, que visam testar os modelos de mensuração e estrutural propostos.

Quanto aos meios utilizados para o cumprimento dos objetivos, a pesquisa empregou o método de levantamento (survey), que pode ser caracterizado como a obtenção de dados primários a partir de uma grande amostra de indivíduos, cujas opiniões, características ou ações se deseja conhecer para obter as conclusões correspondentes aos dados coletados, por meio de análise quantitativa (Hair, Babin, Money, \& Samouel, 2005). Optou-se pelo uso da metodologia quantitativa, em que os dados são objetivos, não dependem da opinião do pesquisador e representam mensuração em números que são usados diretamente para representar a propriedade de algo (Hair et al., 2005). O horizonte temporal desse trabalho é transversal, já que os dados foram coletados em um único período de tempo (Drenth, 1984; Malhotra, 2012).

Foi autorizada a realização da presente pesquisa com os servidores técnicoadministrativos da FUB, com a devida anuência do Diretor de Pós-Graduação do Decanato de Pesquisa e Pós-Graduação (DPP/UnB), bem como do Magnífico Reitor da Universidade, conforme documento constante do Apêndice A.

\subsection{Caracterização do setor}

A Fundação Universidade de Brasília - FUB, instituída pela Lei n ${ }^{\circ}$ 3.998/1961, tem por objetivo criar e manter a Universidade de Brasília - UnB, instituição de ensino superior de 
pesquisa, ensino e extensão em todos os ramos do saber e de divulgação científica, técnica e cultural (Universidade de Brasília [UnB], 2015a). A UnB, inaugurada em abril de 1962, é hoje umas das maiores instituições federais de ensino superior do país. De acordo com o Anuário Estatístico parcial de 2015 (Universidade de Brasília [UnB], 2015b), na extensão de seus quatro campi (Darcy Ribeiro e os campi Gama, Ceilândia e Planaltina), em 2014, a UnB possuía números superiores a trinta e seis mil alunos de graduação, sete mil e novecentos alunos de pós-graduação, dois mil e seiscentos docentes e dois mil e seiscentos servidores técnico-administrativos, totalizando uma comunidade acadêmica de quase cinquenta mil pessoas.

Em 2014, o total de cursos de Graduação da UnB correspondia a 154; de mestrado, 86; e de doutorado, 66 (UnB, 2015b). Além disso, a FUB é constituída por 26 institutos e faculdades, 55 departamentos acadêmicos e 19 centros de pesquisa especializados (Universidade de Brasília [UnB], 2015c).

Em setembro de 2015 foi publicado o levantamento de 2015-2016, realizado pela consultoria britânica Quacquarelli Symonds (QS), que posicionou a UnB entre as 500 melhores universidades do mundo. Entre as instituições nacionais que estão na lista da QS, a UnB está em sexto lugar, empatada com a Universidade Federal de São Paulo (Unifesp). O Ranking QS Top Universities é um sistema de classificação internacional que permite aos estudantes obterem um quadro amplo das características de diversas instituições de ensino superior e compará-las. Nesse ranking, os destaques da UnB na avaliação estão nos quesitos reputação acadêmica e proporção de docentes por alunos matriculados; esse último é um indicador que pretende estabelecer padrão internacional de avaliação para a qualidade do ensino nas instituições. Já entre as universidades da América Latina, a UnB está em $10^{\circ}$ lugar no ranking QS. Nesse caso, os critérios mais bem avaliados da instituição foram a qualificação do corpo docente, o impacto na internet e a reputação acadêmica (http://www.unb.br/noticias/unbagencia/unbagencia.php?id=9634, recuperado em 10, novembro, 2015).

Quanto à classificação do Guia do Estudante 2016, publicado em setembro de 2015, a UnB ocupa o $6^{\circ}$ lugar geral (http://guiadoestudante.abril.com.br/blogs/melhoresfaculdades/usp-se-consagra-como-a-melhor-universidade-publica-do-pais/, recuperado em 13, novembro, 2015) e o $1^{\circ}$ lugar no Centro-Oeste entre as universidades públicas nacionais (http://guiadoestudante.abril.com.br/blogs/melhores-faculdades/melhores-faculdades-regiaobrasil/, recuperado em 13, novembro, 2015). Dos 60 cursos de graduação da UnB avaliados pelo Guia do Estudante 2016, 34 receberam classificação cinco estrelas, ou seja, excelentes; 
21 ficaram com quatro estrelas (muito bons); 4 cursos com três estrelas, isto é, bons; e apenas 1 curso sem estrela (http://www.unb.br/noticias/unbagencia/unbagencia.php?id=9709, recuperado em 13, novembro, 2015).

Sob o panorama gerencial, um aspecto que afeta negativamente a força de trabalho da FUB é o alto índice de desligamentos de servidores: o porcentual é de aproximadamente $57 \%$ de egressos em comparação aos servidores que ingressaram em 2014. Um estudo de rotatividade do cargo de assistente em administração demonstrou que cerca de $15 \%$ de servidores desse cargo se aposentaram ou pediram exoneração/vacância em 2014. Além disso, o atual quadro de pessoal não corresponde ao ideal, o que pode interferir na qualidade dos serviços prestados (UnB, 2015a).

Na FUB não há metas fixadas. Contudo, o Decanato de Gestão de Pessoas (DGP) utiliza alguns indicadores para mensurar o desempenho das atividades. Com relação à capacitação, em 2014 foram ofertadas 2.072 vagas, sendo $42 \%$ na modalidade a distância e 58\% na modalidade presencial. No total, foram realizadas 1.647 capacitações (matrículas feitas em cursos), das quais $81 \%$ por servidores sem função gerencial e $19 \%$ por servidores ocupantes de algum tipo de função gerencial (UnB, 2015a).

\subsection{População e amostra}

Uma população é o conjunto formado por indivíduos ou objetos que tem pelo menos uma variável comum e observável (Morettin, 2010). Nesse sentido, Malhotra (2012) aponta que a amostra é um subgrupo dos elementos de uma população utilizada para a pesquisa. No caso do presente trabalho, a população é composta por cerca de 2.000 servidores técnicoadministrativos lotados no campus Darcy Ribeiro. Optou-se por não incluir os servidores docentes nessa pesquisa devido ao fato de as políticas e práticas de GP para esse público serem diferentes das dos servidores técnico-administrativos. Além disso, o campus Darcy Ribeiro foi definido como o lócus da pesquisa por abranger maior quantidade de servidores técnico-administrativos em comparação aos demais campi.

Para essa pesquisa, a amostra caracterizou-se como não-probabilística e por conveniência (adesão), utilizando-se coleta online (pela internet). A amostra é considerada por conveniência visto que contempla a seleção de elementos mais disponíveis para tomar parte do estudo e que possam oferecer informações necessárias (Hair et al., 2005).

Nesse estudo, a amostra foi utilizada para a validação confirmatória (modelo de mensuração das variáveis), que consiste no objetivo III do estudo; para a verificação da 
predição entre as variáveis (modelo estrutural), proposto no objetivo IV; e ainda para identificar a percepção com relação às políticas e práticas de GP, bem como identificar a resiliência no trabalho dos servidores técnico-administrativos da FUB, propostos nos objetivos I e II, respectivamente. No caso do dimensionamento do tamanho da amostra para a análise fatorial confirmatória, Hair, Black, Babin, Anderson e Tatham (2009), Byrne (2009) e Kline (2011) sugerem entre 10 e 20 sujeitos por variável. Para a presente pesquisa, a escala com maior quantidade de itens é a EPPRH, com 32 itens, requerendo, portanto, 320 sujeitos.

Já no que tange à verificação da predição entre as variáveis, foi utilizada a análise do modelo de regressão (regression model), via modelagem por equações estruturais (Hoyle, 1995; Raykov \& Marcoulides, 2006; Schumacker \& Lomax, 2004). Nesse sentido, é importante selecionar uma amostra mínima que tenha poder estatístico maior que 0,80 (Cohen, 1992), no caso das ciências comportamentais. Para o autor, a análise do poder estatístico considera as relações entre as três variáveis envolvidas em inferência estatística, quais sejam: tamanho da amostra $(\mathrm{N})$, critério de significância $(\alpha)$ e efeito do tamanho da população (ES). Por meio do programa GPower 3.1 e considerando a variável preditora políticas e práticas de gestão de pessoas, com 6 fatores, ES médio, 6 preditores e poder estatístico de 95\%, obteve-se a amostra mínima de 146 sujeitos.

Segundo Kline (2011), para modelos simples, com poucas variáveis, como no caso da presente pesquisa, para utilizar a análise de regressão por meio da Structural Equation Modeling - SEM (Modelagem por Equações Estruturais), a amostra média entre 100 e 200 sujeitos é o mínimo recomendado. Considerando 28 observações e 28 parâmetros, ou seja, zero graus de liberdade, tem-se um modelo recursivo, classificado como identificado (just identified), sendo adequado para teste por meio da modelagem por equações estruturais, usando o critério de máxima verossimilhança (Kline, 2011).

Seguindo as recomendações da literatura, estimou-se um mínimo de 320 sujeitos para o teste dos modelos de mensuração e estrutural. Considerando uma margem de segurança por conta da etapa de tratamento dos dados, a amostra total foi obtida por questionário online e contemplou 490 sujeitos.

\subsubsection{Tratamento dos dados}

O tratamento dos dados iniciou-se com a análise de distribuição de frequências (média, desvio-padrão, variância, mínimo e máximo), visando realizar uma análise descritiva dos dados. Na sequência, utilizou-se o procedimento listwise para a análise de dados faltantes 
(missing values), que consiste na eliminação de questionários que apresentaram algum item em branco (Tabachnick \& Fidell, 2013). Nessa etapa, foram contabilizadas 77 perdas em razão de questionários incompletos.

A investigação quanto à presença de outliers, valores que diferem substancialmente da média e da maioria dos dados, foi realizada pelo método Mahalanobis (Tabachnick \& Fidell, 2013). Com base na verificação da tabela do qui-quadrado, com índice de significância $\mathrm{p}<0,001$ e considerando 47 variáveis, obteve-se o valor de $\chi^{2}=80,077$ e, assim, foram eliminados 20 outliers. Portanto, tem-se uma amostra final de 393 sujeitos, ainda maior que os 320 requeridos.

Em seguida, foram analisados os valores de tolerância, que foram superiores a 0,1 , e os valores referentes ao fator de inflação de variância (VIF), que foram superiores a 5,0, revelando que os dados não apresentaram problemas de multicolinearidade e de singularidade para a amostra pesquisada (Myers, 1990).

Enfim, partiu-se para a análise dos pressupostos para a utilização da análise multivariada, de acordo com Hair et al. (2009). Por último, foram gerados gráficos de probabilidade normal e gráficos de resíduos a fim de verificar a normalidade, linearidade e homocedasticidade dos dados, conforme as recomendações de Field (2009). Todos os pressupostos foram confirmados.

Tem-se, assim, uma amostra final composta por 393 sujeitos que atenderam aos critérios estatísticos supracitados. Essa amostra foi destinada à análise fatorial confirmatória e à análise de regressão. Cabe ressaltar que foi utilizada a modelagem por equações estruturais e analisou-se, ainda, a normalidade multivariada (Marôco, 2010) no software AMOS, a qual também não apresentou problemas.

\subsubsection{Caracterização da amostra}

A amostra foi caracterizada em termos de idade, gênero, nível de escolaridade, tempo de trabalho na FUB e se o respondente possui função gratificada ou cargo de direção. A questão 52 do instrumento de pesquisa, que abordava qual setor/instituto/faculdade o respondente trabalha, teve a exclusiva finalidade de auxiliar a pesquisadora na etapa da coleta de dados. Portanto, essa questão não foi considerada na caracterização da amostra para preservar o anonimato dos respondentes.

No que diz respeito à idade dos respondentes e tendo em vista que essas idades variaram de 20 a 69 anos, tem-se que $36 \%$ dos participantes possuem entre 31 e 40 anos; $23 \%$ entre 20 
e 30 anos; $22 \%$ entre 51 e 60 anos; $15 \%$ entre 41 e 50 anos; e 4\% apresentaram idade de 61 a 69 anos.

Quanto ao gênero, a amostra foi bastante homogênea: 50\% dos respondentes são do gênero feminino e $49 \%$ do masculino. Apenas $1 \%$ dos participantes não respondeu essa questão.

Em se tratando da escolaridade, foi pedido que os respondentes selecionassem o seu grau de escolaridade completo, no qual as opções variaram entre ensino fundamental e doutorado. De acordo com a Figura 4, observa-se que a maior parte dos respondentes tem especialização, representando 43\%. Destacam-se, ainda, o mestrado com $27 \%$ e o ensino superior, representando $21 \%$.

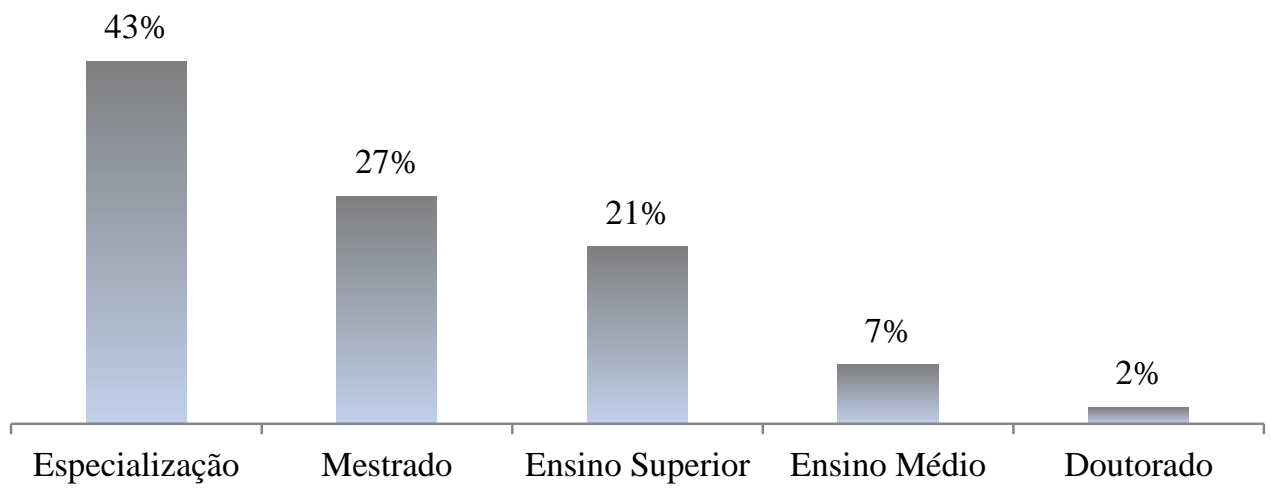

Figura 4. Nível de Escolaridade

Fonte: Elaborada pela autora.

Na sequência, os participantes foram questionados há quanto tempo trabalham na FUB. Conforme ilustra a Figura 5, 28\% dos respondentes possuem entre 1 e 5 anos trabalhando na FUB; $19 \%$ trabalham pelo período de até 1 ano; seguida de 6 a 10 anos, com $18 \%$ de representatividade; e 17\% dos respondentes têm mais de 26 anos de trabalho na FUB. Desses 17\%, 40\% deles estão na FUB há mais de 35 anos. 


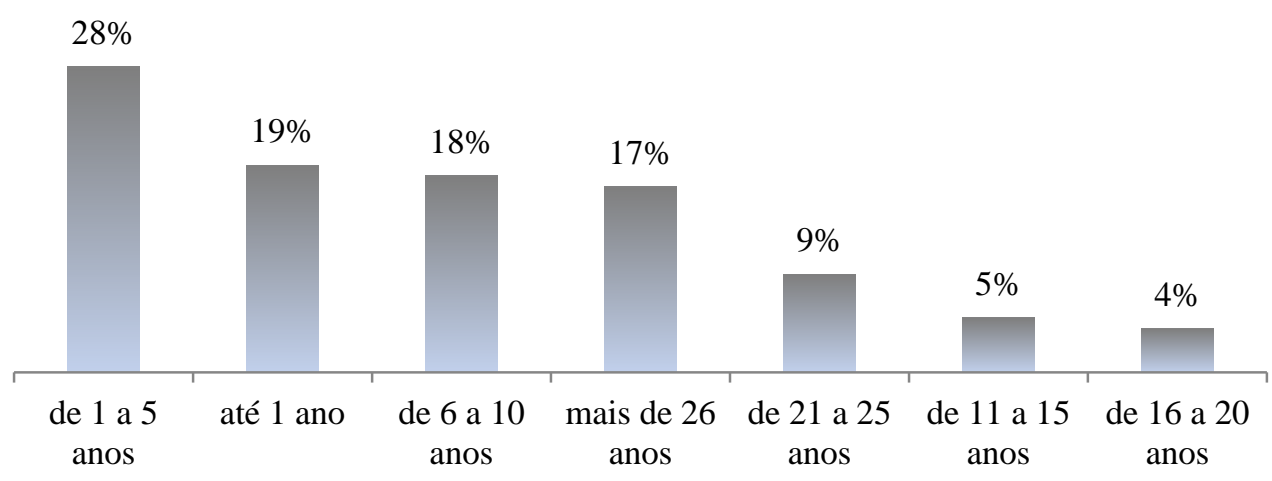

Figura 5. Tempo de trabalho na FUB

Fonte: Elaborada pela autora.

Por último, foi solicitado aos participantes que respondessem se possuem função gratificada (FG) ou cargo de direção (CD). Setenta e cinco por cento dos respondentes alegaram que não possuem $\mathrm{FG}$ ou $\mathrm{CD}$ e $25 \%$ responderam que possuem uma ou outra.

\subsection{Instrumento de pesquisa}

O instrumento de pesquisa aplicado do tipo questionário é composto por três partes, a saber: duas escalas de mensuração, ambas validadas cientificamente, a Escala de Políticas e Práticas de Recursos Humanos (EPPRH) e a Escala de Resiliência no Trabalho, e ainda a parte demográfica-funcional. O instrumento também conteve carta convite para participação em pesquisa acadêmica, bem como orientações para o preenchimento do questionário, além de termo de consentimento de participação acadêmica. O questionário possui ao total 53 itens.

A EPPRH é uma versão aprimorada e mais abrangente (com mais políticas) da Escala de Percepção de Políticas de Gestão de Pessoas (EPPGP), desenvolvida e validada por Demo (2008). A primeira versão da EPPRH, com 6 fatores e 40 itens, foi validada no Brasil por Demo et al. (2012). Com um ajuste ainda melhor na validação confirmatória, mesma quantidade de fatores e agora com 32 itens, a EPPRH foi validada nos Estados Unidos por Demo e Rozzett (2012). A versão reduzida da EPPRH foi traduzida por Demo et al. (2014) e foi a versão utilizada na presente pesquisa.

O objetivo da EPPRH é medir a percepção dos colaboradores sobre a existência de políticas e práticas de RH nas organizações. A versão reduzida da escala é composta por 32 itens, subdivididos em 6 fatores: recrutamento e seleção (6 itens); envolvimento ( 9 itens); treinamento, desenvolvimento \& educação (3 itens); condições de trabalho (5 itens); avaliação de desempenho e competências (5 itens) e remuneração e recompensas (4 itens). O 
instrumento faz uso de escala Likert de cinco pontos, sendo 1 (discordo totalmente) e 5 (concordo totalmente), para avaliar o quanto o respondente estava de acordo com a sentença. A EPPRH possui variância explicada de $58 \%$.

Já a Escala de Resiliência no Trabalho, Batista e Oliveira (2012) partiram do instrumento validado por Batista e Oliveira (2008), que por sua vez originou-se da versão da Escala de Resiliência, previamente adaptada e validada para adolescentes brasileiros por Pesce et al. (2005). Com o objetivo de identificar a presença da resiliência em colaboradores, a Escala de Resiliência no Trabalho (Gomide et al., 2015) possui uma estrutura unifatorial de 15 itens e utiliza a escala Likert de sete pontos, variando de 1 (discordo totalmente) a 7 (concordo totalmente), mas na presente pesquisa foi adaptada para 5 pontos para manter consonância com a estrutura de medição da EPPRH. O percentual de variância explicada pela Escala de Resiliência no Trabalho é de 33,35\%.

Na Tabela 7 são apresentados os índices psicométricos dos instrumentos utilizados.

Tabela 7

Índices psicométricos dos instrumentos

\begin{tabular}{|c|c|c|}
\hline Fatores & Itens & $\begin{array}{l}\text { Índice de confiabilidade (Alfa de } \\
\text { Cronbach / rho de Jöreskog) }\end{array}$ \\
\hline \multicolumn{3}{|c|}{ Escala de Políticas e Práticas de Recursos Humanos (Demo et al., 2014) } \\
\hline Recrutamento e Seleção & $1,2,3,4,5,6$ & $0,81 / 0,77$ \\
\hline Envolvimento & $7,8,9,10,11,12,13,14,15$ & $0,91 / 0,87$ \\
\hline $\begin{array}{l}\text { Treinamento, Desenvolvimento \& } \\
\text { Educação }\end{array}$ & $16,17,18$ & $0,82 / 0,73$ \\
\hline Condições de Trabalho & $19,20,21,22,23$ & $0,81 / 0,80$ \\
\hline $\begin{array}{l}\text { Avaliação de Desempenho e } \\
\text { Competências }\end{array}$ & $24,25,26,27,28$ & $0,86 / 0,90$ \\
\hline Remuneração e Recompensas & $29,30,31,32$ & $0,84 / 0,83$ \\
\hline \multicolumn{3}{|c|}{ Escala de Resiliência no Trabalho (Gomide et al., 2015) } \\
\hline Unifatorial & 1 a 15 & 0,90 \\
\hline
\end{tabular}

Nota. Fonte: Elaborada pela autora.

O questionário, composto pelos dois instrumentos de pesquisa supracitados mais as questões demográfico-funcionais para caracterização da amostra, encontra-se no Apêndice B.

\subsection{Procedimentos de coleta e análise de dados}

O questionário contendo a EPPRH, a Escala de Resiliência no Trabalho e os dados demográfico-funcionais foi disponibilizado na versão online, na plataforma Typeform, distribuído via correio eletrônico. Segundo Malhotra (2012), a captação de visitantes em um site ou de acordo com a divulgação por e-mail entre pessoas é um exemplo de amostragem 
por conveniência. Cabe ressaltar também as vantagens da coleta online, entre elas a flexibilidade, a economia de tempo, o baixo custo e a capacidade de atingir populações específicas, assim como, do ponto de vista do respondente, responder da maneira que for mais conveniente, no tempo e local de cada um (Gonçalves, 2008; Malhotra, 2006).

Os dados provenientes da aplicação dos questionários, compostos pelo instrumento supracitado, foram transferidos ao programa Statistical Package for Social Sciences (SPSS) e, após a etapa de tratamento dos dados, encaminhou-se para a execução dos objetivos específicos I e II, que consistem em identificar a percepção em relação às políticas e práticas de GP e identificar a resiliência no trabalho dos servidores técnico-administrativos da FUB, respectivamente. Para tanto, utilizou-se estatística descritiva com médias, desvios-padrão, mínimo, máximo, moda e distribuição de frequência.

A relação entre as variáveis do estudo foi feita utilizando-se a análise do modelo de regressão por meio da modelagem por equações estruturais, utilizando o critério da máxima verossimilhança, cuja principal função é a especificação e estimação de modelos de relações lineares entre variáveis (Kline, 2011). Dessa forma, a modelagem por equações estruturais foi utilizada para verificar a regressão do modelo proposto, com a utilização do programa estatístico AMOS.

Conforme Hair et al. (2009) e Kline (2011), a modelagem por equações estruturais fundamenta-se em uma técnica que examina a estrutura de interrelações expressas em uma série de equações, unindo a regressão múltipla linear com uma ou mais variáveis dependentes à análise fatorial. Pode-se caracterizar por dois componentes básicos, quais sejam: o modelo estrutural, que consiste em um caminho que relaciona variáveis dependentes com independentes, e contempla o objetivo específico IV (testar o modelo estrutural de predição das políticas e práticas de GP sobre a resiliência no trabalho); e o modelo de mensuração, que permite confirmar as estruturas da EPPRH e da Escala de Resiliência no Trabalho, objetivo específico III (testar os modelos de mensuração das variáveis do estudo fazendo sua validação confirmatória). 


\section{Resultados e Discussão}

Neste capítulo são apresentados os resultados e subsequente discussão, referentes à identificação da percepção dos servidores técnico-administrativos da FUB quanto às políticas e práticas de GP; à identificação da resiliência no trabalho dos servidores técnicoadministrativos da FUB; à validação confirmatória das escalas EPPRH e Resiliência no Trabalho; e, por fim, à análise de regressão de um modelo estrutural de predição das políticas e práticas de GP sobre a resiliência no trabalho, contemplando, assim, os quatro objetivos propostos pelo presente estudo, os quais remetem, em última análise, à consecução do objetivo geral.

\subsection{Identificação da percepção em relação às políticas e práticas de gestão de pessoas}

O primeiro objetivo dessa pesquisa foi identificar a percepção dos servidores técnicoadministrativos da FUB em relação às políticas e práticas de GP. Na Parte I do questionário, os respondentes avaliaram os 32 itens da EPPRH de acordo com uma escala Likert de 1 a 5 , variando de discordo totalmente a concordo totalmente. A Tabela 8 descreve a média, o desvio-padrão, a moda e os valores mínimo e máximo encontrados para cada item da EPPRH, em ordem decrescente de média.

Tabela 8

Média, desvio-padrão, moda, mínimo e máximo dos itens da EPPRH

\begin{tabular}{|c|c|c|c|c|c|c|}
\hline $\begin{array}{l}\mathrm{N}^{\circ} \text { do } \\
\text { Item }\end{array}$ & Item & Média & $\begin{array}{l}\text { Desvio- } \\
\text { padrão }\end{array}$ & Moda & Mínimo & Máximo \\
\hline HR5 & $\begin{array}{l}\text { A FUB divulga aos candidatos informações a respeito } \\
\text { das etapas e critérios do processo seletivo. }\end{array}$ & 3,73 & 0,96 & 4 & 1 & 5 \\
\hline HR20 & $\begin{array}{l}\text { A FUB me oferece benefícios básicos (exemplos: plano } \\
\text { de saúde, auxílio transporte, auxílio alimentação etc.). }\end{array}$ & 3,54 & 1,01 & 4 & 1 & 5 \\
\hline HR1 & $\begin{array}{l}\text { Os processos de recrutamento (externo e interno) de } \\
\text { candidatos a ocuparem vagas na FUB são amplamente } \\
\text { divulgados. }\end{array}$ & 3,53 & 1,04 & 4 & 1 & 5 \\
\hline HR3 & $\begin{array}{l}\text { Os testes de seleção da FUB são conduzidos por pessoas } \\
\text { capacitadas e imparciais. }\end{array}$ & 3,52 & 0,98 & 4 & 1 & 5 \\
\hline HR6 & $\begin{array}{l}\text { A FUB comunica aos candidatos seu desempenho ao } \\
\text { final do processo seletivo. }\end{array}$ & 3,46 & 1,01 & 4 & 1 & 5 \\
\hline HR2 & $\begin{array}{l}\text { Os processos seletivos da FUB são disputados, atraindo } \\
\text { pessoas competentes. }\end{array}$ & 3,27 & 1,05 & 4 & 1 & 5 \\
\hline HR4 & $\begin{array}{l}\text { A FUB utiliza-se de vários instrumentos de seleção } \\
\text { (exemplos: entrevistas, provas etc.). }\end{array}$ & 3,22 & 1,05 & 4 & 1 & 5 \\
\hline HR17 & $\begin{array}{l}\text { Eu consigo aplicar no meu trabalho os conhecimentos e } \\
\text { comportamentos aprendidos nos treinamentos/eventos de } \\
\text { que participo. }\end{array}$ & 3,18 & 1,04 & 4 & 1 & 5 \\
\hline HR14 & $\begin{array}{l}\text { Na FUB, há um clima de confiança e cooperação entre os } \\
\text { colegas de trabalho. }\end{array}$ & 3,11 & 1,07 & 4 & 1 & 5 \\
\hline
\end{tabular}




\begin{tabular}{|c|c|c|c|c|c|c|}
\hline $\begin{array}{l}\mathbf{N}^{\circ} \text { do } \\
\text { Item }\end{array}$ & Item & Média & $\begin{array}{l}\text { Desvio- } \\
\text { padrão }\end{array}$ & Moda & Mínimo & Máximo \\
\hline HR18 & $\begin{array}{l}\text { A FUB estimula a aprendizagem e a produção de } \\
\text { conhecimento. }\end{array}$ & 3,08 & 1,11 & 4 & 1 & 5 \\
\hline HR16 & $\begin{array}{l}\text { A FUB me ajuda a desenvolver as competências } \\
\text { necessárias à boa realização das minhas funções } \\
\text { (exemplos: treinamentos, participação em congressos } \\
\text { etc.). }\end{array}$ & 2,88 & 1,16 & 4 & 1 & 5 \\
\hline HR13 & $\begin{array}{l}\text { Na FUB, há um clima de compreensão e confiança dos } \\
\text { chefes em relação aos seus servidores. }\end{array}$ & 2,75 & 1,10 & 2 & 1 & 5 \\
\hline HR8 & A FUB me trata com respeito e atenção. & 2,72 & 1,06 & 2 & 1 & 5 \\
\hline HR12 & $\begin{array}{l}\text { Na FUB, os servidores e suas chefias desfrutam da troca } \\
\text { constante de informações para o bom desempenho das } \\
\text { funções. }\end{array}$ & 2,72 & 1,10 & 2 & 1 & 5 \\
\hline HR24 & $\begin{array}{l}\text { A FUB realiza avaliações de desempenho e competências } \\
\text { periodicamente. }\end{array}$ & 2,61 & 1,10 & 2 & 1 & 5 \\
\hline HR21 & $\begin{array}{l}\text { Na FUB, existem ações e programas de prevenção de } \\
\text { acidentes e enfrentamento de incidentes. }\end{array}$ & 2,54 & 0,97 & 2 & 1 & 5 \\
\hline HR28 & $\begin{array}{l}\text { Na FUB, os critérios e os resultados da avaliação de } \\
\text { desempenho e competências são divulgados para os } \\
\text { servidores. }\end{array}$ & 2,53 & 1,08 & 3 & 1 & 5 \\
\hline HR19 & $\begin{array}{l}\text { A FUB preocupa-se com a minha saúde e qualidade de } \\
\text { vida. }\end{array}$ & 2,46 & 1,03 & 2 & 1 & 5 \\
\hline HR7 & A FUB se preocupa com meu bem-estar. & 2,43 & 1,06 & 2 & 1 & 5 \\
\hline HR10 & $\begin{array}{l}\text { A FUB estimula a minha participação nas tomadas de } \\
\text { decisão e resolução de problemas. }\end{array}$ & 2,43 & 1,06 & 2 & 1 & 5 \\
\hline HR27 & $\begin{array}{l}\text { Na FUB, os critérios e os resultados da avaliação de } \\
\text { desempenho e competências são discutidos com os } \\
\text { servidores. }\end{array}$ & 2,36 & 1,05 & 2 & 1 & 5 \\
\hline HR29 & $\begin{array}{l}\text { A FUB me oferece remuneração compatível com as } \\
\text { minhas competências e formação/escolaridade. }\end{array}$ & 2,35 & 1,10 & 2 & 1 & 5 \\
\hline HR11 & $\begin{array}{l}\text { A FUB reconhece o trabalho que faço e os resultados que } \\
\text { apresento (exemplos: elogios, matérias em jornais } \\
\text { internos etc.). }\end{array}$ & 2,34 & 0,98 & 2 & 1 & 5 \\
\hline HR15 & Na FUB, há coerência entre discurso e prática gerenciais. & 2,29 & 0,94 & 2 & 1 & 5 \\
\hline HR26 & $\begin{array}{l}\text { Na FUB, a avaliação de desempenho e competências } \\
\text { subsidia a elaboração de um plano de desenvolvimento } \\
\text { dos servidores. }\end{array}$ & 2,28 & 0,99 & 2 & 1 & 5 \\
\hline HR9 & $\begin{array}{l}\text { A FUB procura conhecer minhas necessidades } \mathrm{e} \\
\text { expectativas profissionais. }\end{array}$ & 2,27 & 0,95 & 2 & 1 & 5 \\
\hline HR30 & $\begin{array}{l}\mathrm{Na} \text { FUB, recebo incentivos } \\
\text { promoções/funções } \\
\text { bônus/prêmios/gratificações etc.). }\end{array}$ & 2,22 & 1,07 & 2 & 1 & 5 \\
\hline HR25 & $\begin{array}{l}\text { Na FUB, a avaliação de desempenho e competências } \\
\text { subsidia as decisões sobre promoções e aumento de } \\
\text { salário. }\end{array}$ & 2,20 & 1,04 & 2 & 1 & 5 \\
\hline HR31 & $\begin{array}{l}\text { Na definição de seu sistema de recompensas, a FUB } \\
\text { considera as expectativas e sugestões de seus servidores. }\end{array}$ & 2,10 & 0,88 & 2 & 1 & 5 \\
\hline HR23 & $\begin{array}{l}\text { As instalações e as condições físicas (iluminação, } \\
\text { ventilação, ruído e temperatura) da FUB são } \\
\text { ergonômicas (adequadas e confortáveis). }\end{array}$ & 2,00 & 0,98 & 2 & 1 & 5 \\
\hline HR22 & $\begin{array}{l}\text { A FUB preocupa-se com a segurança de seus servidores, } \\
\text { controlando o acesso de pessoas estranhas nos locais de } \\
\text { trabalho. }\end{array}$ & 1,87 & 0,94 & 1 & 1 & 5 \\
\hline HR32 & $\begin{array}{l}\text { Na FUB, minha remuneração é influenciada pelos meus } \\
\text { resultados. }\end{array}$ & 1,83 & 0,83 & 2 & 1 & 5 \\
\hline
\end{tabular}

Nota. Fonte: Elaborada pela autora. 
Ademais, com relação aos fatores da EPPRH, a Tabela 9 apresenta o resultado da média, desvio-padrão, moda, mínimo e máximo de cada um dos seis fatores, em ordem decrescente de média.

Tabela 9

Média, desvio-padrão, moda, mínimo e máximo dos fatores da EPPRH

\begin{tabular}{ccccccc}
\hline $\begin{array}{c}\text { Itens de } \\
\text { referência }\end{array}$ & Fator & Média & $\begin{array}{c}\text { Desvio- } \\
\text { padrão }\end{array}$ & Moda & Mínimo & Máximo \\
\hline HR1 a HR6 & Recrutamento e Seleção & 3,46 & 0,70 & 4 & 1 & 5 \\
\hline HR16 a HR18 & $\begin{array}{c}\text { Treinamento, } \\
\text { Desenvolvimento \& Educação }\end{array}$ & 3,05 & 0,96 & 4 & 1 & 5 \\
\hline HR7 a HR15 & Envolvimento & 2,56 & 0,78 & 2 & 1 & 5 \\
\hline HR19 a HR23 & Condições de Trabalho & 2,48 & 0,64 & 2 & 1 & 5 \\
\hline HR24 a HR28 & $\begin{array}{c}\text { Avaliação de Desempenho e } \\
\text { Competências }\end{array}$ & 2,40 & 0,88 & 2 & 1 & 5 \\
\hline HR29 a HR32 & Remuneração e Recompensas & 2,13 & 0,71 & 2 & 1 & 5 \\
\hline
\end{tabular}

Nota. Fonte: Elaborada pela autora.

De acordo com as Tabelas 8 e 9, o item que apresentou maior percepção foi o HR5 (A FUB divulga aos candidatos informações a respeito das etapas e critérios do processo seletivo), apresentando média de 3,73 e desvio-padrão de 0,96, do fator Recrutamento e Seleção, e conforme a Tabela 9, foi o que se destacou. Pode-se inferir que essa alta percepção dos respondentes seja em razão da publicação de editais de concurso público, obrigatória em todo processo de seleção para cargo ou emprego público (Constituição da República Federativa do Brasil, 1988; Lei n. 8112, 1990).

Em seguida, o item que apresentou a segunda maior percepção por parte dos respondentes foi o HR20 (A FUB me oferece benefícios básicos - exemplos: plano de saúde, auxílio transporte, auxílio alimentação etc), com média de 3,54, desvio-padrão de 1,01 e moda de 4, do fator Condições de Trabalho. Nesse caso, utilizou-se a moda como medida de tendência central haja vista que o desvio-padrão foi superior a 1. Depreende-se que os servidores percebem essa prática na Universidade, pois tratam-se de benefícios previstos em lei ou Decretos publicados pela União (Decreto n. 977, 1993; Decreto n. 2880, 1998; Decreto n. 3887, 2001; Lei n. 8112, 1990).

Em contrapartida, o item que apresentou menor percepção dos respondentes foi o HR32 (Na FUB, minha remuneração é influenciada pelos meus resultados), apresentando média de 1,83 e desvio-padrão de 0,83 , do fator Remuneração e Recompensas, que de acordo com a Tabela 9, foi o fator com menor média. Tal fato pode ser justificado pela ausência de mecanismo de gratificação por desempenho na FUB. 
A avaliação de desempenho no setor público tem o objetivo de promover a melhoria da qualificação dos serviços e subsidiar as políticas de GP, principalmente quanto à capacitação, desenvolvimento na carreira, remuneração e movimentação de pessoal (Velasco \& Silva, 2011). Para Marconi (2003), é importante criar mecanismos de estímulo salarial que estejam desvinculados da estrutura remuneratória das carreiras e que possibilitem, ainda, recompensar servidores e instituições mais eficientes. Nesse sentido, uma das maneiras de se aperfeiçoar as práticas tradicionais de gestão se dá pelo uso da remuneração variável, baseada nas competências e nos resultados (Guimarães, 2000). Ademais, em estudo recente publicado por Klein e Mascarenhas (2016), a evasão no serviço público parece depender, fundamentalmente, dos fatores motivacionais extrínsecos associados à remuneração, não sendo afetada pelos fatores motivacionais intrínsecos, como a relevância das atividades para a organização e/ou sociedade, nem pela compatibilidade das atividades com a descrição do cargo.

Por outro lado, para Weibel, Rost e Osterloh (2010), os servidores públicos têm, em geral, motivação intrínseca significativa, realizando tarefas em função de seu senso de dever, lealdade e prazer. Nesse contexto, para os autores, a implantação de sistemas de incentivo monetário pode gerar efeitos negativos na motivação. Além disso, a remuneração variável pode significar uma queda no valor do salário real ao longo do tempo, pois a lógica que está por trás "é a composição de uma remuneração na qual o salário fixo significa a parte menor, e os ganhos por produtividade, a maior proporção" (Guimarães, 2000, p. 138). Assim, segundo o autor, essa lógica torna o empregado um prisioneiro da eficiência e da competição a qualquer custo.

Por conseguinte, a alta administração da FUB poderia avaliar criticamente os elementos decorrentes da implementação da gratificação por desempenho, reunindo experiências de outros órgãos ou entidades públicos que já o fazem. Para contribuir com a análise e tomada de decisão dos gestores, não se limitando aqui apenas à organização objeto do presente estudo, algumas reflexões surgem no sentido de construir uma agenda estratégica com indicadores e metas para toda a instituição, o que, por seu turno, poderia melhorar a eficiência dos processos de trabalho.

Posteriormente, o item HR22 (A FUB preocupa-se com a segurança de seus servidores, controlando o acesso de pessoas estranhas nos locais de trabalho), do fator Condições de Trabalho, apresentou a segunda menor percepção, com média de 1,87 e desvio-padrão de 0,94. Assim, esse resultado aponta um alerta aos gestores da FUB, tanto sob o ponto de vista do risco com relação à integridade física de seus colaboradores, quanto do fator motivacional, 
pois, conforme Maslow (1970), o fator segurança (aqui entendido como sentir-se seguro) constitui-se o segundo fator na hierarquia das necessidades e, consoante o autor, a motivação ascende por meio de vários níveis de necessidades, quais sejam: fisiológicas, segurança, sociais, de estima e de autorrealização. De acordo com Maslow (1970), um indivíduo só será motivado por um nível mais superior de necessidade quando os níveis anteriores já estiverem satisfatoriamente preenchidos para ele. Ainda, para Herzberg (1968), aspectos ligados às condições do ambiente de trabalho previnem ou levam à insatisfação dos colaboradores. Posto isso, recomenda-se que os gestores da FUB deem uma maior atenção à segurança no ambiente de trabalho.

Explorando a estatística descritiva dos dados, em termos porcentuais, a distribuição da frequência relativa a cada um dos seis fatores da EPPRH é ilustrada na Figura 6. Os valores variaram entre 1 (discordo totalmente), 2 (discordo), 3 (não concordo nem discordo/não se aplica), 4 (concordo) e 5 (concordo totalmente).

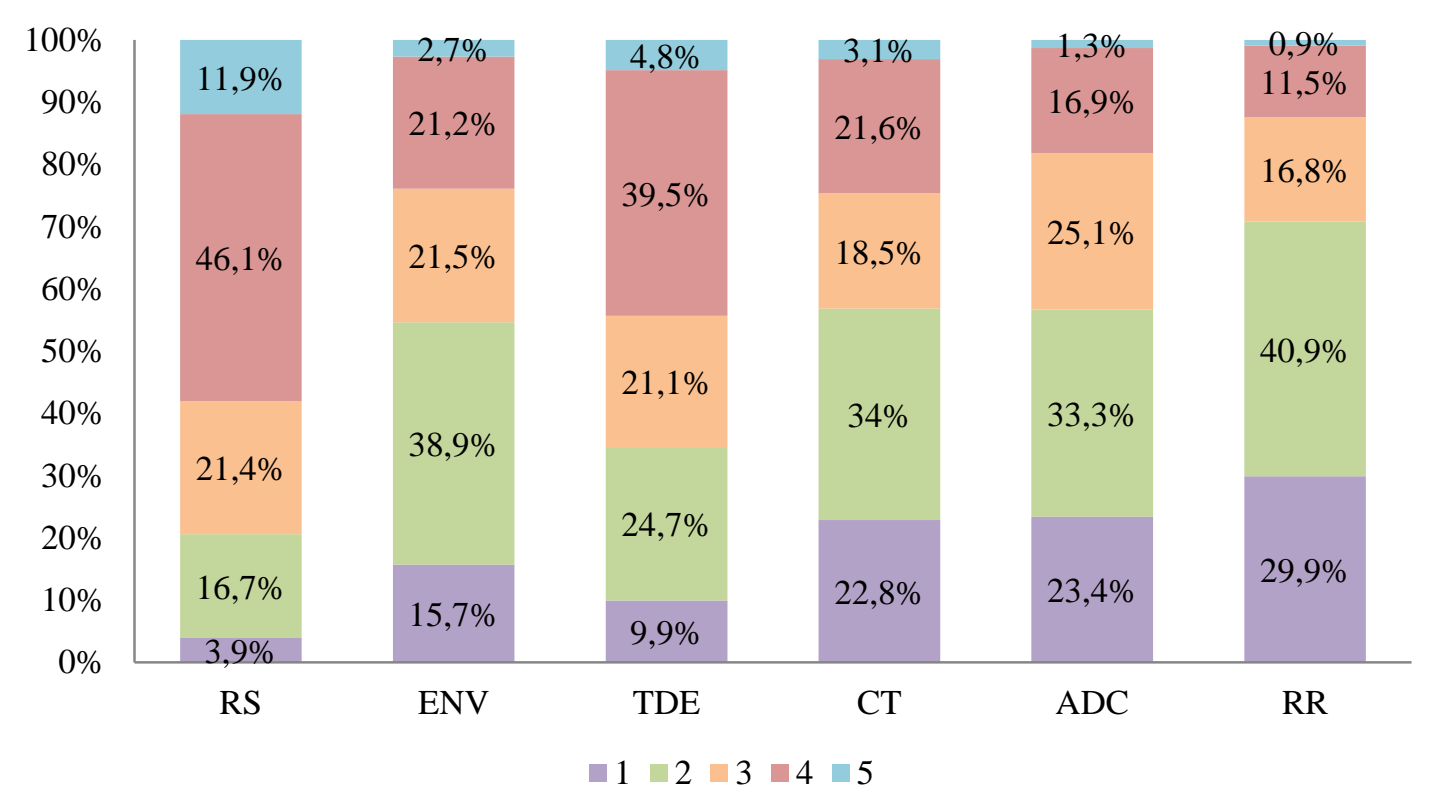

Figura 6. Distribuição da frequência dos fatores da EPPRH Fonte: Elaborada pela autora.

Constatando que uma percepção a partir de 3 já pode ser considerada positiva, as políticas de GP Recrutamento e Seleção, e Treinamento, Desenvolvimento \& Educação foram percebidas pelos respondentes, resultando num porcentual absoluto de avaliações 3, 4 e 5 maior que $50 \%$ em cada uma das políticas. Ao contrário, as políticas de Envolvimento, Condições de Trabalho, Avaliação de Desempenho e Competências, e Remuneração e Recompensas tiveram uma concentração maior (maior que 50\% em cada caso) de avaliações 
1 e 2, sendo, portanto, políticas de GP não-percebidas pela amostra pesquisada, o que constitui pontos críticos de análise para a gestão da FUB.

Embora o item HR20 (A FUB me oferece benefícios básicos - exemplos: plano de saúde, auxílio transporte, auxílio alimentação etc), referente à política de Condições de Trabalho, tenha resultado na segunda maior percepção, com média de 3,54, desvio-padrão de 1,01 e moda de 4, os outros itens concernentes a essa política não são percebidos, concentrando-se nos valores 1 e 2, a exemplo do item HR22 (A FUB preocupa-se com a segurança de seus servidores, controlando o acesso de pessoas estranhas nos locais de trabalho), que apresentou a segunda menor média $(1,87)$ e desvio-padrão de 0,94 . Por isso, tal fato sucedeu em uma não-percepção do conjunto das práticas da política de Condições de Trabalho.

\subsection{Identificação da resiliência no trabalho dos servidores da FUB}

O segundo objetivo desse estudo foi identificar a resiliência no trabalho dos servidores técnico-administrativos da FUB. Na Parte II do questionário, os respondentes avaliaram os 15 itens da Escala de Resiliência no Trabalho de acordo com uma escala Likert de 1 a 5 , variando de discordo totalmente a concordo totalmente. A Tabela 10 descreve a média, o desvio-padrão, a moda e os valores mínimo e máximo encontrados para cada item da Escala de Resiliência no Trabalho, em ordem decrescente de média.

Tabela 10

Média, desvio-padrão, moda, mínimo e máximo da Escala de Resiliência no Trabalho

\begin{tabular}{|c|c|c|c|c|c|c|}
\hline $\begin{array}{l}N^{0} \text { do } \\
\text { Item }\end{array}$ & Item & Média & $\begin{array}{l}\text { Desvio- } \\
\text { padrão }\end{array}$ & Moda & Mínimo & Máximo \\
\hline & \multicolumn{6}{|l|}{ No meu trabalho... } \\
\hline R9 & $\begin{array}{l}\text { Sou uma pessoa com quem as pessoas podem } \\
\text { contar em situações de emergência. }\end{array}$ & 4,27 & 0,67 & 4 & 2 & 5 \\
\hline $\mathrm{R} 14$ & $\begin{array}{l}\text { Manter interesse nas coisas é importante para } \\
\text { mim. }\end{array}$ & 4,19 & 0,61 & 4 & 2 & 5 \\
\hline $\mathrm{R} 15$ & Sou amigo(a) de mim mesmo(a). & 4,10 & 0,79 & 4 & 1 & 5 \\
\hline $\mathrm{R} 4$ & Sou determinado(a). & 4,07 & 0,70 & 4 & 1 & 5 \\
\hline $\mathrm{R} 8$ & Sinto orgulho de ter realizado coisas. & 4,05 & 0,84 & 4 & 1 & 5 \\
\hline $\mathrm{R} 11$ & $\begin{array}{l}\text { Costumo lidar com os problemas de uma forma } \\
\text { ou de outra. }\end{array}$ & 4,00 & 0,64 & 4 & 2 & 5 \\
\hline $\mathrm{R} 13$ & Sou disciplinado(a). & 4,00 & 0,75 & 4 & 1 & 5 \\
\hline $\mathrm{R} 10$ & Normalmente posso achar motivos para rir. & 3,97 & 0,83 & 4 & 1 & 5 \\
\hline $\mathrm{R} 2$ & $\begin{array}{l}\text { Quando estou em uma situação difícil, } \\
\text { normalmente acho uma saída. }\end{array}$ & 3,96 & 0,65 & 4 & 1 & 5 \\
\hline R5 & $\begin{array}{l}\text { Posso olhar normalmente para uma situação de } \\
\text { diversas maneiras. }\end{array}$ & 3,89 & 0,75 & 4 & 1 & 5 \\
\hline
\end{tabular}




\begin{tabular}{clrrrrr}
\hline $\begin{array}{c}\text { No do } \\
\text { Item }\end{array}$ & \multicolumn{1}{c}{ Item } & Média & $\begin{array}{c}\text { Desvio- } \\
\text { padrão }\end{array}$ & Moda & Mínimo & Máximo \\
\hline & No meu trabalho... & & & & & \\
\hline R1 & Mantenho interesse nele. & 3,86 & 0,83 & 4 & 1 & 5 \\
\hline R7 & Meu trabalho tem sentido para mim. & 3,84 & 0,92 & 4 & 1 & 5 \\
\hline R3 & $\begin{array}{l}\text { Tenho energia suficiente para fazer o que } \\
\text { preciso fazer. }\end{array}$ & 3,80 & 0,89 & 4 & 1 & 5 \\
\hline R12 & Quando faço planos, eu os levo até o fim. & 3,63 & 0,86 & 4 & 1 & 5 \\
\hline R6 & $\begin{array}{l}\text { Minha autoconfiança me leva a passar por } \\
\text { períodos difíceis. }\end{array}$ & 3,41 & 0,96 & 4 & 1 & 5 \\
\hline
\end{tabular}

Nota. Fonte: Elaborada pela autora.

Conforme a Tabela 10, o item que apresentou maior média foi o R9 (Sou uma pessoa com quem as pessoas podem contar em situações de emergência), com média de 4,27 e desvio-padrão de 0,67. Já a segunda maior média ocorreu no item R14 (Manter interesse nas coisas é importante para mim), resultando em 4,19 de média e 0,61 de desvio-padrão.

Em compensação, os itens que apresentaram menor média foram R6 (Minha autoconfiança me leva a passar por períodos difíceis), com média de 3,41 e desvio-padrão de 0,96; e R12 (Quando faço planos, eu os levo até o fim), com média de 3,63 e desvio-padrão de 0,86 . No entanto, embora tenham resultado nas menores médias dentre os 15 itens que compõem o instrumento de medida, esses dois itens ainda apresentaram média acima de 3 , que é o ponto neutro da escala, indicando que estão presentes na amostra pesquisada.

Destarte, com um único fator, os 15 itens em conjunto da Escala de Resiliência no Trabalho resultaram em uma média de 3,94; desvio-padrão de 0,46; moda de 4; com os valores mínimo e máximo variando entre 1 e 5 . Tais resultados reforçam aqueles encontrados na Tabela 10, indicando que os servidores técnico-administrativos da FUB percebem a si mesmos como resilientes.

Na definição de Batista e Oliveira (2008), resiliência é a capacidade de lidar com problemas de forma proativa, autônoma e determinada, buscando alternativas, a partir da confiança em si mesmo. Para Ribeiro et al. (2011), ter atitudes resilientes demanda reflexão, capacidade analítica e ânimo, pois é preciso unir forças para ultrapassar obstáculos e retomar aquilo que precisa ser refeito ou superado. Já Coutu (2002) aponta três características da pessoa resiliente: a firme aceitação da realidade; a crença profunda, em geral apoiada por valores fortemente sustentados, de que a vida é significativa; e uma misteriosa habilidade para improvisar.

Nessa direção, no estudo realizado por Onça (2011), a resiliência dos trabalhadores é explicada pela crença das pessoas sobre suas capacidades e/ou seu exercício de controle sobre os eventos que afetam sua vida. Na resiliência, para Yunes (2003), há o aspecto de uma 
crença na capacidade do próprio sujeito em se sobrepor às barreiras que aparecem em seu caminho. Ainda, a convicção na existência da motivação fortalece, segundo Barreira e Nakamura (2006), a crença na existência da resiliência.

Posto isso, em todas as definições que caracterizam a resiliência, é possível identificar em comum, conforme Angst (2009), Tavares (2001) e Barlach et al. (2008), a resistência, a flexibilidade, a capacidade de autorregulação e de autorrecuperação, o interesse e a disponibilidade. Tais conceitos reforçam os resultados obtidos no segundo objetivo dessa pesquisa, a saber, identificar a resiliência no trabalho dos servidores técnico-administrativos da FUB, já que os itens que compõem a Escala de Resiliência no Trabalho resultaram em uma média acima de 3, indicando que os servidores técnico-administrativos da FUB percebem-se resilientes no trabalho. Destaca-se, ainda, que a resiliência pode ser desencadeada e desaparecer em determinados momentos da vida, bem como estar presente em algumas áreas e ausente em outras (Poletto \& Koller, 2008).

Em termos porcentuais, a distribuição da frequência relativa a cada um dos 15 itens da Escala de Resiliência no Trabalho é demonstrada pela Figura 7.

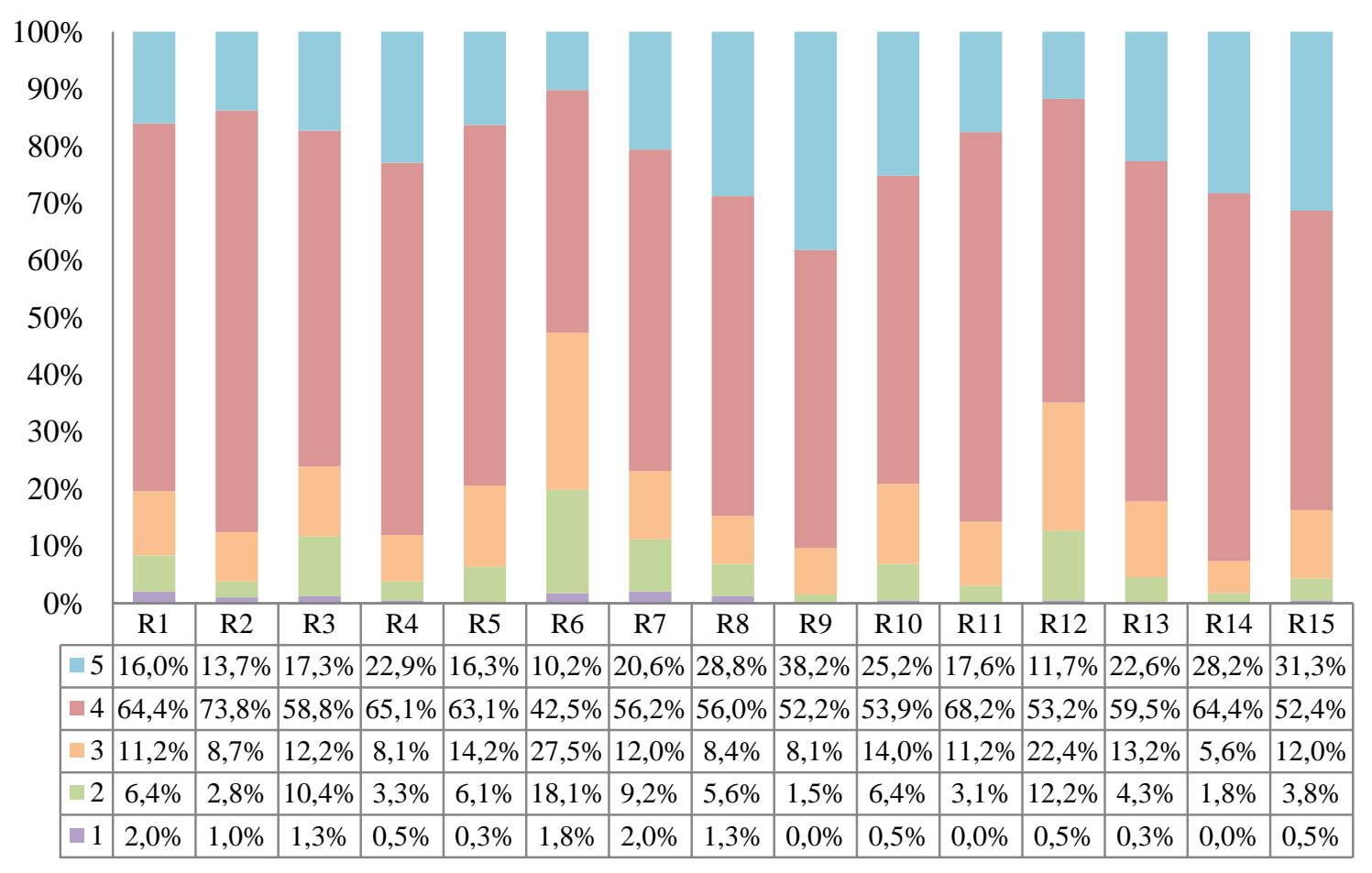

Figura 7. Distribuição da frequência dos itens da Escala de Resiliência no Trabalho Fonte: Elaborada pela autora.

Ao considerar que avaliações 3, 4 ou 5 indicam que a amostra pesquisada apresenta a resiliência no trabalho, conclui-se que para mais de $80 \%$ de respondentes a avaliação foi igual 
ou superior a 3 em cada um dos itens, indicando uma forte presença da resiliência no trabalho dos servidores técnico-administrativos da FUB, o que pode ser considerado um bom resultado para os gestores da FUB, já que servidores resilientes alcançam resultados positivos independente das contingências (Cimbalista, 2006), uma vez que a resiliência prediz a adaptação a condições adversas no trabalho (Batista \& Oliveira, 2008).

\subsection{Validação confirmatória dos modelos de mensuração}

Visando cumprir o objetivo específico III, qual seja testar o modelo de mensuração das variáveis do estudo fazendo sua validação confirmatória, partiu-se para a análise fatorial confirmatória por meio da modelagem por equações estruturais (SEM), método de estimação da verossimilhança, uma vez que é o método de estimação mais usado em SEM por ser mais robusto a problemas de normalidade e também por ser eficaz tanto para amostras pequenas quanto para amostras grandes (Hair, Black, Babin, Anderson, \& Tatham, 2009).

A análise por meio da SEM envolve o modelo de mensuração - como os construtos são representados, e o modelo estrutural - como os construtos se relacionam entre si (Hair et al., 2009). Assim, a fim de determinar a aceitabilidade de um modelo SEM, o pesquisador deve usar um índice incremental e um índice absoluto, além do valor do qui-quadrado e dos graus de liberdade associados. Um modelo que relata o valor $\chi^{2}$ normado (CMIN/DF ou NC, em que CMIN é a estatística do $\chi^{2}$ e DF são os graus de liberdade do modelo), CFI (Comparative Fit Index ou índice de ajuste comparativo) e RMSEA (raiz do erro médio quadrático de aproximação) possuirá informação suficiente para sua avaliação (Hair et al., 2009).

Dessa maneira, a verificação do ajuste global de um modelo à amostra pesquisada pode ser realizada por meio de um indicador de ajuste absoluto que utiliza a estatística de teste quiquadrado (NC) e a estatística RMSEA, que também pressupõe uma má qualidade do ajuste (valores maiores indicam ajustes pobres), e que representa melhor quão bem um modelo se ajusta a uma população e não apenas a uma amostra usada para estimação (Kline, 2011); e, por fim, por um indicador de ajuste incremental, como o CFI, que por ser mais insensível à complexidade dos modelos, está entre os índices mais utilizados (Hair et al., 2009).

Ainda, Kline (2011) estabelece os valores satisfatórios para um modelo estrutural, a saber: valores para $\mathrm{NC}(\mathrm{CMIN} / \mathrm{DF})$ de 2,0 ou 3,0 e no máximo até 5,0; valores para CFI iguais ou superiores a 0,90; e valores para RMSEA inferiores a 0,05 ou até 0,10 .

Posto isso, a validação confirmatória de cada um dos modelos será apresentada nos próximos dois subtópicos. 


\subsubsection{Validação confirmatória do modelo de políticas de práticas de gestão de pessoas}

A estrutura final da EPPRH abrangeu 30 itens. Ressalta-se que a solução fatorial de seis fatores da estrutura original da escala, validada no Brasil e nos Estados Unidos (Demo et al., 2014), foi mantida, com a exclusão de dois itens.

Com o propósito de verificar as dimensões da escala, os modelos unifatorial e multifatorial foram testados e comparados, seguindo as recomendações de parcimônia de Byrne (2009). O modelo unifatorial apresentou índices piores $(\mathrm{NC}=4,6 ; \mathrm{CFI}=0,72$; RMSEA = 0,10) quando comparados aos dados do modelo multifatorial de seis fatores, conforme apresenta a Tabela 11. Tais dados tornam possível afirmar que a estrutura multifatorial possui um bom ajuste, uma vez que todos os parâmetros estão dentro das recomendações de Kline (2011).

Tabela 11

Índices de ajuste da análise confirmatória da EPPRH

\begin{tabular}{ccc}
\hline Parâmetros & Referência (Kline, 2011) & EPPRH \\
\hline $\mathrm{NC}\left(\chi^{2} / \mathrm{DF}\right)$ & $<3,0$ & 2,24 \\
\hline $\mathrm{CFI}$ & $\geq 0,90$ & 0,92 \\
\hline RMSEA & $<0,08$ & 0,06 \\
\hline
\end{tabular}

Nota. Fonte: Elaborada pela autora.

Ademais, as cargas fatoriais de 26 itens da validação confirmatória foram acima de 0,5, revelando boa qualidade e validade da escala (Hair et al., 2009).

A Figura 8 apresenta o modelo final de mensuração da EPPRH obtido na análise fatorial confirmatória, com os respectivos parâmetros. 


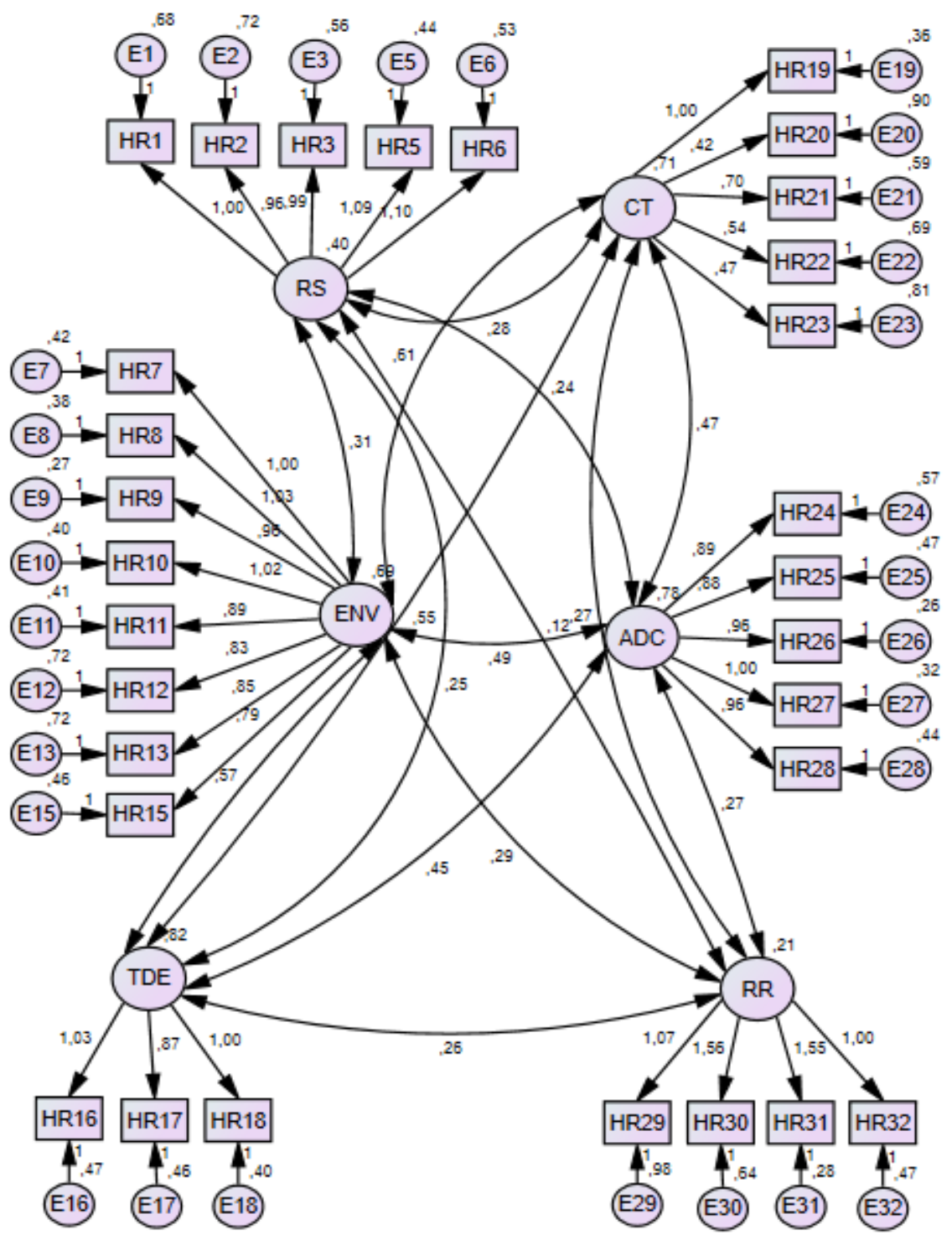

Figura 8. Modelo de análise confirmatória da EPPRH

Nota: $\chi^{2}(390)=872,78 ; \mathrm{p}<0,001 ; \mathrm{NC}=2,24 ; \mathrm{CFI}=0,92 ; \mathrm{RMSEA}=0,06$

Fonte: Elaborada pela autora.

A confiabilidade dos seis fatores foi analisada pelo rho de Jöreskog, medida de confiabilidade mais precisa que o Alfa de Cronbach para modelagem por equações estruturais, visto que se baseia em cargas fatoriais e não nas correlações observadas entre as variáveis (Chin, 1998). O fator Recrutamento e Seleção obteve $\rho=0,78$; Envolvimento $\rho=0,91$; Treinamento, Desenvolvimento \& Educação $\rho=0,84$; Condições de Trabalho $\rho=0,80$; Avaliação de Desempenho e Competências $\rho=0,94$; e, por fim, o fator Remuneração e Recompensas apresentou $\rho=0,72$. De acordo com Chin (1998), esses valores são considerados bastante satisfatórios, uma vez que os índices de Jöreskog devem ser superiores a 0,7.

Em síntese, os resultados revelam que a EPPRH possui validade interna e externa (a estrutura de seis fatores foi testada pela terceira vez com amostras diferentes) e 
confiabilidade, ou seja, constitui uma medida operacional fidedigna para uso em diagnósticos organizacionais e estudos relacionais.

\subsubsection{Validação confirmatória do modelo de resiliência no trabalho}

Uma vez que na análise fatorial confirmatória é testado em que medida determinadas variáveis são representativas de um conceito/dimensão (Figueiredo \& Silva, 2010), os itens R6, R10, R11, R12, R14 e R15 apresentaram baixas cargas $(<0,5)$, sendo então retirados do modelo, pois não contribuíram para a explicação do construto de maneira significativa, oferecendo ajuste insatisfatório. Dessa forma, a estrutura final da Escala de Resiliência no Trabalho abrangeu 9 itens. Destaca-se que a solução unifatorial da estrutura original da escala foi mantida.

Por conseguinte, analisando os índices, torna-se possível afirmar que a escala possui um bom ajuste, dado que todos os parâmetros estão de acordo com as recomendações de Kline (2011), conforme apresenta a Tabela 12.

Tabela 12
\begin{tabular}{ccc} 
Índices de ajuste da análise confirmatória da Escala de Resiliência no Trabalho \\
\hline Parâmetros & Referência (Kline, 2011) & Escala de Resiliência no Trabalho \\
\hline $\mathrm{NC}\left(\chi^{2} \mathrm{DF}\right)$ & $<3,0$ & 3,0 \\
\hline $\mathrm{CFI}$ & $\geq 0,90$ & 0,96 \\
\hline $\mathrm{RMSEA}$ & $<0,08$ & 0,07 \\
\hline
\end{tabular}

Nota. Fonte: Elaborada pela autora.

As cargas fatoriais dos itens da validação confirmatória variaram entre 0,51 e 0,78, revelando boa qualidade e validade da escala (Hair et al., 2009).

Ademais, com a intenção de melhorar o ajuste obtido, os índices de modificação (I.M.) também foram analisados, conforme estabelecido por Kline (2011). Os I.M. entre as variáveis R1 (Mantenho interesse nele) e R7 (Meu trabalho tem sentido para mim); e R7 (Meu trabalho tem sentido para mim) e R8 (Sinto orgulho de ter realizado coisas) foram altos e significativos. Dessa forma, uma seta dupla foi introduzida entre as variáveis R1 e R7; e R7 e R8, indicando correlação positiva entre os pares de itens, sendo que há, efetivamente, amparo teórico para essa associação.

Com base nos resultados do estudo de Morin (2001), um trabalho tem sentido se ele corresponde aos interesses e às competências das pessoas. Além disso, a autora afirma que se o trabalho for feito de maneira eficiente; se conduz a alguma coisa; se beneficia outras 
pessoas; se ele permite aprender, realizar-se e superar-se; e se ele permite exprimir-se e exercer seu poder, esse trabalho tem sentido. Para Hackman e Oldham (1976), um trabalho tem sentido para uma determinada pessoa quando ela o considera importante, útil e legítimo.

Dessa forma, para Maslow (2001), o caminho para a felicidade humana encontra-se relacionado à autorrealização conquistada por meio do compromisso com um trabalho importante e que valha a pena. Sob perspectiva semelhante, Job (2003a) observou em sua pesquisa que, independentemente do nível hierárquico, todos identificam o trabalho com a sua autorrealização, confirmando que, embora o fator financeiro seja relevante, as pessoas esperam algo a mais do seu emprego.

Morin (2001) corrobora que o prazer e o sentimento de realização podem ser obtidos na execução de tarefas que dão um sentido ao trabalho, pois o trabalho permite oportunidades para vencer desafios ou perseguir ideais. Ainda nessa concepção, o sentido do trabalho é dado pelo reconhecimento de alguém, que muitas vezes distingue o trabalho desse sujeito como útil (Morin, Tonelli, \& Pliopas, 2007).

Posto isso, a Figura 9 apresenta o modelo final de mensuração da Escala de Resiliência no Trabalho obtido na análise fatorial confirmatória, com os respectivos parâmetros.

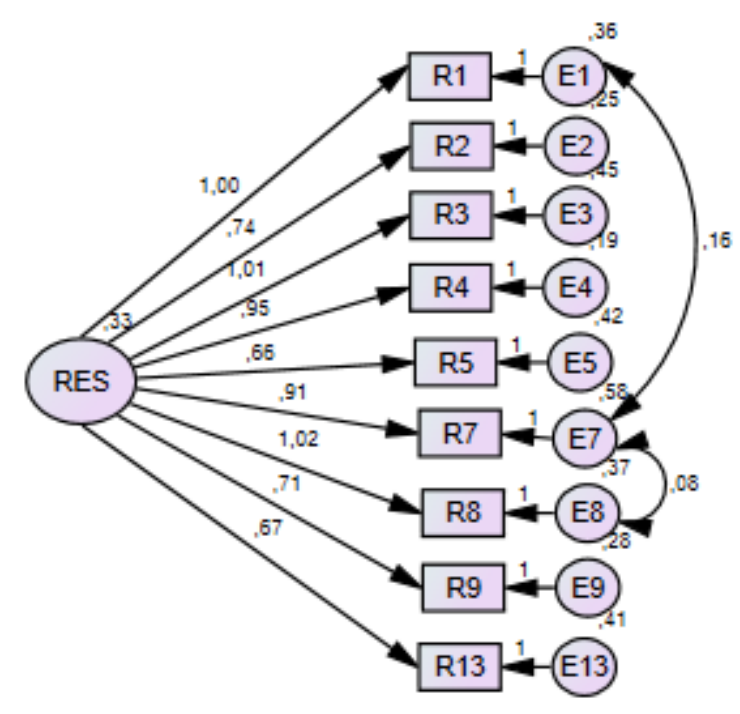

Figura 9. Modelo de análise confirmatória da Escala de Resiliência no Trabalho Nota: $\chi^{2}(25)=75,492 ; \mathrm{p}<0,001 ; \mathrm{NC}=3,0 ; \mathrm{CFI}=0,96 ; \mathrm{RMSEA}=0,07$

Fonte: Elaborada pela autora.

Assim como na EPPRH, a confiabilidade da estrutura unifatorial da Escala de Resiliência no Trabalho foi analisada pelo rho de Jöreskog, que apresentou $\rho=0,86$, indicando um índice bastante satisfatório (Chin, 1998). 
Em suma, a partir dos resultados coligidos, conclui-se que a escala de Resiliência no Trabalho possui validade e confiabilidade, podendo ser usada em estudos científicos gerenciais.

\subsection{Modelo estrutural de predição entre políticas e práticas de gestão de pessoas e resiliência no trabalho}

O quarto e último objetivo proposto foi testar o modelo estrutural de predição das políticas e práticas de gestão de pessoas sobre a resiliência no trabalho.

Primeiramente foram analisadas as correlações entre todas as variáveis estudadas, a saber, as políticas e práticas de gestão de pessoas, representadas pelos seis fatores: recrutamento e seleção; envolvimento; treinamento, desenvolvimento \& educação; condições de trabalho; avaliação de desempenho e competências; e remuneração e recompensas; e resiliência no trabalho.

As correlações encontradas foram positivas e apenas o fator envolvimento apresentou correlação moderada (de 0,31 a 0,5) com resiliência no trabalho; os demais fatores apresentaram correlação fraca (de 0,1 a 0,30) com essa variável, conforme Cohen (1992). Como todas as correlações foram significativas no nível $\mathrm{p}<0,01$, partiu-se para a análise de predição entre elas (Field, 2009), no caso as políticas e práticas de gestão de pessoas como preditoras da resiliência no trabalho. A Tabela 13 sintetiza as correlações entre as variáveis.

Tabela 13

Correlações entre as variáveis do estudo

\begin{tabular}{ccccccc}
\hline Variáveis & RS & ENV & TDE & CT & ADC & RR \\
\hline RES & $0,20^{* *}$ & $0,31^{* *}$ & $0,25^{* *}$ & $0,21^{* *}$ & $0,16^{* *}$ & $0,22^{* *}$ \\
\hline
\end{tabular}

Nota. $* * \mathrm{p}<0,01$. Fonte: Elaborada pela autora.

Assim, para se atingir o quarto objetivo, recorreu-se à análise de regressão, por meio da modelagem por equações estruturais, utilizando-se a estimação da máxima verossimilhança. A análise de regressão é preferida em relação à análise de caminhos quando se testa diversas variáveis independentes como preditoras de uma única variável dependente (Hoyle, 1995; Raykov \& Marcoulides, 2006; Schumacker \& Lomax, 2004). A Figura 10 ilustra o resultado da análise de regressão para o modelo proposto. 


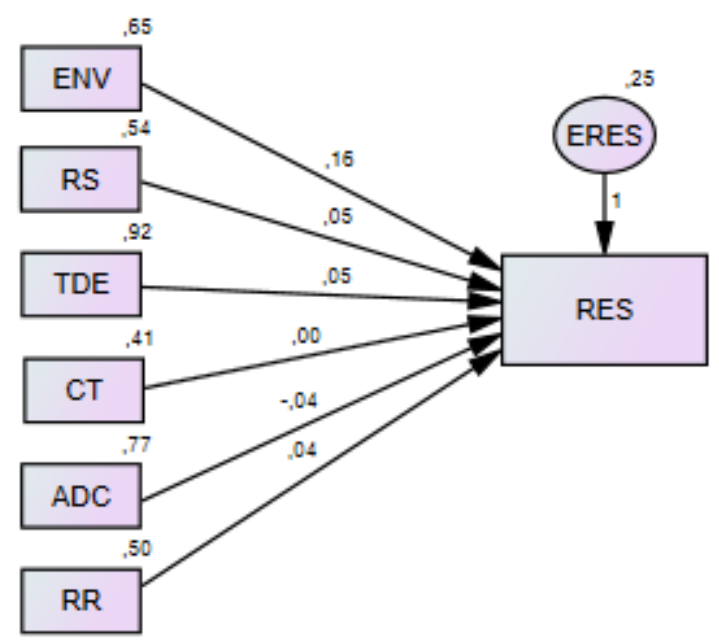

Figura 10. Resultado da análise de regressão Fonte: Elaborada pela autora.

A Tabela 14 apresenta os índices de regressão obtidos.

Tabela 14

Índices de regressão

\begin{tabular}{lccccc}
\hline & Estimate & S.E. & C.R. & P & Label \\
\hline RES <--- ENV & $\mathbf{0 , 1 5 7}$ & $\mathbf{0 , 0 3 1}$ & $\mathbf{5 , 0 2}$ & $* * *$ & par_1 \\
\hline RES $<--$ TDE & 0,047 & 0,026 & 1,784 & 0,074 & par_2 \\
\hline RES $<---$ CT & $-0,004$ & 0,039 & $-0,096$ & 0,923 & par_3 \\
\hline RES $<---$ ADC & $-0,035$ & 0,029 & $-1,22$ & 0,222 & par_4 \\
\hline RES $<---$ RR & 0,042 & 0,036 & 1,175 & 0,24 & par_5 \\
\hline RES $<---$ RS & 0,05 & 0,034 & 1,46 & 0,144 & par_6 \\
\hline
\end{tabular}

Nota. Fonte: Elaborada pela autora.

Constata-se, desse modo, que o único preditor da resiliência no trabalho foi o fator envolvimento. A Figura 11 sintetiza os resultados da análise de regressão, desvelando a quantidade da variância da variável dependente, no caso, resiliência no trabalho, que é explicada pela variável independente, nesse caso, o fator envolvimento $\left(\mathrm{R}^{2}=7,8 \%\right)$, bem como o coeficiente de correlação padronizado $(\beta=0,243)$, que representa a magnitude e a direção do relacionamento entre o preditor e a variável-critério. Conforme preceitua Cohen (1992), podese considerar um pequeno efeito, pois $\mathrm{R}^{2}<13 \%$ e, ainda, uma correlação fraca, pois $0,1<\beta<0,30$. 


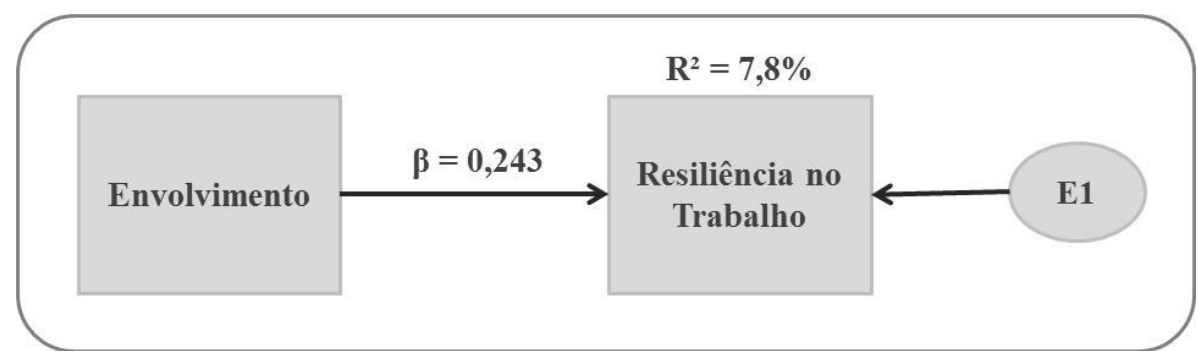

Figura 11. Síntese do modelo de predição

Fonte: Elaborada pela autora.

Conforme apontado pela literatura, constata-se que políticas de gestão de pessoas efetivamente antecedem atitudes em uma organização, como é o caso, para citar alguns exemplos, das variáveis-critério: comprometimento organizacional (Bastos, 1994; Demo et al., 2013; Dias \& Morais, 1994); bem-estar no trabalho (Horta et al., 2012; Jesus \& Rowe, 2015; Martins \& Demo, 2014; Poli, 2013; Souza et al., 2014); e confiança na organização (Horta et al., 2012); além de importantes resultados organizacionais, como o desempenho (Brandão, Borges-Andrade, \& Guimarães, 2012; Freitas \& Borges-Andrade, 2004); a satisfação no trabalho (Demo et al., 2013; Majumder, 2012; Nannetti et al., 2015; Santos \& Mourão, 2011); uma menor rotatividade organizacional (Sheehan, 2013); e a efetividade organizacional (Gomide \& Tanabe, 2012; Guest \& Conway, 2011; Kim \& Lee, 2012).

Também, verifica-se que a política de envolvimento se destaca predizendo diversas atitudes, comportamentos ou resultados. A Figura 12 retrata os estudos empíricos que pesquisaram os consequentes da variável envolvimento, incluindo a presente pesquisa. 


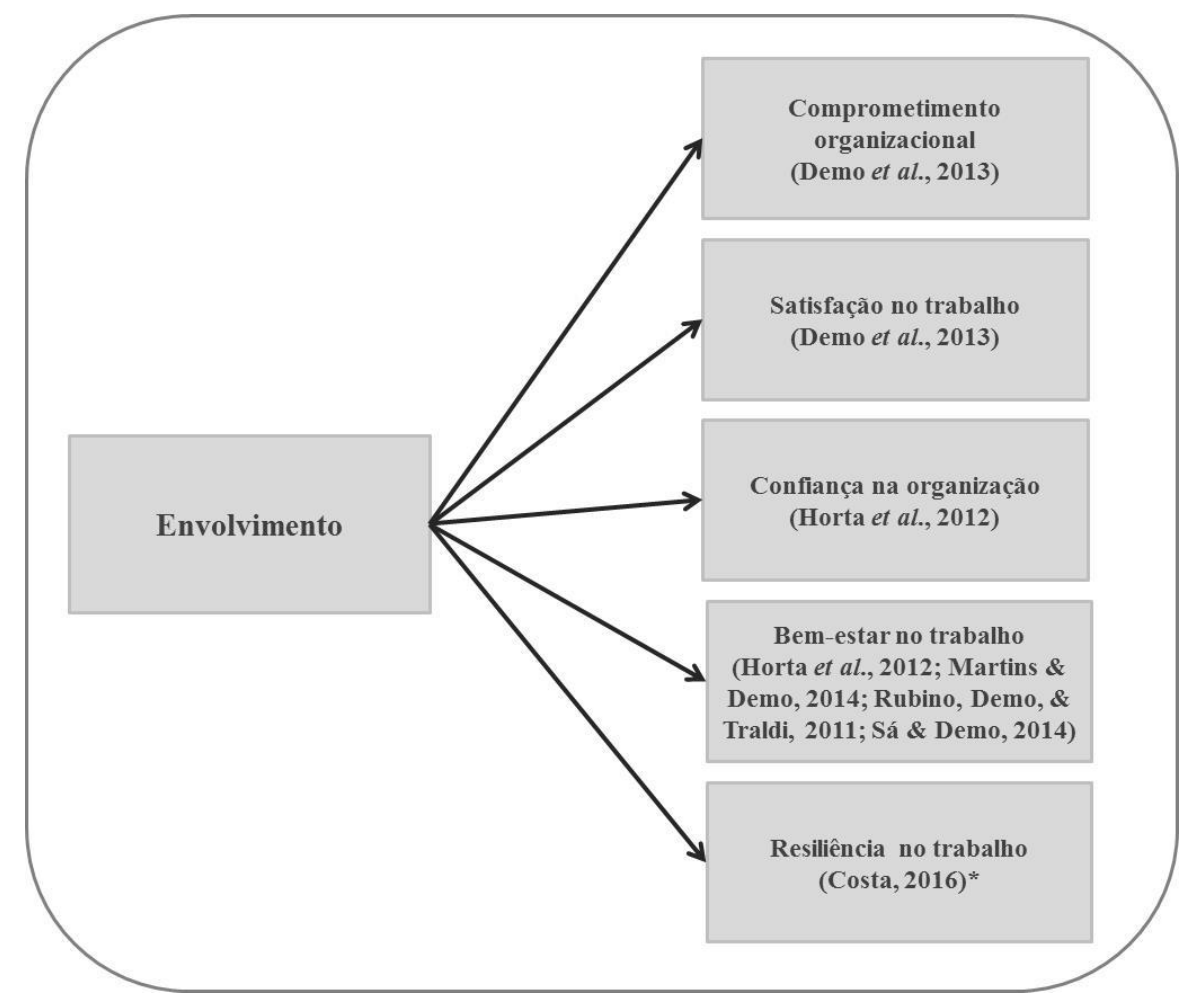

Figura 12. Estudos que abordaram consequentes de envolvimento

Nota: * refere-se à presente pesquisa.

Fonte: Elaborada pela autora.

Contudo, por se tratar de um modelo exploratório, as variáveis da presente pesquisa também foram analisadas sob a ótica inversa: a variável resiliência no trabalho predizendo as políticas e práticas de gestão de pessoas. Como resultado, os índices de regressão foram mais favoráveis no modelo em que a resiliência no trabalho é variável dependente. De fato, a interação dos indivíduos com o contexto e a cultura organizacional, da qual políticas e práticas fazem parte, pode influenciá-los a agirem de maneira resiliente (Ribeiro et al., 2011). Dessa forma, para os autores, os indivíduos utilizam-se de fatores de proteção disponíveis e atribuem a tais situações adversas um significado que permita sua superação, de maneira que vivenciem essas condições adversas sem que elas promovam seu adoecimento físico e/ou psíquico.

Portanto, tendo em vista os resultados apontados, entre os fatores que compõem as políticas e práticas de gestão de pessoas, o fator envolvimento está mais estritamente relacionado com a resiliência no trabalho. Infere-se que as práticas de envolvimento tenham mais flexibilidade, maior possibilidade de aplicação no setor público, sendo, portanto, um espaço, do ponto de vista gerencial, mais factível de se trabalhar e, possivelmente por isso, envolvimento foi a única política preditora de resiliência no trabalho. Por se tratar de uma 
instituição pública, é complexo o gerenciamento das demais políticas, visto que é uma organização subordinada a leis e decretos.

Esse resultado fortalece o que argumenta a literatura, de que a resiliência apresenta-se como resultado de fatores de proteção (Job, 2003b; Pesce, Assis, Santos, \& Oliveira, 2004). Os fatores de proteção, segundo Job (2003b), podem ser considerados como redutores das influências negativas e ainda como formas adaptativas de enfrentar uma dificuldade, em que podem ser citados a autonomia, a autoestima, o respeito, o reconhecimento, a participação da família e dos amigos e o apoio dos pares e das chefias/superiores. Essas formas de enfrentar adversidades são estimuladas em práticas de gestão de pessoas relativas à política de envolvimento dos colaboradores (Demo et al., 2014).

Destarte, para Siqueira e Gomide (2008), o suporte social no trabalho é um importante fator de proteção e promoção da saúde e do bem-estar. Outrossim, para Batista (2010), supõese que a percepção de suporte organizacional atenue a vulnerabilidade e o risco, reduzindo a exposição do indivíduo a agentes estressores e a adversidades, uma vez que a organização promove o retorno aos esforços realizados por seus empregados, ao mesmo tempo em que propicia um ambiente mais acolhedor aos trabalhadores, pois se preocupa com seu bem-estar. Assim sendo, a ausência de suporte social é apontada como um fator de risco e sua presença como um fator de proteção (Pinheiro, 2004; Sapienza \& Pedromônico, 2005).

Nessa perspectiva, de acordo com alguns autores (Angst, 2009; Luthar et al., 2000), o suporte social ou o contexto de apoio é um facilitador para o processo de resiliência. $\mathrm{Na}$ mesma vertente, os fatores de proteção auxiliam a redução do impacto de risco e de reações negativas e, como tais, são preditivos de resiliência (Pesce et al., 2004).

Por conseguinte, em consonância com os resultados da presente pesquisa, as práticas relativas à política de envolvimento correspondem a um antecedente da resiliência no trabalho. Depreende-se que gestores organizacionais, no afã de incentivar a resiliência em seus colaboradores, devem dar atenção especial ao planejamento e implementação de práticas de envolvimento, quer seja ao estimular a participação ou intensificar a comunicação; praticar o reconhecimento e feedback contínuos; prover um tratamento respeitoso, preocupando-se com o bem-estar de seus colaboradores; manter um clima de compreensão e confiança entre subordinados e entre colegas; integrar os colaboradores; adaptar os colaboradores aos seus cargos; dar autonomia na realização das tarefas e na tomada de decisões; manter coerência entre o discurso e a prática gerencial; ou ainda, enfatizar a construção de relacionamentos interpessoais que se traduzam em um melhor clima organizacional (Bohlander \& Snell, 2009; 
Dessler, 2002; Dietz, Wilkinson, \& Redman, 2010; Muckinsky, 2004; Siqueira, 2008; Sisson, 1994; Ulrich et al., 1991).

A seguir, a conclusão do estudo, que sumariza os principais resultados, destaca as principais contribuições acadêmicas e gerenciais, e apresenta limitações e recomendações para estudos futuros. 


\section{Conclusão}

O presente estudo permitiu alcançar os objetivos específicos estabelecidos, garantindo, assim, a consecução do objetivo geral, além de abordar aspectos relevantes à literatura de gestão de pessoas, bem como da atualmente propalada psicologia positiva sobre a possível relação entre políticas e práticas de gestão de pessoas e resiliência no trabalho.

Assim, este capítulo pretende apresentar uma síntese dos resultados da pesquisa empreendida, contribuições acadêmicas, implicações gerenciais, limitações e sugestões para pesquisas futuras.

\subsection{Síntese dos principais resultados}

Esse estudo buscou, em seu objetivo geral, identificar e descrever a influência das políticas e práticas de gestão de pessoas na resiliência no trabalho dos servidores técnicoadministrativos da FUB. Como resultado, tem-se que a política de envolvimento é preditora da resiliência no trabalho, desvelando uma pequena, porém significativa explicação para a resiliência no trabalho.

Para a consecução do objetivo específico I, identificar a percepção em relação às políticas e práticas de gestão de pessoas dos servidores técnico-administrativos da FUB, analisando os fatores que compõem as políticas e práticas, recrutamento e seleção foi o mais bem avaliado na opinião dos respondentes (média de 3,46 e desvio-padrão de 0,70). Por outro lado, o fator mais mal avaliado foi remuneração e recompensas (média de 2,13 e desviopadrão de 0,71). Já com relação à avaliação dos itens, ou seja, às práticas de gestão de pessoas, o item "A FUB divulga aos candidatos informações a respeito das etapas e critérios do processo seletivo" obteve melhor avaliação (média de 3,73 e desvio-padrão de 0,96), seguido por "A FUB me oferece benefícios básicos (exemplos: plano de saúde, auxílio transporte, auxílio alimentação etc.)", apresentando média de 3,54, desvio-padrão de 1,01 e moda de 4. Em contrapartida, os itens com pior avaliação foram "Na FUB, minha remuneração é influenciada pelos meus resultados", com média de 1,83 e desvio-padrão de 0,83 e "A FUB preocupa-se com a segurança de seus servidores, controlando o acesso de pessoas estranhas nos locais de trabalho", resultando em uma média de 1,87 e desvio-padrão de 0,94 . 
No que tange ao objetivo específico II, identificar a resiliência no trabalho dos servidores técnico-administrativos da FUB, a variável resiliência no trabalho obteve média geral de 3,94, com desvio-padrão de 0,46. O item mais bem avaliado foi "Sou uma pessoa com quem as pessoas podem contar em situações de emergência", com média de 4,27 e desvio-padrão de 0,67. Já o item com pior avaliação por parte dos respondentes foi "Minha autoconfiança me leva a passar por períodos difíceis", apresentando média de 3,41 e desviopadrão de 0,96 .

Quanto à validação confirmatória dos instrumentos de pesquisa utilizados, cumprindo o objetivo III (testar os modelos de mensuração das variáveis do estudo fazendo sua validação confirmatória), a estrutura final da EPPRH manteve os 6 fatores, mas com 30 itens, o que foi positivo, pois instrumentos de medida com uma estrutura mais enxuta podem ter uma maior taxa de resposta (Saunders, Lewis, \& Thornhill, 2000); e a Escala de Resiliência no Trabalho, estruturada com um fator, teve melhor ajuste com 9 itens e, ainda, com a introdução de uma seta dupla entre as variáveis R1 e R7, e R7 e R8, indicando correlação positiva entre os pares de itens.

Por fim, o objetivo específico IV, que visava testar o modelo estrutural de predição das políticas e práticas de gestão de pessoas sobre a resiliência no trabalho, revelou como único preditor a política de envolvimento, com efeito de $7,8 \%$.

Dessa maneira, tem-se o cumprimento do objetivo geral, respondendo à problemática da pesquisa, visto que práticas de GP, especialmente as de envolvimento, predizem a resiliência no trabalho.

\subsection{Contribuições acadêmicas e gerenciais}

A presente pesquisa, a partir de sua revisão teórica até a apresentação dos resultados, contribuiu para os estudos nas áreas de gestão de pessoas e psicologia organizacional, completando uma lacuna identificada na literatura, visto que não foram encontrados estudos que explorem a relação entre a percepção das políticas e práticas de gestão de pessoas e a resiliência no trabalho. Ademais, abordou temas importantes para a gestão empresarial, contribuindo com a literatura ainda incipiente nesse assunto, especialmente no caso da resiliência no trabalho.

Além disso, como contribuição acadêmica, esse estudo propôs a validação confirmatória de dois instrumentos de pesquisa e obteve bons índices psicométricos: a Escala de Políticas e Práticas de Recursos Humanos (Demo et al., 2014) e a Escala de Resiliência no Trabalho 
(Gomide et al., 2015), o que viabiliza a realização de estudos relacionais a partir de medidas confiáveis e com validade interna e externa. Ressalta-se que essa pesquisa avançou ao realizar a validação confirmatória da Escala de Resiliência no Trabalho, a qual havia sido validada apenas com métodos exploratórios.

Para a consecução dos objetivos desse estudo, foram utilizadas técnicas avançadas de estatística, como a análise fatorial confirmatória e a modelagem por equações estruturais e, conforme destacado por Hair et al. (2009), um dos principais objetivos de técnicas multivariadas é expandir a habilidade explanatória do pesquisador e a eficiência estatística, o que configura uma contribuição metodológica.

Com relação às implicações gerenciais, esse estudo apresentou um diagnóstico para os gestores da instituição, visto que identificou a percepção das atuais políticas e práticas de gestão de pessoas, bem como a autoavaliação da resiliência no trabalho dos servidores técnico-administrativos da FUB.

Como sugerem os dados do presente estudo, a resiliência no trabalho é uma consequente da percepção da política de envolvimento. Essa consideração reflete, portanto, a necessidade de um conjunto de práticas de envolvimento bem desenvolvidas, na medida em que influenciam a resiliência dos trabalhadores. Sendo assim, habilidades sociais e vínculos apoiadores que auxiliam a superação das dificuldades são considerados elementos a serem desenvolvidos/mantidos nas organizações.

Outrossim, esse estudo teve como lócus de pesquisa o setor público, agregando, portanto, pelo seu caráter inovador, tendo em vista a prevalência de estudos relacionados na área privada, tanto para políticas e práticas de gestão de pessoas quanto para a resiliência no trabalho.

\subsection{Limitações e recomendações para estudos futuros}

No que diz respeito às limitações e recomendações para futuras pesquisas, esse estudo consiste em um primeiro passo na proposição e investigação de novas relações entre variáveis, contribuindo, mesmo que de forma seminal, para as pesquisas da área do comportamento organizacional, ao mesclar variáveis da área de administração (políticas e práticas de GP) e da psicologia organizacional (resiliência no trabalho). Por isso, por se tratar de um estudo exploratório, mais pesquisas são necessárias para corroborar, ou não, o que foi aqui encontrado. Nesse sentido, estudos multimétodo, incorporando análises qualitativas, são importantes e necessários para aprofundar a compreensão da relação entre os construtos, uma 
vez que possibilitam a propalada triangulação metodológica, permitindo uma melhor compreensão do fenômeno, ao mesmo tempo em que esforços para compreendê-lo ou mensurá-lo são engendrados. Isso é especialmente importante para fenômenos que estão sendo estudados há pouco tempo, caso da resiliência no trabalho, no Brasil.

Outra limitação refere-se ao fato de os dados terem sido coletados em um único período. Assim, recomenda-se que estudos futuros utilizem dados longitudinais, inclusive em amostras de outras organizações com naturezas diferentes, como organizações privadas e do terceiro setor. Sugere-se, também, estudos comparativos com outras instituições de ensino superior, a fim de se verificar se a estrutura por ora obtida para os instrumentos de pesquisa utilizados se confirma para outra amostra de natureza semelhante, em que pode haver a necessidade de inclusão ou exclusão de alguns itens. Ainda, por ter sido conduzida em uma única instituição, fatores relacionados à cultura organizacional podem ter gerado vieses de interpretação dos itens das escalas utilizadas.

Além disso, esse estudo propôs a validação confirmatória de dois instrumentos de pesquisa com bons índices psicométricos: a EPPRH e a Escala de Resiliência no Trabalho. Não obstante, fica o convite para que tais estruturas sejam confirmadas em novas pesquisas, no afã de se incrementar os índices de ajuste obtidos, bem como de se prover validade externa para a Escala de Resiliência no Trabalho, haja vista que aqui foi produzida sua primeira validação confirmatória e muitos itens foram retirados da proposta inicial.

No tocante à revisão bibliométrica de políticas e práticas de GP ora realizada, e em complementação à agenda de pesquisa proposta por Demo et al. (2015), sugere-se a realização de estudos relacionando as políticas de GP, especialmente quanto à remuneração e recompensas, e envolvimento, as recorrentemente menos estudadas em comparação à política de TD\&E, por exemplo, já bastante consolidada. Recomenda-se, ainda, uma maior exploração em pesquisas que identifiquem variáveis que influenciam ou são influenciadas pelas políticas de GP, na medida em que é reconhecido seu papel estratégico nas organizações. Além disso, a criação e validação de instrumentos de medida também são necessárias para a construção e o aprofundamento do conhecimento na área de gestão de pessoas e psicologia organizacional.

Já na temática da resiliência no trabalho, com base na revisão bibliométrica aqui realizada, observou-se a predominância de estudos oriundos da psicologia, ensejando pesquisas futuras sobre o construto dentro do campo da administração, haja vista seu papel nos resultados organizacionais. Com relação ao enquadramento dos estudos, visto que a maioria dos trabalhos encontrados na revisão bibliométrica são teórico-empíricos, recomendase o desenvolvimento de ensaios teóricos que discutam pressupostos, modelos e medidas 
desenvolvidos. Além disso, é bem-vinda a realização de mais pesquisas no terceiro setor, o de organizações filantrópicas, que talvez, por princípio, já nasça com o pressuposto de resiliência.

Espera-se que esse estudo facilite a difusão da análise fatorial confirmatória como técnica de mensuração na área de gestão estratégica de pessoas. Da mesma forma, enseja-se a expansão da modelagem por equações estruturais. Afinal, medidas confiáveis e válidas, bem como técnicas avançadas de tratamento e análise estatística de dados constituem elementos fundamentais na construção do conhecimento científico.

Por fim, apesar das limitações apresentadas, o principal objetivo desse estudo foi alcançado, desvelando a influência da política de envolvimento na resiliência no trabalho. Retomando-se o problema de pesquisa proposto, se as políticas e práticas de gestão de pessoas influenciam a resiliência no trabalho, a resposta é afirmativa. Quanto mais os colaboradores perceberem esforços da gestão em envolvê-los, mais eles tenderão a ser resilientes. Esse resultado lança luz para futuros estudos de antecedentes da resiliência no trabalho, o que se traduzirá, possivelmente, em um maior bem-estar dos colaboradores e em melhores resultados para a organização. 


\section{Referências}

Abdullah, H. (2010). Delineating and charting the systematic approach of HRD process. The Journal of International Social Research, 3(11), 11-22.

Adebisi, S. A., \& Oladipo, A. O. (2015). Reward System as strategy for improving employees' productivity in Nigeria. Revista Eletrônica de Estratégia \& Negócios, 8(1), 56-84.

ALDamoe, F. M. A., Yazam, M., \& Ahmid, K. B. (2011). The mediating effect of HRM outcomes (employee retention) on the relationship between HRM practices and organizational performance. International Journal of Human Resource Studies, 2(1), $75-88$.

Alvarez, A. S., Moraes, M. C. L., \& Rabinovich, E. P. (1998). Resiliência: um estudo com brasileiros institucionalizados. Revista Brasileira de Crescimento e Desenvolvimento Humano, 8(1/2), 64-69.

Angst, R. (2009). Psicologia e Resiliência: uma revisão de literatura. Psicologia Argumento. 27(58), 253-260.

Antoniazzi, A. D., Dell'Aglio, D. D., \& Bandeira, D. R. (1998). O conceito de coping: uma revisão teórica. Estudos de Psicologia, 3(2), 273-294.

Araújo, R. F., \& Alvarenga, L. (2011). A bibliometria na pesquisa científica da pós-graduação brasileira de 1987 a 2007. Revista Eletrônica de Biblioteconomia, 16(31), 51-70.

Armstrong, M. (2009). Armstrong's handbook of human resource management practice (11st ed.). London: Kogan Page.

Armstrong, M. (2014). Armstrong's handbook of human resource management practice (13rd ed.). London: Kogan Page.

Badejo, A. E. (2015). Strategic human resource management practices and employees' career development in selected commercial banks in Lagos State, Nigeria. European Journal of Business and Management, 7(2), 83-94.

Barlach, L., Limongi-França, A. C., \& Malvezzi, S. (2008). O conceito de resiliência aplicado ao trabalho nas organizações. Revista Interamericana de Psicologia, 42(1), 101-112.

Barney, J. (1991). Firm resources and sustained competitive advantage. Journal of Management, 17(1), 99-120.

Barreira, D. D., \& Nakamura, A. P. (2006). Resiliência e auto-eficácia percebida: articulações entre conceitos. Aletheia, (23), 75-80. 
Barreto, L. M. T. S., Silva, M. P., Fischer, A. L., Albuquerque, L. G., \& Amorim, W. A. C. (2011). Temas emergentes em Gestão de Pessoas: uma análise da produção acadêmica. Revista de Administração da UFSM, 4(2), 215-232.

Baruth, K. E., \& Carroll, J. J. (2002). A formal assessment of resilience: The Baruth Protective Factors Inventory. The Journal of Individual Psychology, 58(3), 235-244.

Bastos, A. V. B. (1994). Comprometimento organizacional: seus antecedentes em distintos setores da administração e grupos ocupacionais. Temas em Psicologia, 2(1), 73-90.

Batista, R. L. (2010). Percepção de suporte organizacional, afeto positivo, afeto negativo e resiliência: antecedentes da confiança do empregado na organização (Dissertação de mestrado). Universidade Federal de Uberlândia, Uberlândia, MG, Brasil.

Batista, R. L., \& Oliveira, A. de F. (2008). Validação da escala de resiliência para o contexto organizacional. Sessão de pôster apresentada no Congresso Brasileiro de Psicologia Organizacional e do Trabalho, Florianópolis, SC, Brasil, 3.

Batista, R. L., \& Oliveira, A. de F. (2012). Antecedentes da confiança do empregado na organização. Estudos de Psicologia, 17(2), 247-254.

Belancieri, M. F., Beluci, M. L., Silva, D. V. R., \& Gasparelo, E. A. (2010). A resiliência em trabalhadores da área da enfermagem. Estudos de Psicologia (Campinas), 27(2), 227233.

Bohlander, G. W., \& Snell, S. (2009). Administração de recursos humanos (14a ed.). São Paulo: Cengage.

Borges-Andrade, J. E., Abbad, G., \& Mourão, L. (2006). Treinamento, desenvolvimento e educação em organizações de trabalho. Porto Alegre: Artmed.

Boselie, P., Dietz, G., \& Boone, C. (2005). Comunalities and contradictions in HRM and performance research. Human Resource Management Journal, 15(3), 67-94.

Boudreau, J., \& Lawler, E., III (2014). Stubborn traditionalism in HRM: causes and consequences. Human Resource Management Review, 24(3), 232-244.

Brandão, H. P., Borges-Andrade, J. E., \& Guimarães, T. A. (2012). Desempenho organizacional e suas relações com competências gerenciais, suporte organizacional e treinamento. Revista de Administração (São Paulo), 47(4), 523-539.

Brandão, J. M., Mahfoud, M., \& Gianordoli-Nascimento, I. F. (2011). A construção do conceito de resiliência em psicologia: discutindo as origens. Paidéia, 21(49), 263-271.

Brandão, H. P., Silva, R. A. C. D., Freitas, I. A., Pereira, S. C. M., \& Santos, W. S. F. (2013). Gestão de pessoas como fator de sucesso na incorporação da Nossa Caixa pelo Banco do Brasil. Revista de Administração Contemporânea, 17(5), 598-619. 
Buren, H. J. V., III, Greenwood, M., \& Sheehan, C. (2011). Strategic human resource management and the decline of employee focus. Human Resource Management Review, 21(3), 209-219.

Busnello, F., Schaefer, L., \& Kristensen, C. (2009). Eventos estressores e estratégias de coping em adolescentes: implicações na aprendizagem. Revista Semestral da Associação Brasileira de Psicologia Escolar e Educacional, 2(13), 315-323.

Byrne, B. M. (2009). Structural equation modeling with AMOS: basic concepts, applications, and programming (2nd ed.). New York: Routledge.

Campanella, T. (2006). Urban resilience and the recovery of New Orleans. Journal of the American Planning Association, 72(2), 141-146.

Campbell-Sills L., \& Stein, M. B. (2007). Psychometric Analysis and refinement of the Connor-Davidson Resilience Scale (CD-RISC): validation of a 10-Item measure of resilience. Journal of Traumatic Stress, 20(6), 1019-1028.

Cantarello, S., Filippini, R., \& Nosella, A. (2012). Linking human resources management practices and customer satisfaction on product quality. The International Journal of Human Resources Management, 13(18), 3906-3924.

Cardoso, L. R. (2006). Avaliando sistemas de remuneração baseados em habilidades e competências: a visão dos profissionais de gestão de pessoas. Revista Brasileira de Gestão de Negócios, 8(21), 13-23.

Carvalho, V. D., Borges, L. O., Vikan, A., \& Hjemdal, O. (2011). Resiliência e socialização organizacional entre servidores públicos brasileiros e noruegueses. Revista de Administração Contemporânea, 15(5), 815-833.

Carvalho, V. D., Teodoro, M. L. M., \& Borges, L. O. (2014). Escala de resiliência para adultos: aplicação entre servidores públicos. Avaliação Psicológica, 13(2), 287-295.

Carson, K. D., \& Bedeian, A. G. (1994). Career commitment: construction of a measure and examination of its psychometric properties. Journal of Vocational Behavior, 44(3), 237262.

Cascio, W. F. (2015). Strategic HRM: too important for an insular approach. Human Resource Management, 54(3), 423-426.

Cecconello, A. M. (2003). Resiliência e vulnerabilidade em famílias em situação de risco (Tese de doutorado). Universidade Federal do Rio Grande do Sul, Porto Alegre, RS, Brasil.

Chin, W. W. (1998). The partial least squares approach to structural equation modeling. In Marcoulides, G. A. (Ed.). Modern methods for business research. Methodology for 
business and management. (pp. 295-336). Mahwah, NJ: Lawrence Erlbaum Associates Publishers.

Cimbalista, S. (2006). Reflexões sobre o trabalho e a subjetividade de trabalhadores resilientes sob o sistema de produção flexível. Revista da FAE, 9(2), 13-28.

Codo, W. (1988). Saúde mental e trabalho: uma urgência prática. Psicologia: Ciência e Profissão, 8(2), 20-24.

Cohen, J. (1992). A power primer. Psychological Bulletin, 112(1), 155-159.

Connor, K. M., \& Davidson, J. R. T. (2003). Development of a new resilience scale: The Connor-Davidson Resilience Scale (CD-RISC). Depression and Anxiety, 18(2), 76-82.

Constituição da República Federativa do Brasil de 1988. (1988). Recuperado de http://www.planalto.gov.br/ccivil_03/constituicao/constituicaocompilado.htm

Costa, M. T. P., Borges, L. de O., \& Barros, S. C. (2015). Condições de trabalho e saúde psíquica: um estudo em dois hospitais universitários. Revista Psicologia: Organizações e Trabalho, 15(1), 43-58.

Coutu, D. L. (2002). How resilience works. Harvard Business Review, 80(5), 46-50.

Curado, I., Wood, T., Jr., \& Lins, J. (1995). Perfil da gestão de recursos humanos na grande São Paulo. São Paulo: Senac.

Deadrick, D. L., \& Stone, D. L. (2014). Human resource management: past, present, and future. Human Resource Management Review, 24(3), 193-195.

Decreto $n$. 977, 1993, de 10 de setembro de 1993. (1993). Dispõe sobre a assistência préescolar destinada aos dependentes dos servidores públicos da Administração Pública Federal direta, autárquica e fundacional. Recuperado de http://www.planalto.gov.br/ccivil_03/decreto/antigos/d0977.htm

Decreto n. 2880, de 15 de dezembro de 1998. (1998). Regulamenta o Auxílio-Transporte dos servidores e empregados públicos da administração federal direta, autárquica e fundacional do Poder Executivo da União e altera o Decreto $\mathrm{n}^{\circ}$ 95.247, de 17 de $\begin{array}{lllll}\text { novembro de } & \text { de }\end{array}$ http://www.planalto.gov.br/ccivil_03/decreto/d2880.htm

Decreto n. 3887, de 16 de agosto de 2001. (2001). Regulamenta o art. 22 da Lei $\mathrm{n}^{\circ} 8.460$, de 17 de setembro de 1992, que dispõe sobre o auxílio-alimentação destinado aos servidores civis ativos da Administração Pública Federal direta, autárquica e fundacional. Recuperado de http://www.planalto.gov.br/ccivil_03/decreto/2001/D3887.htm 
Demo, G. (2008). Desenvolvimento e validação da escala de percepção de políticas de gestão de pessoas (EPPGP). Revista de Administração Mackenzie, 9(6), 77-101.

Demo, G. (2010). Políticas de gestão de pessoas, valores pessoais e justiça organizacional. Revista de Administração Mackenzie, 11(5), 55-81.

Demo, G. (2012). Políticas de gestão de pessoas em organizações: estado da arte, produção nacional, agenda de pesquisa, medidas e estudos relacionais. São Paulo: Atlas.

Demo, G., Fogaça, N., Fernandes, T., \& Sá, P. (2015). Políticas e Práticas de Gestão de Pessoas: revisão bibliométrica da produção nacional em periódicos de primeira linha e institucionalização da pesquisa no Brasil entre 2010 e 2014. Anais do Encontro de Gestão de Pessoas e Relações de Trabalho, Salvador, BA, 5.

Demo, G., Fogaça, N., Nunes, I., Edrei, L., \& Francischeto, L. (2011). Políticas de gestão de pessoas no novo milênio: cenário dos estudos publicados nos periódicos da área de administração entre 2000 e 2010. Revista de Administração Mackenzie, 12(5), 15-42.

Demo, G., Martins, P. R., \& Roure, P. (2013). Políticas de gestão de pessoas, comprometimento organizacional e satisfação no trabalho na Livraria Cultura. Revista Alcance, 20(2), 237-254.

Demo, G., Neiva, E. R., Nunes, I., \& Rozzett, K. (2012). Human Resources Management Policies and Practices Scale (HRMPPS): exploratory and confirmatory factor analysis. Brazilian Administration Review, 9(4), 395-420.

Demo, G., Neiva, E. R., Nunes, I., \& Rozzett, K. (2014). Políticas e práticas de recursos humanos. In Siqueira, M. M. M. (Org.), Novas Medidas do Comportamento Organizacional: Ferramentas de Diagnóstico e de Gestão (pp. 240-245). Porto Alegre: Artmed.

Demo, G., Nunes, I., Mendes, N. M. D., Ferreira, L. A., \& Melo, B. B. (2011). Políticas de gestão de pessoas: cenário dos estudos publicados nos periódicos da área de Administração. Revista Organizações em Contexto (Online), 7(14), 57-84.

Demo, G., \& Rozzett, K. (2012). Human Resource Management Policies and Practices (HRMPP): scale validation in the United States. International Journal of Strategic Management, 12(3), 41-66.

Deadrick, D. L., \& Gibson, P. A. (2009). Revisiting the research-practice gap in HR: a longitudinal analysis. Human Resource Management Review, 19(2), 144-153.

Dessler, G. (2002). Human resource management (9th ed.). New Jersey: Prentice Hall.

Dessler, G. (2003). Administração de recursos humanos (2a ed.). (Oderich, C. L., Trad.). São Paulo: Pearson Prentice Hall. 
Devanna, M. A., Fombrun, C. J., \& Tichy, N. M. (1984). A framework for strategic human resource management. In Fombrun, C. J., Tichy, M. M., \& Devanna, M. A. (Eds.) Strategic Human Resource Management (pp. 33-51). New York: John Wiley.

Dias, M. A. M. J., \& Borges, R. S. G. (2015). Estilos de liderança e desempenho de equipes no setor público. Revista Eletrônica de Administração (Porto Alegre), 21(1), 200-221.

Dias, J. M. G., \& Moraes, L. F. R. (1994). Preditores do comprometimento organizacional na EMATER. Temas em Psicologia, 2(1), 91-102.

Dietz, G., Wilkinson, A., \& Redman, T. (2010). Involvement and participation. In Wilkinson, A., Bacon, N., Redman T., \& Snell, S. (Eds.). The SAGE handbook of human resource management (pp. 245-268). London: Sage.

Drenth, P. J. D. (1984). Research in work and organizational psychology: principies and methods. In Drenth, P. J. D., Thierry, H., Willems, P. J., \& Wolf, C. J. (Eds.), Handbook of work and organizational psychology (pp. 13-50). Chichester, UK: John Wiley and Sons.

Dutra, J. S. (1987). Profissionais de recursos humanos: um grupo à procura de legitimação (Dissertação de mestrado). Fundação Getúlio Vargas, São Paulo, SP, Brasil.

Dybå, T., \& Dingsøyr, T. (2008). Strength of evidence in Systematic Reviews in software engineering. Proceedings of the Second ACM-IEEE international symposium on Empirical software engineering and measurement. Empirical Software Engineering and Measurement (ESEM'08), 178-187.

Eisenstein, E., \& Souza, R. P. de. (1993). Situações de risco à saúde de crianças e adolescentes. Petrópolis, RJ: Vozes.

Emílio, E. V., \& Martins, M. C. F. (2012). Resiliência e autoconceito profissional em policiais militares: um estudo descritivo. Mudanças - Psicologia da Saúde, 20(1-2), 2329.

Field, A. (2009). Descobrindo a estatística usando o SPSS. Porto Alegre: Artmed.

Figueiredo, D. B., Filho, \& Silva, J. A., Jr. (2010). Visão além do alcance: uma introdução à análise fatorial. Opinião Pública, 16(1), 160-185.

Fischer, A. L. (1998). A constituição do modelo competitivo de gestão de pessoas no Brasil: um estudo sobre as organizações consideradas exemplares (Tese de doutorado). Universidade de São Paulo, São Paulo, SP, Brasil.

Freitas, I. A., \& Borges-Andrade, J. E. (2004). Efeitos de treinamento nos desempenhos individual e organizacional. Revista de Administração de Empresas, 44(3), 44-56. 
Frenkel, S., Restubog, S. L., \& Bednall, T. (2012). How employee perceptions of HR policy and practice influence discretionary work effort and co-worker assistance: evidence from two organizations. The International Journal of Human Resource Management, 23(20), 4193-4210.

Gerhart, B. (2010). Compensation. In Wilkinson, A., Bacon, N, Redman, T., \& Snell, S. (Eds.) The SAGE handbook of human resource management (pp. 210-230). London: Sage.

Goldstein, I. L. (1996). Training in work organizations. In Dunnete, M., \& Hough L. M. (Eds.). Handbook of industrial and organizational psychology (pp. 507-619). Palo Alto, CA: Consulting Psychology Press.

Gomide, S., Jr., Silvestrin, L. H. B., \& Oliveira, A. de F. (2015). Bem-estar no trabalho: o impacto das satisfações com os suportes organizacionais e o papel mediador da resiliência no trabalho. Revista Psicologia: Organizações e Trabalho, 15(1), 19-29.

Gomide, S., Jr., \& Tanabe, T. R. (2012). Políticas de gestão de pessoas e efetividade organizacional. In Demo, G. (Org.). Políticas de gestão de pessoas nas organizações: estado da arte, produção nacional, agenda de pesquisa, medidas e estudos relacionais (pp. 175-195). São Paulo: Atlas.

Gonçalves, D. I. F. (2008). Pesquisas de marketing pela internet: as percepções sob a ótica dos entrevistados. Revista de Administração Mackenzie, 9(7), 70-88.

Gonzalez, R. A., \& Bruni, A. L. (2015). Esforço discricionário no trabalho: elementos conceituais e proposta para uma agenda de pesquisa. Anais do Encontro de Gestão de Pessoas e Relações de Trabalho, Salvador, BA, Brasil, 5.

Guest, D. (1987). Human resource management and industrial relations. The Journal of Management Studies, 24(5), 503-521.

Guest, D. (1989). Personnel and HRM: can you tell the difference? Personnel Management, (21), 48-51.

Guest, D. (1998). Is the psychological contract worth taking seriously? Journal of Organisational Behaviour, 19(S1), 649-664.

Guest, D., \& Conway, N. (2011). The impact of HR practices, HR effectiveness and a 'strong HR system' on organizational outcomes: a stakeholder perspective. The International Journal of Human Resource Management, 22(8), 1686-1702.

Guimarães, T. A. (2000). A nova administração pública e a abordagem da competência. Revista de Administração Pública, 34(3), 125-140. 
Gurgel, L. G., Plentz, R. D. M., Joly, M. C. R. A., \& Reppold, C. T. (2013). Avaliação da resiliência em adultos e idosos: revisão de instrumentos. Estudos de Psicologia (Campinas), 30(4), 487-496.

Hackman, J. R., \& Oldham, G. R. (1976). Motivation through the design of work: test of a theory. Organizational Behavior and Human Performance, 16(2), 250-279.

Hair, J. F. Jr., Babin, B., Money, A. H., \& Samouel, P. (2005). Fundamentos de métodos de pesquisa em administração. Porto Alegre: Bookman.

Hair, J. F., Jr., Black, W. C., Babin, B. J., Anderson, R. E., \& Tatham, R. L. (2009). Análise multivariada de dados (6a ed.). Porto Alegre: Bookman.

Harland, L., Harrison, W., Jones, J. R., \& Reiter-Palmon, R. (2005). Leadership behaviors and subordinate resilience. Journal of Leadership \& Organizational Studies, 11(2), 2-14.

Hernandez, J. (2007). Impactos da percepção de saúde organizacional no bem-estar no trabalho (Dissertação de mestrado). Universidade Federal de Uberlândia, Uberlândia, MG, Brasil.

Herzberg, F. I. (1968). One more time: how do you motivate employees? Harvard Business Review, 46(1), 53-62.

Hipólito, J. A. M. (2001). Tendências no campo da remuneração para o novo milênio. In Dutra, J. S. (Org.). Gestão por competências (5a ed., pp. 71-94). São Paulo: Gente.

Hjemdal, O., Roazzi, A., Dias, M. G. B. B., Roazzi, M., \& Vikan, A. (2009). Exploring the psychometric properties of the resilience scale for adults in a Brazilian sample. In Elizur, D., \& Yaniv, E. (Orgs.). Facet new horizons in theory construction and data analysis (pp. 120-138). Jerusalém: FTA.

Hockenbury, D. H., \& Hockenbury, S. E. (2003). Descobrindo a Psicologia. Barueri, SP: Manole.

Horta, P., Demo, G., \& Roure, P. (2012). Políticas de Gestão de Pessoas, confiança e bemestar no trabalho: estudo em uma multinacional. Revista de Administração Contemporânea, 16(4), 566-585.

Hoyle, R. H. (1995). Structural equation modeling: concepts, issues, and applications. Thousand Oaks, CA: Sage Publications.

Huselid, M. A. (1995). The impact of human resource management practices on turnover, productivity, and corporate financial performance. Academy of Management Journal, 38(3), 635-672. 
Inyang, B. J., \& Akaegbu, J. B. (2014). Redefining the role of the Human Resource Professional (HRP) in the Nigerian public service for enhanced performance. International Journal of Business Administration, 5(1), 90-98.

Jesus, R. G., \& Rowe, D. E. O. (2015). Percepção de políticas de gestão de pessoas e comprometimento organizacional: o papel mediador da percepção de justiça organizacional. Tourism \& Management Studies, 11(2), 211-218.

Jia, L., Shaw, J. D., Tsui, A. S., \& Park, T. Y. (2014). A social-structural perspective on employee-organization relationships and team creativity. Academy of Management Journal, 57(3), 869-891.

Job, F. P. P. (2003a). Os sentidos do trabalho e a importância da resiliência nas organizações (Tese de doutorado). Escola de Administração de Empresas de São Paulo, São Paulo, SP, Brasil.

Job, F. P. P. (2003b). Resiliência na organização: estudo de caso da medição e avaliação da resiliência de indivíduos em uma organização industrial. Revista Faculdade de Ciências Médicas de Sorocaba, 5(1), 33-42.

Katou, A. A. (2012). Investigating reverse causality between human resource policies and organizational performance in small firms. Management Research Review, 35(2), 134156.

Kim, A., \& Lee, C. (2012). How does HRM enhance strategic capabilities? Evidence from the Korean management consulting industry. The International Journal of Human Resource Management, 23(1), 126-146.

Klein, F. A., \& Mascarenhas, A. O. (2016). Motivação, satisfação profissional e evasão no serviço público: o caso da carreira de especialistas em Políticas Públicas e Gestão Governamental. Revista de Administração Pública, 50(1), 17-39.

Kline, R. B. (2011). Principles and practice of structural equation modeling (3rd ed.). New York: The Guilford Press.

Lacombe, M., \& Chu, R. (2008). Políticas e práticas de gestão de pessoas: as abordagens estratégica e institucional. Revista de Administração de Empresas, 48(1), 25-35.

Lacombe, B. M. B., \& Tonelli, M. J. (2001). O discurso e a prática: o que nos dizem os especialistas e o que nos mostram as práticas das empresas sobre os modelos de gestão de recursos humanos. Revista de Administração Contemporânea, 5(2), 157-174.

Ladain, M. C. V., Costa, I. de S. A., \& Salles, D. M. R. (2012). As práticas de gestão de pessoas nas empresas de economia de comunhão: estudo de caso no Polo Spartaco. Cadernos Ebape, 10(4), 858-882. 
Latham, G., Sulsky, L. M., \& Macdonald, H. (2007). Performance management. In Boxall, P., Purcell, J., \& Wright, P. (Orgs.). The Oxford handbook of human resource management (pp. 364-381). New York: Oxford University Press.

Lazarus, R. S., \& Folkman, S. (1984). Stress, appraisal, and coping. New York: Springer.

Legge, K. (1995). Human resource management: rethorics and realities. London: Macmillan.

Legge, K. (2006). Human resource management. In Ackroyd, S., Batt, R., Thompson, \& P., Tolbert, P. (Eds.). The Oxford handbook of work and organization. Oxford, UK: Oxford University Press.

Lei n. 8112, de 11 de dezembro de 1990. (1990). Dispõe sobre o regime jurídico dos servidores públicos civis da União, das autarquias e das fundações públicas federais. Recuperado de http://www.planalto.gov.br/ccivil_03/leis/L8112cons.htm

Leite, N. R. P., \& Albuquerque, L. G. (2011). Gestão estratégica de pessoas, comprometimento e contrato psicológico: o caso Vale. Revista de Administração RAUSP, 46(1), 19-31.

Leite, N., Leite, F., \& Albuquerque, L. (2013). A gestão de pessoas e as estratégias de atração, desenvolvimento e retenção de profissionais: o caso Petrobras. Revista Ibero-Americana de Estratégia, 12(4), 91-122.

Lievens, F., \& Chapman, D. (2010). Recruitment and selection. In Wilkinson, A., Bacon, N., Redman T., \& Snell, S. (Eds.). The SAGE handbook of human resource management (pp. 135-154). London: Sage.

Lopes, V. R., \& Martins, M. C. F. (2011). Validação fatorial da Escala de Resiliência de Connor-Davidson (Cd-Risk-10) para brasileiros. Revista Psicologia: Organizações e Trabalho, 11(2), 36-50.

Loudoun, R., \& Johnstone, R. (2010). Occupational health and safety in the modern world of work. In Wilkinson, A., Bacon, N., Redman T., \& Snell, S. (Eds.). The SAGE handbook of human resource management (pp. 286-307). London: Sage.

Luthans, F. (2002). Positive organizational behavior: developing and managing psychological strengths. Academy of Management Executive, 16(1), 57-72.

Luthans, F., \& Youssef, C. M. (2007). Emerging positive organizational behavior. Journal of Management, 33(3), 321-349.

Luthar, S. S., Cicchetti, B., \& Becker, B. (2000). The construct of resilience: a critical evaluation and guidelines for future work. Child Development, 71(3), 543-562.

Maccali, N., Kuabara, P. S. S., Takahashi, A. R. W., Roglio, K. de D., \& Bohes, S. de T. M. (2015). As práticas de recursos humanos para a gestão da diversidade: a inclusão de 
deficientes intelectuais em uma federação pública do Brasil. Revista de Administração Mackenzie, 16(2), 157-187.

Magalhães, M. O. (2013). Propriedades Psicométricas da versão brasileira da escala de comprometimento com a carreira. Psicologia: Ciência e Profissão, 33(2), 303-317.

Majumder, M. T. H. (2012). HRM practices and employees'satisfaction towards private banking sector in Bangladesh. International Review of Management and Marketing, 2(1), 52-58.

Malhotra, N. K. (2006). Pesquisa de Marketing: uma orientação aplicada (4a ed.). Porto Alegre: Bookman.

Malhotra, N. K. (2012). Pesquisa de marketing (6a ed.). Porto Alegre: Bookman.

Marconi, N. (2003). A evolução do perfil da força de trabalho e das remunerações nos setores público e privado ao longo da década de 1990. Revista do Serviço Público, 54(1), 0945.

Mariotti, D. F., \& Souza, Y. S. (2009). Relações de confiança na dinâmica de uma organização. Anais do Encontro Nacional da Associação Nacional de Pós-Graduação e Pesquisa em Administração, Brasília, DF, Brasil, 29.

Marôco, J. (2010). Análise de equações estruturais: Fundamentos teóricos, software e aplicações. Lisboa: Report Number.

Martín-Alcázar, F., Romero-Fernández, P. M., \& Sánchez-Gardey, G. (2005). Strategic human resource management: integrating the universalistic, contingent, configurational and contextual perspectives. International Journal of Human Resource Management, 16(5), 633-659.

Martins, M., \& Demo, G. (2014). Bem-estar no trabalho na Disney: o papel das políticas e práticas de gestão de pessoas. Revista Eletrônica Gestão \& Saúde, edição especial, 3605-3632.

Martins, M. C. F., Emílio, E. R., \& Siqueira, M. M. M. (2011). Construção e validação da Escala de Avaliação de Resiliência - EAR. Anais eletrônicos do Congresso NorteNordeste de Psicologia, Salvador, BA, Brasil, 7.

Mascarenhas, A. O., \& Barbosa, A. C. Q. (2013). Produção científica brasileira em gestão de pessoas no período 2000-2010. Revista de Administração de Empresas, 53(1), 35-45.

Mascarenhas, A. O., \& Kirschbaum, C. (2008). Fundamentos de gestão estratégica de pessoas. In Mascarenhas, A. O. (Org). Gestão estratégica de pessoas: evolução, teoria e crítica (pp. 23-30). São Paulo: Cengage Learning.

Maslow, A. H. (1970). Motivation and personality (2a ed.). Nova Iorque: Harper \& How. 
Maslow, A. H. (2001). Maslow no Gerenciamento (Casquilho, E., Trad.). Rio de Janeiro: Qualitymark. (Obra original publicada em 1965)

Mathis, R. L., \& Jackson, J. H. (2003). Human resource management (10th ed.). Ohio: SouthWestern/Thomson.

Masten, A. S. (2001). Ordinary magic: resilience processes in development. American Psychologist, 56(3), 227-238.

Mendes, A. M. (2002). Algumas contribuições teóricas do referencial psicanalítico para as pesquisas sobre organizações. Estudos de Psicologia, 7(número especial), 89-96.

Meneses, P. P. M., Coelho, F. A., Jr., Ferreira, R. R., Paschoal, T., \& Silva, A. I. da, Filho. (2014). A produção científica brasileira sobre a gestão de recursos humanos entre 2001 e 2010. Revista de Administração Mackenzie, 15(4), 110-134.

Menezes, L. M., Wood, S., \& Gelade, G. (2010). The integration of human resource and operation management practices and its link with performance: a longitudinal latent class study. Journal of Operations Management, 28(6), 455-471.

Minello, I. F., \& Scherer, I. B. (2014). Características resilientes do empreendedor associadas ao insucesso empresarial. Revista de Ciências da Administração, 16(38), 228-245.

Morettin, L. G. (2010). Estatística básica: probabilidade e inferência. São Paulo: Pearson Prentice Hall.

Morin, E. M. (2001). Os sentidos do trabalho. Revista de Administração de Empresas, 41(3), 08-19.

Morin, E., Tonelli, M. J., \& Pliopas, A. L. V. (2007). O trabalho e seus sentidos. Psicologia \& Sociedade, 19(edição especial), 47-56.

Morris, S., \& Snell, S. (2010). The evolution of HR strategy: adaptations to increasing global complexity. In Wilkinson, A., Bacon, N., Redman T., \& Snell, S. (Eds.). The SAGE handbook of human resource management (pp. 84-99). London: Sage.

Muckinsky, P. M. (2004). Psicologia organizacional. São Paulo: Pioneira Thomson Learning.

Myers, R. H. (1990). Classical and modern regression with applications. Boston: PWS-Kent Publishing Company.

Nalin, C. P., \& França, L. H. F. P. (2015). A importância da resiliência para o bem-estar na aposentadoria. Paidéia. 25(61), 191-199.

Nannetti, M. A., Mesquita, J. M. C., \& Teixeira, L. A. A. (2015). A relação entre a satisfação dos funcionários e a satisfação dos clientes: estudo nas empresas de software do município de Belo Horizonte. Revista de Administração (FEA-USP), 50(1), 56-72. 
Neiva, E. R., \& Goulart, P. A. (2012). Mudança organizacional e Gestão de Pessoas: um estudo sobre as atitudes em relação a mudança. In Demo, G. (Org.). Políticas de Gestão de Pessoas nas Organizações (pp.196-219). São Paulo: Editora Atlas.

Nishii, L. H., Lepak, D. P., \& Schneider, B. (2008). Employee attributions of the "Why" of HR practices: their effects on employee attitudes and behaviors, and customer satisfaction. Personnel Psychology, 8(3), 503-545.

Nunnally, J. C., \& Bernstein, I. H. (1994). Psychometric theory (3rd ed.). New York: McGraw-Hill.

Oliveira, M. A., Reis, V. L., Zanelato, L. S., \& Neme, C. M. B. (2008). Resiliência: análise das publicações no período de 2000 a 2006. Psicologia: Ciência e Profissão, 28(4), 754-766.

Onça, S. S. (2011). Resiliência em trabalhadores: impacto da auto-eficácia e da percepção de suporte social (Dissertação de mestrado). Universidade Metodista de São Paulo, São Paulo, SP, Brasil.

Pasquali, L. (2008). Instrumentos psicológicos: manual prático de elaboração (2a ed.). Brasília: LabPAM-IBAPP.

Pesce, R. P., Assis, S. G., Avanci, J. Q., Santos, N. C., Malaquias, J. V., \& Carvalhaes, R. (2005). Adaptação transcultural, confiabilidade e validade da escala de resiliência. Cadernos de Saúde Pública, 21(2), 436-448.

Pesce, R. P., Assis, S. G., Santos, N., \& Oliveira, R. V. C. (2004). Risco e proteção: em busca de um equilíbrio promotor de resiliência. Psicologia: Teoria e Pesquisa, 20(2), 135143.

Pfeffer, J. (2005). Producing sustainable competitive advantage through effective management of people. Academy of Management Executive, 19(4), 95-106.

Pinheiro, D. P. N. (2004). A resiliência em discussão. Psicologia em Estudo, 9(1), 67-75.

Poletto, M., \& Koller, S. H. (2008). Contextos ecológicos: promotores de resiliência, fatores de risco e de proteção. Estudos de Psicologia (Campinas), 25(3), 405-416.

Poletto, M., Wagner, T. M. C., \& Koller, S. H. (2004). Resiliência e desenvolvimento infantil de crianças que cuidam de crianças: uma visão em perspectiva. Psicologia: Teoria e Pesquisa, 20(3), 241-250.

Poli, B. V. S. (2013). Bem-estar no trabalho: impacto das políticas de gestão de pessoas e da confiança organizacional (Dissertação de mestrado). Universidade Federal de Uberlândia, Uberlândia, MG, Brasil. 
Ralha-Simões, H. (2001). Resiliência e desenvolvimento pessoal. In Tavares, J. (Org). Resiliência e Educação (pp. 95-113). São Paulo: Cortez.

Raykov, T., \& Marcoulides, G. A. (2006). A first course in structural equation modeling (2nd ed.). Mahwah, NJ: Lawrence Erlbaum Associates.

Reppold, C. T., Mayer, J. C., Almeida, L. S., \& Hutz, C. S. (2012). Avaliação da resiliência: controvérsia em torno do uso de escalas. Psicologia: Reflexão e Crítica, 25(2), 248-255.

Ribeiro, A. C. A., Mattos, B. M., Antonelli, C. S., Canêo, L. C., \& Goulart, E., Jr. (2011). Resiliência no trabalho contemporâneo: promoção e/ou desgaste da saúde mental. Psicologia em Estudo (Maringá), 16(4), 623-633.

Ribeiro, I., Roglio, K. D., \& Pécora, J. E., Jr. (2013). Instrumento para identificação das relações entre estratégias competitivas e práticas de gestão de pessoas. Revista Ciências Sociais em Perspectiva, 12(22), 01-24.

Rodrigues, W. A., Reis Neto, M. T., \& Gonçalves, C., Filho. (2014). As influências na motivação para o trabalho em ambientes com metas e recompensas: um estudo no setor público. Revista de Administração Pública, 48(1), 253-273.

Rubino, T., Demo, G., \& Traldi, M. T. F. (2011). As políticas de gestão de pessoas influenciam o bem-estar no trabalho? Anais do Congresso Iberoamericano de Psicologia das Organizações e do Trabalho, Florianópolis, SC, Brasil, 2.

Rutter, M. (1993). Resilience: some conceptual considerations. Journal of Adolescent Health, 14(8), 626-631.

Rutter, M. (2007). Resilience, competence and coping. Child Abuse and Neglect, 31(3), 205209.

Rynes, S., L., Gerhart, B., \& Minette, K. A. (2004). The importance of pay in employee motivation: discrepancies between what people say and what they do. Human Resource Management, 43(4), 381-394.

Sá, P., \& Demo, G. (2014). Bem-estar no trabalho na Fiat: o papel das políticas e práticas de gestão de pessoas. Revista Eletrônica Gestão \& Saúde, edição especial, 3581-3604.

Santos, R. A., \& Moreira, M. C. N. (2014). Resiliência e morte: o profissional de enfermagem frente ao cuidado de crianças e adolescentes no processo de finitude da vida. Ciência \& Saúde Coletiva, 19(12), 4869-4878.

Santos, J. R. V. S., \& Mourão, L. (2011). Impacto do treinamento como variável preditora da satisfação com o trabalho. Revista de Administração da Universidade de São Paulo (RAUSP), 46(3), 305-318. 
Sapienza, G., \& Pedromônico, M. R. M. (2005). Risco, proteção e resiliência no desenvolvimento da criança e do adolescente. Psicologia em Estudo, 10(2), 209-216.

Saunders, M. N. K., Lewis, P., \& Thornhill, A. C. (2000). Research methods for business students. London: Pearson Education.

Scheible, A., \& Bastos, A.V. (2006). Comprometimento com a carreira: explorando o conceito de entrincheiramento. Anais do Encontro da Associação Nacional de PósGraduação e Pesquisa em Administração, Salvador, BA, Brasil, 30.

Schneider, B., \& Bowen, D. (1985). Employee and customer perceptions of service in banks: replication and extension. Journal of Applied Psychology, 70(3), 423-433.

Schumacker, R. E., \& Lomax, R. G. (2004). A beginner's guide to structural equation modeling. Mahwah, NJ: Lawrence Erlbaum Associates.

Serpell, A., \& Ferrada, X. (2007). A competency-based model for construction supervisors in developing countries. Personnel Review, 36(4), 585-602.

Sheehan, M. (2013). Human resource management and performance: evidence from small and medium-sized firms. International Small Business Journal, 32(5), 545-570.

Sinclair, V. G., \& Wallston, K. A. (2004). The development and psychometric evaluation of the Brief Resilient Coping Scale. Assessment, 11(1), 94-101.

Singar, E. J., \& Ramdsen, J. (1972). Human Resources: obtaining results from people at work. UK: McGraw-Hill.

Siqueira, M. M. M. (1995). Antecedentes de comportamento de cidadania organizacional: a análise de um modelo pós-cognitivo (Tese de doutorado). Universidade de Brasília, Brasília, DF, Brasil.

Siqueira, M. M. M. (2008). Envolvimento com o trabalho. In Siqueira, M. M. M. (Org.). Medidas do comportamento organizacional: ferramentas de diagnóstico e de gestão (pp. 139-143). Porto Alegre: Artmed.

Siqueira, M. M. M., \& Gomide, S., Jr. (2008). Suporte no Trabalho. In Siqueira, M. M. M. (Org.). Medidas do comportamento organizacional: ferramentas de diagnóstico e de gestão (pp. 283-294). Porto Alegre: Artmed.

Sisson, K. (1994). Personnel management: paradigms, practice and prospects. In Sisson, K. (Ed.). Personnel management (2nd ed., pp. 3-50). Oxford, UK: Blackwell.

Souza, J., Bertolini, G. R. F., \& Ribeiro, I. (2014). Bem-estar no trabalho e políticas de gestão de pessoas em uma organização sem fins lucrativos. Revista Eletrônica de Estratégia \& Negócios, 7(2), 03-22. 
Souza, M. T. S., \& Cerveny, C. M. O. (2006). Resiliência psicológica: revisão da literatura e análise da produção científica. Revista Interamericana de Psicologia, 40(1), 119-126.

Stone, D. L., Stone-Romero, E. F., \& Lukaszewski, K. (2007). The impact of cultural values on acceptance and effectiveness of human resource management policies and practices. Human Resource Management Review, 17(2), 152-165.

Storey, J. (1995). New perspectives in human resource management. London: Routledge

Subramony, M. (2009). A meta-analytic investigation of the relationship between HRM bundles and firm performance. Human Resource Management, 48(5), 745-768.

Tabachnick, B. G., \& Fidell, L. S. (2013). Using Multivariate Statistics (6th ed). Boston: Pearson.

Taboada, N. G., Legal, E. J., \& Machado, N. (2006). Resiliência: em busca de um conceito. Revista Brasileira de Crescimento e Desenvolvimento Humano, 16(3), 104-113.

Takviriyanun, N. (2008). Development and testing of the Resilience Factors Scale for Thai adolescents. Nursing and Health Sciences, 10(3), 203-208.

Tavares, J. (2001). A resiliência na sociedade emergente. In Tavares, J. (Org.). Resiliência e educação (pp. 43-76). São Paulo: Cortez.

Tetrick, L. E., \& Winslow, C. J. (2015). Workplace stress management interventions and health promotion. Annual Review of Organizational Psychology and Organizational Behavior, 2(1), 583-603.

Todd, J. L., \& Worell, J. (2000). Resilience in low-income employed African American women. Psychology of Women Quarterly, 24(2), 119-128.

Tonelli, M. J., Caldas, M. P., Lacombe, B. M. B., \& Tinoco, T. (2003). Produção acadêmica em recursos humanos no Brasil: 1991-2000. Revista de Administração de Empresas, 43(1), 105-122.

Trindade, L. H., Trindade, C. G., \& Nogueira, E. C. O. R. (2015). Lacunas na pesquisa em gestão de pessoas: uma proposta de agenda para pesquisas futuras. Perspectivas em Gestão \& Conhecimento, 5(1), 169-183.

Turner, R., Huemann, M., \& Keegan, A. (2008). Human resource management in the project oriented organization: employee well-being and ethical treatment. The International Journal of Project Management, 26(5), 577-585.

Tzafrir, S. S. (2005). The relationship between trust, HRM practices and firm performance. The International Journal of Human Resource Management, 16(9), 1600-1622. 
Ulrich, D., Halbrook, R., Meder, D., Stuchlik, M., \& Thorpe, S. (1991). Employee and customer attachment: synergies for competitive. Human Resource Planning, 14(2), 89102.

Universidade de Brasília. (2015b). Novo Anuário Estatístico da UnB 2015. Período: 2010 a 2014 - Versão Parcial. Recuperado de http://dpo.unb.br/documentos/anuario/Anuarioparcial_2015.pdf

Universidade de Brasília. (2015c). Relatório de Autoavaliação Institucional 2014. Recuperado de http://www.dpo.unb.br/documentos/relatorio_autoavaliacao_2014.pdf

Universidade de Brasília. (2015a). Relatório de Gestão Exercício 2014. Recuperado de http://dpo.unb.br/documentos/Relatorio_Gestao_2014.pdf

Uysal, G. (2012). For the development of effective HRM systems: inter-relationships between HRM practices using correlation analysis. World Review of Entrepreneurship, Management and Sustainable Development, 8(1), 01-12.

Vakola, M., Soderquist, K. E., \& Pratascos, G. P. (2007). Competence management in support of organizational change. International Journal of Manpower, 28(3/4), 260-275.

Vanhove, A. J., Herian, M., Perez, A. I. U., Harms, P. D., \& Lester, P. B. (2015). Can resilience be developed at work? A meta-analytic review of resilience-building programme effectiveness. Journal of Occupational and Organizational Psychology, 89(2), 278-307.

Vasconcelos, I. F. F. G., Cyrino, A. B., D’Oliveira, L. M., \& Prallon, E. P. (2015). Resiliência organizacional e inovação sustentável: um estudo sobre o modelo de gestão de pessoas de uma empresa brasileira de energia. Cadernos EBAPE, 13(4), 910-929.

Velasco, S. M. V., \& Silva, M. T. (2011). Sistemática da avaliação de desempenho na Administração Pública Federal. Anais do Congresso Consad (Conselho Nacional de Secretários de Administração) de Gestão Pública, Brasília, DF, 4.

Ventura, V. L. da S., \& Leite, N. R. P. (2014). Percepção da influência da gestão estratégica de pessoas no comprometimento organizacional. Revista Pretexto, 15(3), 11-28.

Vieira, M. A., Silva, A. D., Jr., \& Silva, P. D. O. M. D. (2014). Influências das políticas e práticas de gestão de pessoas na institucionalização da cultura de segurança. Production (Guarapari), 24(1), 200-211.

Wagnild, G. M., \& Young, H. M. (1993). Development and psychometric evaluation of the Resilience Scale. Journal of Nursing Measurement, 1(2), 165-178.

Waller, M. A. (2001). Resilience in ecosystemic context: evolution of the concept. American Journal of Orthopsychiatry, 71(3), 290-297. 
Weibel A., Rost K., \& Osterloh, M. (2010). Pay for performance in the public sector benefits and (hidden) costs. Journal of Public Administration Research and Theory, 20(2), 387412.

Winterton, J. (2007). Training, development and competence. In Boxall, P., Purcell, J., Wright, P. (Orgs.). The Oxford handbook of human resource management (pp. 324343). New York: Oxford University Press.

Wood Jr., T., Tonelli, M. J., \& Cooke, B. (2011). Colonização e neo-colonização da gestão de recursos humanos no Brasil (1950-2010). Revista de Administração de Empresas, 51(3), 232-243.

Yunes, M. A. M. (2003). Psicologia positiva e resiliência: o foco no indivíduo e na família. Psicologia em Estudo, 8(edição especial), 75-84. 


\section{APÊNDICES}

\section{APÊNDICE A - Autorização da pesquisa}

\section{Autorização para Realização de Pesquisa}

Solicito autorização para realizar pesquisa de mestrado com os servidores técnicoadministrativos da Fundação Universidade de Brasília. A pesquisa será realizada, preferencialmente, via coleta de dados online e, caso necessário, presencialmente pela pesquisadora em envelopes lacrados. Para não prejudicar o cronograma da pesquisa, a aplicação dos questionários deverá acontecer entre os meses de fevereiro e abril de 2016.

Com o título "Políticas e práticas de gestão de pessoas produzem servidores públicos resilientes? Validação de um modelo estrutural", sob orientação da Profa. Dra. Gisela Demo, do Programa de Pós-Graduação em Administração desta Universidade PPGA/UnB, a pesquisa objetiva identificar e descrever a influência das políticas e práticas de gestão de pessoas na resiliência no trabalho dos servidores técnicoadministrativos da FUB. O questionário da pesquisa encontra-se anexado a esta autorização. Os dados da pesquisa serão confidenciais e serão utilizados exclusivamente para fins acadêmicos.

O cronograma de reuniões do Comitê de Ética em Pesquisa do Instituto de Ciências Humanas da UnB - CEP/IH está incompatível com o cronograma da pesquisa, pois este Comitê reunir-se-á em 19 de fevereiro de 2016, atrasando, assim, em mais de 1 mês o cronograma da pesquisa.

Portanto, solicito autorização do Decanato de Pesquisa e Pós-Graduação e ainda do dirigente máximo da Instituição, o Magnífico Reitor Prof. Ivan Camargo.

Estou à disposição para quaisquer esclarecimentos.

Atenciosamente,
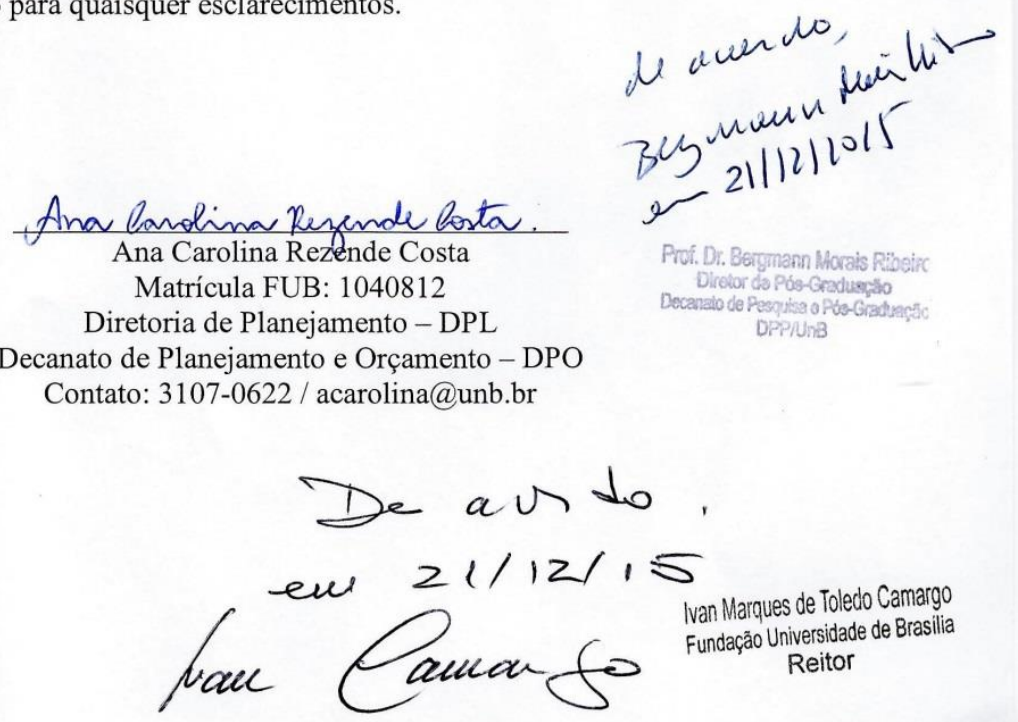


\section{APÊNDICE B - Questionário}

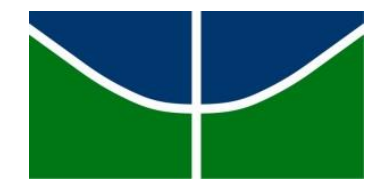

Universidade de Brasília - UnB

Programa de Pós-Graduação em Administração - PPGA

\section{Convite e Informações para Participação em Pesquisa Acadêmica}

$\mathrm{O}$ (a) sr.(a) está sendo convidado(a) a participar de uma pesquisa elaborada pela Professora Doutora Gisela Demo, do Programa de Pós-Graduação em Administração da UnB, e pela mestranda em Administração Ana Carolina Rezende Costa, sobre Políticas e Práticas de Gestão de Pessoas e Resiliência no Trabalho - resiliência é um processo de adaptação positiva dos indivíduos que vivenciam experiências de adversidade (Luthar, Cicchetti, \& Becker, 2000).

$\mathrm{O}$ (a) sr.(a) só estará apto(a) a participar da pesquisa se for servidor(a) técnicoadministrativo da Fundação Universidade de Brasília - FUB, lotado(a) no campus Darcy Ribeiro.

Gostaríamos de contar com sua colaboração no sentido de responder ao questionário a seguir com as devidas orientações para preenchimento. O tempo médio estimado para responder às questões é de 10 minutos.

Precisamos de sua sinceridade nas respostas. Lembre-se de que não há respostas certas ou erradas. Todas são corretas desde que correspondam ao que o(a) sr.(a) pensa.

É importante ressaltar que as questões demográfico-funcionais ao fim do questionário buscam apenas caracterizar a amostra da pesquisa. Além disso, os dados desta pesquisa são confidenciais e serão utilizados exclusivamente para fins acadêmicos.

A sua participação nesta pesquisa é voluntária, de maneira que o(a) sr.(a) fica livre para interromper a sua participação quando e se achar conveniente. Por gentileza, evite deixar itens em branco, há opções de resposta para quem preferir não se manifestar (exemplos: não concordo nem discordo/não se aplica).

Para esclarecer dúvidas e fazer comentários a qualquer momento ou mesmo para conhecer os resultados desta pesquisa, não hesite em contatar: acarolina@unb.br

Agradecemos sua colaboração!

Atenciosamente,

Ana Carolina Rezende Costa. 


\section{TERMO DE CONSENTIMENTO}

Ao responder às questões deste questionário, afirmo que li e entendi as informações relativas a esta pesquisa e que voluntariamente concordo em participar dela.

\section{PARTE I: Políticas e Práticas de Gestão de Pessoas}

$\mathrm{O}$ (a) sr.(a) deve avaliar cada uma das afirmativas seguintes de acordo com a escala abaixo, indicando o quanto o(a) sr.(a) concorda ou discorda de cada uma delas, escolhendo o número (de 1 a 5) que melhor reflete a sua percepção em relação às políticas de recursos humanos da FUB. Por favor, não deixe nenhum item em branco!

\begin{tabular}{|c|c|c|c|c|}
\hline 1 & 2 & $\mathbf{3}$ & $\mathbf{4}$ & $\mathbf{5}$ \\
\hline $\begin{array}{c}\text { Discordo } \\
\text { totalmente }\end{array}$ & Discordo & $\begin{array}{c}\text { Não concordo } \\
\text { nem discordo / } \\
\text { Não se aplica }\end{array}$ & Concordo & $\begin{array}{c}\text { Concordo } \\
\text { totalmente }\end{array}$ \\
\hline
\end{tabular}

\begin{tabular}{|c|c|}
\hline 1 & $\begin{array}{l}\text { Os processos de recrutamento (externo e interno) de candidatos a ocuparem } \\
\text { vagas na FUB são amplamente divulgados. }\end{array}$ \\
\hline 2 & Os processos seletivos da FUB são disputados, atraindo pessoas competentes. \\
\hline 3 & $\begin{array}{l}\text { Os testes de seleção da FUB são conduzidos por pessoas capacitadas e } \\
\text { imparciais. }\end{array}$ \\
\hline 4 & $\begin{array}{l}\text { A FUB utiliza-se de vários instrumentos de seleção (exemplos: entrevistas, } \\
\text { provas etc.). }\end{array}$ \\
\hline 5 & $\begin{array}{l}\text { A FUB divulga aos candidatos informações a respeito das etapas e critérios } \\
\text { do processo seletivo. }\end{array}$ \\
\hline 6 & $\begin{array}{l}\text { A FUB comunica aos candidatos seu desempenho ao final do processo } \\
\text { seletivo. }\end{array}$ \\
\hline 7 & A FUB se preocupa com meu bem-estar. \\
\hline 8 & A FUB me trata com respeito e atenção. \\
\hline 9 & A FUB procura conhecer minhas necessidades e expectativas profissionais. \\
\hline 10 & $\begin{array}{l}\text { A FUB estimula a minha participação nas tomadas de decisão e resolução de } \\
\text { problemas. }\end{array}$ \\
\hline 11 & $\begin{array}{l}\text { A FUB reconhece o trabalho que faço e os resultados que apresento } \\
\text { (exemplos: elogios, matérias em jornais internos etc.). }\end{array}$ \\
\hline 12 & $\begin{array}{l}\text { Na FUB, os servidores e suas chefias desfrutam da troca constante de } \\
\text { informações para o bom desempenho das funções. }\end{array}$ \\
\hline 13 & $\begin{array}{l}\text { Na FUB, há um clima de compreensão e confiança dos chefes em relação aos } \\
\text { seus servidores. }\end{array}$ \\
\hline 14 & $\begin{array}{l}\text { Na FUB, há um clima de confiança e cooperação entre os colegas de } \\
\text { trabalho. }\end{array}$ \\
\hline 15 & Na FUB, há coerência entre discurso e prática gerenciais. \\
\hline
\end{tabular}




\begin{tabular}{|c|c|}
\hline 16 & $\begin{array}{l}\text { A FUB me ajuda a desenvolver as competências necessárias à boa realização } \\
\text { das minhas funções (exemplos: treinamentos, participação em congressos } \\
\text { etc.). }\end{array}$ \\
\hline 17 & $\begin{array}{l}\text { Eu consigo aplicar no meu trabalho os conhecimentos e comportamentos } \\
\text { aprendidos nos treinamentos/eventos de que participo. }\end{array}$ \\
\hline 18 & A FUB estimula a aprendizagem e a produção de conhecimento. \\
\hline 19 & A FUB preocupa-se com a minha saúde e qualidade de vida. \\
\hline 20 & $\begin{array}{l}\text { A FUB me oferece benefícios básicos (exemplos: plano de saúde, auxílio } \\
\text { transporte, auxílio alimentação etc.). }\end{array}$ \\
\hline 21 & $\begin{array}{l}\mathrm{Na} \text { FUB, existem ações e programas de prevenção de acidentes e } \\
\text { enfrentamento de incidentes. }\end{array}$ \\
\hline 22 & $\begin{array}{l}\text { A FUB preocupa-se com a segurança de seus servidores, controlando o } \\
\text { acesso de pessoas estranhas nos locais de trabalho. }\end{array}$ \\
\hline 23 & $\begin{array}{l}\text { As instalações e as condições físicas (iluminação, ventilação, ruído e } \\
\text { temperatura) da FUB são ergonômicas (adequadas e confortáveis). }\end{array}$ \\
\hline 24 & A FUB realiza avaliações de desempenho e competências periodicamente. \\
\hline 25 & $\begin{array}{l}\text { Na FUB, a avaliação de desempenho e competências subsidia as decisões } \\
\text { sobre promoções e aumento de salário. }\end{array}$ \\
\hline 26 & $\begin{array}{l}\text { Na FUB, a avaliação de desempenho e competências subsidia a elaboração de } \\
\text { um plano de desenvolvimento dos servidores. }\end{array}$ \\
\hline 27 & $\begin{array}{l}\mathrm{Na} \text { FUB, os critérios e os resultados da avaliação de desempenho e } \\
\text { competências são discutidos com os servidores. }\end{array}$ \\
\hline 28 & $\begin{array}{l}\mathrm{Na} \text { FUB, os critérios e os resultados da avaliação de desempenho e } \\
\text { competências são divulgados para os servidores. }\end{array}$ \\
\hline 29 & $\begin{array}{l}\text { A FUB me oferece remuneração compatível com as minhas competências e } \\
\text { formação/escolaridade. }\end{array}$ \\
\hline 30 & $\begin{array}{l}\mathrm{Na} \text { FUB, recebo incentivos (exemplos: promoções/funções comissionadas, } \\
\text { bônus/prêmios/gratificações etc.). }\end{array}$ \\
\hline 31 & $\begin{array}{l}\mathrm{Na} \text { definição de seu sistema de recompensas, a FUB considera as } \\
\text { expectativas e sugestões de seus servidores. }\end{array}$ \\
\hline 32 & ninha remuneração é influenciada pelos meus resultados. \\
\hline
\end{tabular}

\section{PARTE II: Resiliência no Trabalho}

Abaixo encontram-se relacionadas algumas situações. Marque (indicando um número de 1 a 5) o quanto o(a) sr.(a) concorda ou discorda de cada uma das afirmações. Por favor, não deixe nenhum item em branco!

\begin{tabular}{|c|c|c|c|c|}
\hline $\mathbf{1}$ & $\mathbf{2}$ & $\mathbf{3}$ & $\mathbf{4}$ & $\mathbf{5}$ \\
\hline $\begin{array}{c}\text { Discordo } \\
\text { totalmente }\end{array}$ & Discordo & $\begin{array}{c}\text { Não concordo } \\
\text { nem discordo }\end{array}$ & Concordo & $\begin{array}{c}\text { Concordo } \\
\text { totalmente }\end{array}$ \\
\hline
\end{tabular}

\section{No meu trabalho...}

33 Mantenho interesse nele. 


\begin{tabular}{|l|l|l|}
\hline 34 & Quando estou em uma situação difícil, normalmente acho uma saída. & \\
\hline 35 & Tenho energia suficiente para fazer o que preciso fazer. & \\
\hline 36 & Sou determinado(a). & \\
\hline 37 & Posso olhar normalmente para uma situação de diversas maneiras. & \\
\hline 38 & Minha autoconfiança me leva a passar por períodos difíceis. & \\
\hline 39 & Meu trabalho tem sentido para mim. & \\
\hline 40 & Sinto orgulho de ter realizado coisas. & \\
\hline 41 & $\begin{array}{l}\text { Sou uma pessoa com quem as pessoas podem contar emões de } \\
\text { emergência. }\end{array}$ & \\
\hline 42 & Normalmente posso achar motivos para rir. & \\
\hline 43 & Costumo lidar com os problemas de uma forma ou de outra. & \\
\hline 44 & Quando faço planos, eu os levo até o fim. & \\
\hline 45 & Sou disciplinado(a). & \\
\hline 46 & Manter interesse nas coisas é importante para mim. & \\
\hline 47 & Sou amigo(a) de mim mesmo(a). & \\
\hline
\end{tabular}

\section{PARTE III: Dados Demográfico-funcionais}

48. Qual a sua idade?

49. Gênero:
( ) Feminino
( ) Masculino

50. Qual o seu nível de escolaridade completo?
( ) Ensino Fundamental
( ) Ensino Médio
( ) Ensino Superior
( ) Especialização
( ) Mestrado
( ) Doutorado

51. Há quanto tempo o(a) sr.(a) trabalha na FUB (em anos e meses. Exemplo: 2 anos e 7 meses.)? anos e meses.

52. Em qual setor/instituto/faculdade o(a) sr.(a) trabalha?

53. $\mathrm{O}$ (a) sr.(a) possui FG (função gratificada) ou CD (cargo de direção)?

( ) Sim ( ) Não 


\section{ANEXOS}

\section{ANEXO A - Lista de periódicos com classificação Qualis igual a superior a B1 - Administração, Ciências Contábeis e Turismo}

\begin{tabular}{|c|c|}
\hline \multicolumn{2}{|c|}{$\mathbf{A 2}$} \\
\hline BAR. Brazilian Administration Review & RAE Eletrônica (Online) \\
\hline Cadernos EBAPE.BR (FGV) & RAUSP-e (São Paulo) \\
\hline Cadernos de Saúde Pública (ENSP. Impresso) & Revista Brasileira de Gestão de Negócios (Online) \\
\hline Dados (Rio de Janeiro. Impresso) & $\begin{array}{l}\text { Revista Brasileira de Gestão de Negócios (São Paulo. } \\
\text { Impresso) }\end{array}$ \\
\hline Organizações \& Sociedade (Impresso) & Revista Contabilidade \& Finanças (Impresso) \\
\hline Organizações \& Sociedade (Online) & Revista Contabilidade \& Finanças (Online) \\
\hline $\begin{array}{l}\text { RAC. Revista de Administração Contemporânea } \\
\text { (Impresso) }\end{array}$ & Revista de Administração (FEA-USP) \\
\hline $\begin{array}{l}\text { RAC. Revista de Administração Contemporânea } \\
\text { (Online) }\end{array}$ & Revista de Administração (São Paulo. Online) \\
\hline RAE (Impresso) & Revista de Administração Pública (Impresso) \\
\hline \multicolumn{2}{|c|}{ B1 } \\
\hline Ambiente \& Sociedade (Online) & Psicologia: Reflexão e Crítica (UFRGS. Impresso) \\
\hline Ambiente e Sociedade (Campinas) & $\begin{array}{l}\text { RAM. Revista de Administração Mackenzie } \\
\text { (Impresso) }\end{array}$ \\
\hline $\begin{array}{l}\text { Arquivo Brasileiro de Medicina Veterinária e } \\
\text { Zootecnia }\end{array}$ & RAM. Revista de Administração Mackenzie (Online) \\
\hline $\begin{array}{l}\text { BBR. Brazilian Business Review (Edição em } \\
\text { português. Online) }\end{array}$ & $\begin{array}{l}\text { REAd. Revista Eletrônica de Administração (Porto } \\
\text { Alegre. Online) }\end{array}$ \\
\hline $\begin{array}{l}\text { BBR. Brazilian Business Review (English Edition. } \\
\text { Online) }\end{array}$ & Revista Brasileira de Ciências Sociais (Impresso) \\
\hline Bragantia (São Paulo, SP. Impresso) & Revista Brasileira de Economia (Impresso) \\
\hline Caderno CRH (UFBA. Impresso) & Revista Brasileira de Enfermagem (Impresso) \\
\hline Caderno Virtual de Turismo (UFRJ) & Revista Brasileira de Estudos de População (Impresso) \\
\hline Ciência e Saúde Coletiva (Impresso) & Revista Brasileira de Estudos de População REBEP \\
\hline Contabilidade Vista \& Revista & Revista Brasileira de Fruticultura (Impresso) \\
\hline Economia Aplicada (Impresso) & Revista Brasileira de Paleontologia \\
\hline Economia e Sociedade (UNICAMP. Impresso) & Revista Brasileira de Reumatologia (Impresso) \\
\hline Enfoque & $\begin{array}{l}\text { Revista Brasileira de Saúde Materno Infantil } \\
\text { (Impresso) }\end{array}$ \\
\hline Enfoque: Reflexão Contábil (Impresso) & Revista Contemporânea de Contabilidade \\
\hline Engenharia Agrícola (Impresso) & Revista Contemporânea de Contabilidade (UFSC) \\
\hline Estudos Econômicos & Revista Universo Contábil \\
\hline Estudos Econômicos (São Paulo. Impresso) & Revista da Escola de Enfermagem da USP (Impresso) \\
\hline Gestão \& Produção & Revista de Contabilidade e Organizações \\
\hline Gestão \& Produção (UFSCAR. Impresso) & Revista de Economia Contemporânea (Impresso) \\
\hline História, Ciências, Saúde-Manguinhos (Impresso) & Revista de Economia Política (Impresso) \\
\hline Iheringia. Série Zoologia (Impresso) & Revista de Economia e Sociologia Rural (Impresso) \\
\hline Nova Economia (UFMG. Impresso) & Revista de Gestão da Tecnologia e Sistemas de \\
\hline
\end{tabular}




\begin{tabular}{ll}
\hline & Informação (Online) \\
\hline Novos Estudos CEBRAP (Impresso) & Revista de Sociologia e Política (UFPR. Impresso) \\
\hline Perspectivas em Ciência da Informação (Online) & Revista Árvore (Impresso) \\
\hline Pesquisa Veterinária Brasileira (Impresso) & Sociedade e Estado (UnB. Impresso) \\
\hline Pesquisa Veterinária Brasileira (Online) & Sociologias (UFRGS. Impresso) \\
\hline
\end{tabular}




\section{ANEXO B - Lista de periódicos com classificação Qualis igual ou superior a B1 - Psicologia}

\begin{tabular}{|c|c|}
\hline \multicolumn{2}{|c|}{ A1 } \\
\hline Estudos de Psicologia (Natal. Online) & Psicologia em Estudo (Impresso) \\
\hline Estudos de Psicologia (PUCCAMP. Impresso) & Psicologia em Estudo (Online) \\
\hline Estudos de Psicologia (UFRN) & Psicologia: Reflexão e Crítica (UFRGS. Impresso) \\
\hline Paidéia (USP. Online) & Psicologia: Teoria e Pesquisa (Brasília. Online) \\
\hline Paidéia (USP. Ribeirao Preto. Impresso) & Psicologia: Teoria e Pesquisa (UnB. Impresso) \\
\hline \multicolumn{2}{|c|}{ A2 } \\
\hline Arquivos Brasileiros de Psicologia (Online) & Psicologia: Ciência e Profissão (Impresso) \\
\hline Arquivos de Neuro-Psiquiatria (Impresso) & Psicologia: Ciência e Profissão (Online) \\
\hline Avaliação Psicológica (Impresso) & Psicologia: Teoria e Prática (Impresso) \\
\hline $\begin{array}{l}\text { Brazilian Journal of Medical and Biological } \\
\text { Research }\end{array}$ & $\begin{array}{l}\text { Revista Brasileira de Crescimento e Desenvolvimento } \\
\text { Humano }\end{array}$ \\
\hline $\begin{array}{l}\text { Brazilian journal of medical and biological } \\
\text { research }\end{array}$ & Revista Brasileira de Orientação Profissional \\
\hline Cadernos de Saúde Pública (ENSP. Impresso) & Revista Brasileira de Psicologia Escolar e Educacional \\
\hline Cadernos de Saúde Pública (Online) & $\begin{array}{l}\text { Revista Brasileira de Psiquiatria (São Paulo. } 1999 . \\
\text { Impresso) }\end{array}$ \\
\hline Ciência \& Saúde Coletiva (Online) & Revista Brasileira de Zootecnia (Online) \\
\hline Ciência e Saúde Coletiva (Impresso) & Revista Estudos Feministas (UFSC. Impresso) \\
\hline Estudos e Pesquisas em Psicologia (Online) & Revista Latino-Americana de Enfermagem (Online) \\
\hline $\begin{array}{l}\text { Estudos e Pesquisas em Psicologia (UERJ. } \\
\text { Impresso) }\end{array}$ & $\begin{array}{l}\text { Revista Latino-Americana de Enfermagem (USP. } \\
\text { Ribeirão Preto. Impresso) }\end{array}$ \\
\hline Psico (PUCRS. Impresso) & Revista Latinoamericana de Psicologia \\
\hline Psico (PUCRS. Online) & $\begin{array}{l}\text { Revista Latinoamericana de Psicopatologia } \\
\text { Fundamental (Impresso) }\end{array}$ \\
\hline Psico-USF (Impresso) & Revista Psicologia Escolar e Edcuacional \\
\hline Psicologia \& Sociedade (Online) & Revista Psicologia: Organizações e Trabalho \\
\hline Psicologia Clínica (PUCRJ. Impresso) & Revista de Psicologia : Teoria e Prática (Online) \\
\hline Psicologia Escolar e Educacional (Impresso) & Revista de Psiquiatria Clínica (São Paulo. Impresso) \\
\hline Psicologia USP (Impresso) & Revista de Psiquiatria do Rio Grande do Sul (Impresso) \\
\hline Psicologia USP (Online) & Temas em Psicologia (Ribeirão Preto) \\
\hline Psicologia e Sociedade (Impresso) & Ágora ( PPGTP/UFRJ) \\
\hline \multicolumn{2}{|c|}{ B1 } \\
\hline Acta Cirúrgica Brasileira (Online) & Revista Brasileira de Educação Médica (Impresso) \\
\hline Ambiente \& Sociedade (Online) & Revista Brasileira de Enfermagem (Impresso) \\
\hline Avaliação (UNICAMP) & Revista Brasileira de Epidemiologia (Impresso) \\
\hline $\begin{array}{l}\text { Bolema. Boletim de Educação Matemática (UNESP. } \\
\text { Rio Claro. Impresso) }\end{array}$ & Revista Brasileira de Gestão de Negócios (Online) \\
\hline Boletim de Psicologia & $\begin{array}{l}\text { Revista Brasileira de Gestão de Negócios (São Paulo. } \\
\text { Impresso) }\end{array}$ \\
\hline Brazilian Journal of Biology (Impresso) & $\begin{array}{l}\text { Revista Brasileira de Gestão e Desenvolvimento } \\
\text { Regional }\end{array}$ \\
\hline Brazilian Journal of Otorhinolaryngology (Impresso) & Revista Brasileira de Medicina do Esporte (Impresso) \\
\hline
\end{tabular}




\begin{tabular}{|c|c|}
\hline Brazilian Journal of Otorhinolaryngology (Online) & Revista Brasileira de Reumatologia (Impresso) \\
\hline Cadernos EBAPE.BR (FGV) & $\begin{array}{l}\text { Revista Brasileira de Terapia Comportamental e } \\
\text { Cognitiva (Impresso) }\end{array}$ \\
\hline Ciência \& Educação & $\begin{array}{l}\text { Revista Brasileira de Terapia Comportamental e } \\
\text { Cognitiva (Online) }\end{array}$ \\
\hline Ciências \& Cognição (UFRJ) & Revista CEFAC (Impresso) \\
\hline Contextos Clínicos & Revista CEFAC (Online) \\
\hline Educação e Realidade & Revista Educação em Questão (UFRN. Impresso) \\
\hline Educação em Revista (UFMG. Impresso) & Revista Eletrônica de Enfermagem \\
\hline Ensaio (Fundação Cesgranrio. Impresso) & Revista Enfermagem UERJ \\
\hline Fisioterapia e Pesquisa & Revista Mal-Estar e Subjetividade (versão eletrônica) \\
\hline Fractal: Revista de Psicologia & Revista Paulista de Pediatria (Impresso) \\
\hline História, Ciências, Saúde-Manguinhos (Impresso) & Revista da Abordagem Gestáltica (Impresso) \\
\hline Interação em Psicologia (Impresso) & Revista da Abordagem Gestáltica (Online) \\
\hline Interação em Psicologia (Online) & Revista da Educação física (UEM. Online) \\
\hline Interface (Botucatu. Impresso) & Revista da Escola de Enfermagem da USP (Impresso) \\
\hline Jornal Brasileiro de Psiquiatria (UFRJ. Impresso) & Revista da Escola de Enfermagem da USP (Online) \\
\hline Motriz : Revista de Educação Física (Online) & Revista da SPAGESP \\
\hline Online Brazilian Journal of Nursing & Revista de Administração (FEA-USP) \\
\hline Planta Medica & Revista de Administração (São Paulo. Online) \\
\hline Produção (São Paulo. Impresso) & Revista de Administração Pública (Impresso) \\
\hline Psicologia da Educação (Impresso) & Revista de Estudos Feministas \\
\hline Psicologia da Educação (Online) & Revista de Nutrição (Impresso) \\
\hline Psicologia desde el Caribe & $\begin{array}{l}\text { SMAD. Revista Eletrônica Saúde Mental Álcool e } \\
\text { Drogas (Edição em português) }\end{array}$ \\
\hline Psicologia em Pesquisa (UFJF) & Saude em Debate \\
\hline Psicologia em Revista (Impressa) & Saúde e Sociedade (Online) \\
\hline Psicologia em Revista (Online) & Saúde e Sociedade (USP. Impresso) \\
\hline Psicologia, Educação e Cultura & Scientiae Studia (USP) \\
\hline Psicologia, Saúde \& Doenças & Serviço Social \& Sociedade \\
\hline Psicooncología & São Paulo Medical Journal (Impresso) \\
\hline Psicopedagogia (São Paulo) & Tempo Psicanalítico \\
\hline Psicopedagogia On Line & Texto \& Contexto Enfermagem (UFSC. Impresso) \\
\hline $\begin{array}{l}\text { RAC. Revista de Administração Contemporânea } \\
\text { (Online) }\end{array}$ & Textos \& Contextos (Porto Alegre) \\
\hline RAM. Revista de Administração Mackenzie (Online) & Trabalho, Educação e Saúde (Online) \\
\hline $\begin{array}{l}\text { REAd. Revista Eletrônica de Administração (Porto } \\
\text { Alegre. Online) }\end{array}$ & Vínculo (São Paulo. Impresso) \\
\hline $\begin{array}{l}\text { Revista Brasileira de Cirurgia Cardiovascular } \\
\text { (Impresso) }\end{array}$ & $\begin{array}{l}\text { Zoologia (Curitiba): an international journal for } \\
\text { zoology }\end{array}$ \\
\hline Revista Brasileira de Educação Especial & Zoologia (Curitiba. Online) \\
\hline
\end{tabular}

